\title{
Stereochemical Analysis of Naturally Occurring Cyclopropyl Fatty Acids
}

By:

Laura J. Stuart

\begin{abstract}
A Thesis submitted to the Faculty of Graduate Studies
in partial fulfillment of the requirements for the degree of

Master of Science
\end{abstract}

to

The Faculty of Graduate Studies

Department of Chemistry

Carleton University

Ottawa, Canada

August 2005

(C) Laura J. Stuart, 2005. 


$\begin{array}{ll}\begin{array}{l}\text { Library and } \\ \text { Archives Canada }\end{array} & \begin{array}{l}\text { Bibliothèque et } \\ \text { Archives Canada }\end{array} \\ \begin{array}{l}\text { Published Heritage } \\ \text { Branch }\end{array} & \begin{array}{l}\text { Direction du } \\ \text { Patrimoine de l'édition }\end{array} \\ \begin{array}{l}\text { 395 Wellington Street } \\ \text { Ottawa ON K1A ON4 }\end{array} & \begin{array}{l}\text { 395, rue Wellington } \\ \text { Ottawa ON K1A ON4 } \\ \text { Canada }\end{array}\end{array}$

Your file Votre référence

ISBN: 0-494-10146-6

Ourfile Notre référence

ISBN: 0-494-10146-6

NOTICE:

The author has granted a nonexclusive license allowing Library and Archives Canada to reproduce, publish, archive, preserve, conserve, communicate to the public by telecommunication or on the Internet, loan, distribute and sell theses worldwide, for commercial or noncommercial purposes, in microform, paper, electronic and/or any other formats.

The author retains copyright ownership and moral rights in this thesis. Neither the thesis nor substantial extracts from it may be printed or otherwise reproduced without the author's permission.
AVIS:

L'auteur a accordé une licence non exclusive permettant à la Bibliothèque et Archives Canada de reproduire, publier, archiver, sauvegarder, conserver, transmettre au public par télécommunication ou par l'Internet, prêter, distribuer et vendre des thèses partout dans le monde, à des fins commerciales ou autres, sur support microforme, papier, électronique et/ou autres formats.

L'auteur conserve la propriété du droit d'auteur et des droits moraux qui protège cette thèse. $\mathrm{Ni}$ la thèse ni des extraits substantiels de celle-ci ne doivent être imprimés ou autrement reproduits sans son autorisation.
In compliance with the Canadian

Privacy Act some supporting forms may have been removed from this thesis.

While these forms may be included in the document page count, their removal does not represent any loss of content from the thesis.
Conformément à la loi canadienne sur la protection de la vie privée, quelques formulaires secondaires ont été enlevés de cette thèse.

Bien que ces formulaires aient inclus dans la pagination, il n'y aura aucun contenu manquant.

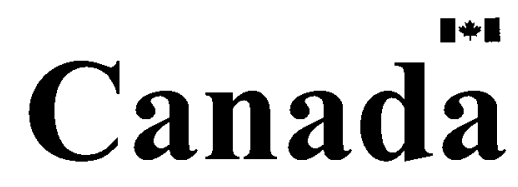




\begin{abstract}
The study of cyclopropanoid fatty acid (CFA) biosynthesis is receiving renewed attention as the role these unusual lipids play in pathogenicity of various bacterial species becomes better understood. CFAs from bacterial and plant sources were oxidized to their corresponding $\alpha$-cyclopropyl ketones and their chiroptical activity compared to molecules with known stereochemistry. This information was used to establish the stereochemistry of three member ring of these fatty acids. This project led to the determination of the absolute configuration of three CFAs (one phyto, two bacterial) and confirmed the configuration of two CFAs previously examined. Sources of both enantiomers of dihydrosterculate were investigated with a view to future research on the stereochemistry of DHS desaturation.

The homology of CFA synthases from different bacterial species was also briefly explored in an attempt to explain the apparent bimodal capability of this enzyme in $L$. plantarum.
\end{abstract}




\section{Acknowledgements}

I would like to thank Dr. P.H. Buist for the opportunity to work on an interesting project in a great environment. The knowledge he has shared and the support he has given will always be appreciated.

I would also like to thank all of the talented technical people who helped me with this project: Tony O’Neil (Carleton University) for help with polarimetry, Keith Bourque (Carleton University) for NMR analyses, Clem Kazakoff (University of Ottawa) for GC/MS analyses, Ilona Fiser (Carleton University) for help with cell cultures, and Jose Miguel Cruz (Carleton University) for the BLAST analysis.

The lab was always full of great people who all helped me along the way. Kim Lao has been the best lab mate past 3 years, and deserves many thanks.

I have received a great amount of support from my friends and family, for which I am very grateful. My mom, Jean, is especially deserving of recognition, since without her constant guidance, I would not be here today. I would also like to thank Mike for being so patient and understanding for the past 6 years.

Funding from NSERC was appreciated. 
Title Page

Acceptance Sheet

Abstract

iii

Acknowledgements

iv

Table of Contents

$\mathrm{V}$

List of Figures

vii

List of Tables

$\mathrm{x}$

List of Abbreviations

$\mathrm{xi}$

\section{Chapter 1 Introduction}

1.1 Lipids 1

1.1.1 Background 1

1.1.2 Fatty Acids 1

$\begin{array}{lll}\text { 1.1.3 Triacylglycerols } & 3\end{array}$

1.1.4 Phospholipids 5

$\begin{array}{lll}1.2 & \text { Cyclopropyl Fatty Acids } & 7\end{array}$

$\begin{array}{lll}\text { 1.2.1 History, Structure and Nomenclature } & 7\end{array}$

$\begin{array}{lll}\text { 1.2.2 Biosynthesis } & 9\end{array}$

$\begin{array}{lll}\text { 1.2.3 Purpose of CFAs } & 15\end{array}$

$\begin{array}{lll}1.3 & \text { Stereochemistry of Cyclopropanation } & 19\end{array}$

1.4 Project Goals 25 


\section{Chapter 2 Results and Discussion}

2.1 Synthesis and Trial Oxidation of Racemic Methyl

Dihydrosterculate

2.2 Absolute configuration of Dihydrosterculate isolated from

Litchi chinensis

2.3a Absolute configuration of Dihydrosterculate isolated from

Lactobacillus plantarum

2.3b Attempted configurational analysis of Lactobacillus acid isolated Lactobacillus plantarum

2.4 Absolute Configuration of Cyclopropyl Fatty Acids isolated from $E$. coli

2.5 Saccharomyces cerevisiae Incubation Experiments

2.6 Conclusions and Future Directions

\section{Chapter 3 Experimental}

\subsection{General}

3.2 Synthesis of Racemic Methyl Dihydrosterculate

3.2.1 Trial Oxidation of Cyclopropyl Fatty Acids 
1.1.2 Glycerol Molecule 4

1.1.3 a) Dehydration Reaction Between Glycerol and Stearic acid 4

b) Space-fill model of Tristearin

c) Space-fill model of trilinolenin.

1.1.4 Phosphatidylcholine 5

1.1.5 Fluid Mosaic Model of Biological Membranes 6

1.2.1 Cis-vaccenic and Lactobacillic Acids $\quad 7$

1.2.2 Desaturation of Dihydrosterculic Acid to Sterculic Acid. 8

1.2.3 Olefinic precursors to CFAs 10

a) cis-vaccenic to lactobacillic acid (LB);

b) Oleic to Dihydrosterculic acid(DHS)

c) palmitoleic to palmitoyl CFA (PAL).

1.2.4 Methyl Addition to an Olefin to form a Cyclopropyl Ring. 11

1.2.5 Formation of natural products methyl addition to olefins 12

$\begin{array}{lll}\text { 1.2.6 Chiral-methyl group experiments } & 14\end{array}$

1.2.7 Model for bimodal binding of a single CFA synthase $\quad 15$

1.2.8 Mycolic Acid from M. tuberculosis $\quad 17$

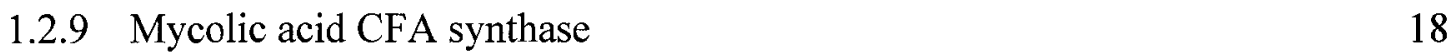

1.3.1 Ball and Stick Enantiomers $\quad 19$

1.3.2 $R$ and $S$ Convention for Designating Chiral Centres $\quad 20$

1.3.3 Oxidation of LB to $\alpha$-cyclopropyl ketones and MS peaks 22

1.3.4 Optical properties of Chiral $\alpha$-keto Cyclopropyl 23

1.3.5 Chiroptical properties of $\alpha$-keto Cyclopropyl Ketones of LB 23 
1.3.6 $R \& S$ Convention for $\alpha$-Cyclopropyl ketones and

Cyclopropanes

2.1.1 Chromium Trioxide Oxidation of CFAs 26

$\begin{array}{lll}2.1 .2 & \text { a) Simmons-Smith Reaction } & 27\end{array}$

b) Simmons-Smith Reaction Mechanism $\quad 27$

$\begin{array}{lll}2.1 .3 & \text { a) mCPBA } & 28\end{array}$

b) mCPBA Epoxidation of Double Bonds

2.1.4 ${ }^{1}$ H NMR of mCPBA Treated Methyl Dihydrosterculate 29

2.1.5 ${ }^{13}$ C NMR of mCPBA Treated Methyl Dihydrosterculate 30

2.1.6 Key Areas of ${ }^{13}$ C NMR from Racemic DHS 30

2.1.7 TLC (10:1 Hex:Et $\left.{ }_{2} \mathrm{O}\right)$ of Oxidized Racemic DHS 31

2.2.1 Processing of Litchi seeds for triglyceride extraction 33

2.2.2 Gas Chromatographs of FAMEs isolated from L. chinensis 35

2.2.3 TLC of oxidized DHS mixture 36

2.2.4 MS of $\alpha$-cyclopropyl ketones of DHS from L. chinensis 37

2.2.5 Methyl Lactobacillate Reference Structures and $\alpha$ cyclopropyl Ketones of DHS from Litchi chinensis. $\quad 41$

2.2.6 Methyl Dihydrosterculate from Litchi chinensis $\quad 42$

2.3.1 ${ }^{13} \mathrm{C}$ NMR Showing DHS and LB Isomers from L. plantarum 47

2.3.2 TLC separation of $\alpha$-cyclopropyl ketones from L. plantarum 49

2.3.3 Mass Spectrum of Ketone Fraction $1 \quad 50$

2.3.4 Mass Spectrum of Ketone Fraction 2 50

2.3.5 a) ${ }^{13} \mathrm{C}$ NMR of Ketone Fraction $\mathrm{A}$

b) ${ }^{13} \mathrm{C}$ NMR of Ketone Fraction $\mathrm{B}$

2.3.6 Lactobacillic acid Reference Structures and $\alpha$-cyclopropyl 54 Ketones of DHS from Lactobacillus plantarum 
2.3.8 DHS from Lactobacillus plantarum $\quad 55$

2.3.9 Proposed Interaction of CFA Synthase with Oleate and Cis- 60 vaccenate

2.3.10 Results of Protein Alignment of CFA Synthases $\quad 62$

2.4.1 Lactobacillate and the CFA Produced by E. coli (PAL) 63

2.4.2 Proton NMR Spectrum of E. coli Phospholipids 64

2.4 .3 a) Extracted E. coli FAMEs $\quad 65$

b) E. coli FAMEs after mCPBA

2.4.4 TLC separation of $\alpha$-cyclopropyl ketones from L. plantarum 66

2.4.5 GC/MS Data for Ketone Fraction 1 from E. coli 67

2.4.6 GC/MS Data for Ketone Fraction 2 from E. coli 68

2.4.7 GC/MS Data for Ketone Fraction 3 from E. coli 68

2.4.8 Lactobacillic acid Reference Structures and $\alpha$-cyclopropyl $\quad 73$ Ketones of LB from E.coli

2.4.9 PAL From Escherichia coli $\quad 74$

2.4.10 Methyl Lactobacillate from L. plantarum and E. coli $\quad 74$

2.5.1 Gas Chromatograph of FAMEs from S. cerevisiae 76

2.5.2 Gas Chromatograph of FAMEs from S. cerevisiae Incubated 76 with Racemic DHS

2.6.1 Absolute configurations of
a) DHS from L. chinensis
b) DHS from L. plantarum
c) PAL from $E$. coli
d) Lactobacillate from L. plantarum and E. coli. 
1.1.1 Nomenclature of common fatty acids 3

121 Bacterial Genera known to produce Cyclopropyl fatty acids 8

2.2.1 ${ }^{13} \mathrm{C}$ NMR Data for Litchi DHS and keto derivatives 38

2.3.1 ${ }^{13} \mathrm{C}$ NMR Shifts for DHS and LB from L. plantarum Grown $\quad 47$ in MRS Broth

2.3.2 ${ }^{13} \mathrm{C}$ NMR Shifts for $\alpha$-cyclopropyl ketones of DHS 52 and LB from L. plantarum Grown in MRS Broth.

2.3.3 Molecular Rotations of 8-keto and 11-keto DHS from L. chinensis and L. plantarum.

2.4.1 ${ }^{13} \mathrm{C}$ NMR Shifts for Ecoli CFAs and $\alpha$-cyclopropyl ketones 69 


\section{List of Abbreviations}

$\begin{array}{ll}\text { CFA } & \text { Cyclopropyl Fatty Acid } \\ \text { UFA } & \text { Unsaturated Fatty Acid } \\ \text { LB } & \text { Lactobacillic Acid (C18 } \Delta 11) \\ \text { DHS } & \text { Dihydrosterculic Acid }(\mathrm{C} 18 \Delta 9) \\ \text { PAL } & (\text { C16 } \triangle 9) \\ \text { FAME } & \text { Fatty Acid Methyl Ester } \\ m \text {-CPBA } & \text { meta-ChloroPerbenzoic Acid } \\ \text { AdoMet } & \text { Adenosyl methionine } \\ \text { KIE } & \text { Kinetic Isotope Effect } \\ \text { CoA } & \text { Coenzyme A }\end{array}$




\section{Chapter 1 Introduction}

\subsection{Lipids}

\subsubsection{Background}

Biological materials have long been divided into four major categories: lipids, proteins, carbohydrates, and minerals. ${ }^{1}$ The lipid group is made up of hydrophobic natural products that are insoluble in water or are amphipathic. Lipids are involved in many biological processes, including the construction of membranes, biosignaling, and energy storage. ${ }^{2}$ Many lipids contain two features: a polar head group and a hydrophobic tail region. Variation in the head and tail regions leads to a vast number of lipidic compounds which can be subdivided into seven main classes: hydrocarbons, phospholipids, fatty acids, triacylglycerols, glycolipids, steroids, and terpenes. ${ }^{2}$ The nature of the head group provides a further basis for differentiating these molecules: these can be either uncharged, charged, or zwitterionic at physiological $\mathrm{pH}{ }^{1}$

\subsubsection{Fatty Acids}

Fatty acids are carboxylic acids that usually contain an aliphatic region of between 14 and 20 carbons. Many fatty acids feature a long straight chain of carboncarbon single bonds and are known as saturated fatty acids. However, if two hydrogen atoms are removed from neighboring carbons in such a fatty acid, a double bond is formed. Fatty acids with one or more double bonds are said to be unsaturated. Desaturation typically yields double bonds in the cis-orientation because the enzymes responsible for this reaction operate through a pro- $R$-selective, syn-dehydrogenation process. $^{3}$ 
Stearic Acid

\section{$\mathrm{CH}_{3}\left(\mathrm{CH}_{2}\right)_{16} \mathrm{COOH}$}
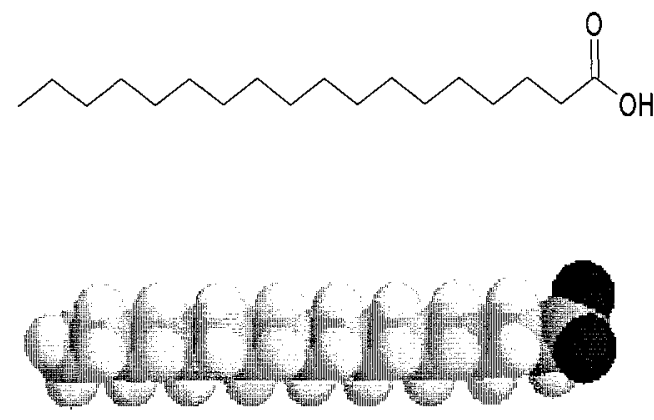

Oleic Acid

$\mathrm{CH}_{3}\left(\mathrm{CH}_{2}\right)_{7} \mathrm{CH}=\mathrm{CH}\left(\mathrm{CH}_{2}\right)_{7} \mathrm{COOH}$
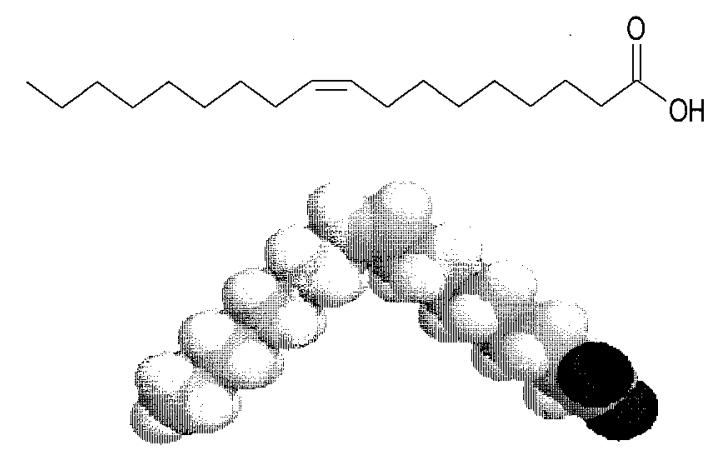

Figure 1.1.1 Stearic acid (saturated) and Oleic acid (unsaturated)

(Modified from ref 4)

Fatty acids occurring in nature normally have chain lengths ranging from 14 to 20 carbons, with even numbered homologues being significantly more common. In most plants and animals, fatty acids with 16 or 18 carbons are predominant. ${ }^{1}$ The nomenclature of fatty acids is based on the longest hydrocarbon chain containing the carboxylic acid group (COOH). For example, a saturated fatty acid with 16 carbons would be called hexadecanoic acid. Carbons are numbered starting with the carboxyl carbon and moving toward the terminal methyl group. The number of double bonds is denoted by the use of "ene", "diene", "triene", etc. and the position of the double bond is indicated by the vinyl carbon number closest to the carboxyl group. ${ }^{1}$ For example, a monounsaturated 18 carbon fatty acid with a double bond at the 9,10 position would be named cis-9-octadecenoic acid. Short hand notation and trivial names are also routinely used in discussing the most common fatty acids. 
Table 1.1.1 Nomenclature of common fatty acids

\section{Systematic Name}

Hexadecanoic acid

Cis-9-hexadecenoic acid

Octadecanoic acid

Cis-9-octadecenoic acid

Cis-11-octadecenoic acid

Cis, cis-9, 12-octadecadienoic acid
Shorthand Notation

$\mathrm{C}_{16: 0}$

$\mathrm{C}_{16: 1}$

$\mathrm{C}_{18: 0}$

$\mathrm{C}_{18: 1}$

$\mathrm{C}_{18: 1}$

$\mathrm{C}_{18: 2}$
Trivial Name

Palmitic acid

Palmitoleic acid

Stearic acid

Oleic acid

\subsubsection{Triacylglycerols}

Triacylglycerols, or triglycerides, contain a glycerol backbone esterified to three fatty acid chains. The absence of a charged polar head group render triglycerides quite hydrophobic. ${ }^{5}$ Triglycerides serve primarily as energy storage material since upon oxidation fatty acids yield more than twice the calories per gram than do either carbohydrates or proteins. They are the major components of fats (such as butter or lard) and oils (such as those from seeds). The main difference between a fat and an oil is the percentage of unsaturated fatty acids present in the triglycerides. Because unsaturated fatty acids are bent, they cannot pack as tightly as their saturated homologues. This causes a decrease in melting point, thereby producing an oil at room temperature, whereas the tightly packed saturated fatty acids are solids at room temperature. ${ }^{6}$ 
<smiles>OCC(O)CO</smiles>

Figure 1.1.2 Glycerol Molecule
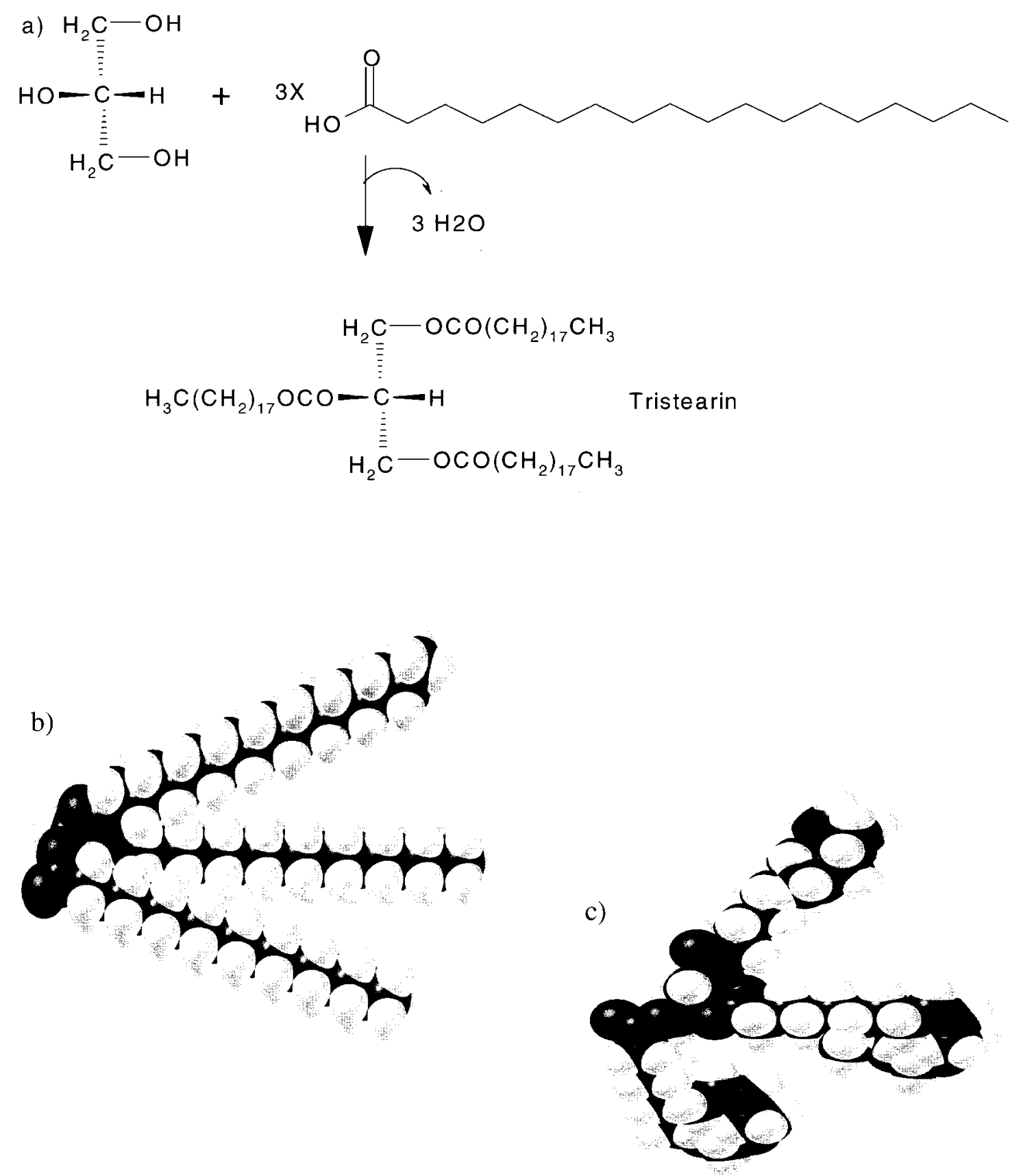

Figure 1.1.3 a) Dehydration Reaction Between Glycerol and Stearic acid to produce tristearin; b) Space-fill model of Tristearin; c) Space-fill model of trilinolenin. 


\subsubsection{Phospholipids}

Phospholipids differ from triacylglycerols in that the fatty acid attached to the C-3 position of the glycerol backbone is replaced with a phosphate group. A fourth constituent is typically linked to phosphate via an ester bond. The fourth constituent is most commonly either hydrogen, choline, ethanolamine, serine, glycerol, or inositol. ${ }^{1}$ It is the presence of a hydrophilic head group and a hydrophobic tail that causes phospholipids to form a bilayer when in an aqueous environment. ${ }^{7}$
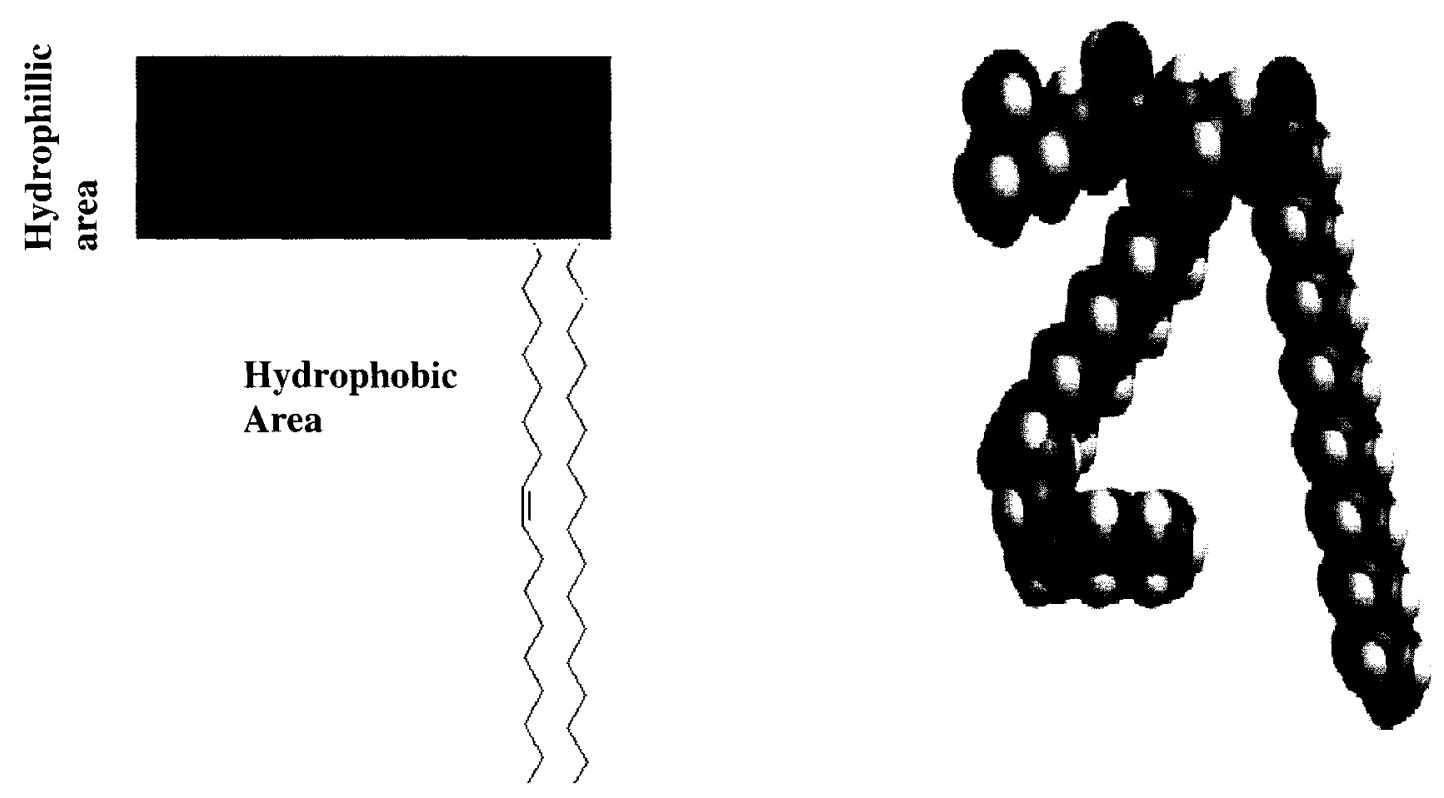

Figure 1.1.4 Phosphatidylcholine (Adapted from ref 8)

The overall molecule is electrically neutral, but the negatively charged phosphate group and the positively charged ammonium group provide the highly polar head region essential to membrane structure. ${ }^{9}$ Phospholipid bilayers are ubiquitous to living organisms. They are required to maintain a structural boundary between the outside and the inside of the cell and also serve as an area of both hydrophobicity and hydrophilicity 
into which proteins can embed themselves. Fluidity of cellular membranes is carefully controlled by the degree of desaturation in the fatty acid tail groups. Membrane lipids commonly contain one saturated and one unsaturated fatty acid, allowing most of the membrane to remain fluid at physiological temperatures. ${ }^{2}$

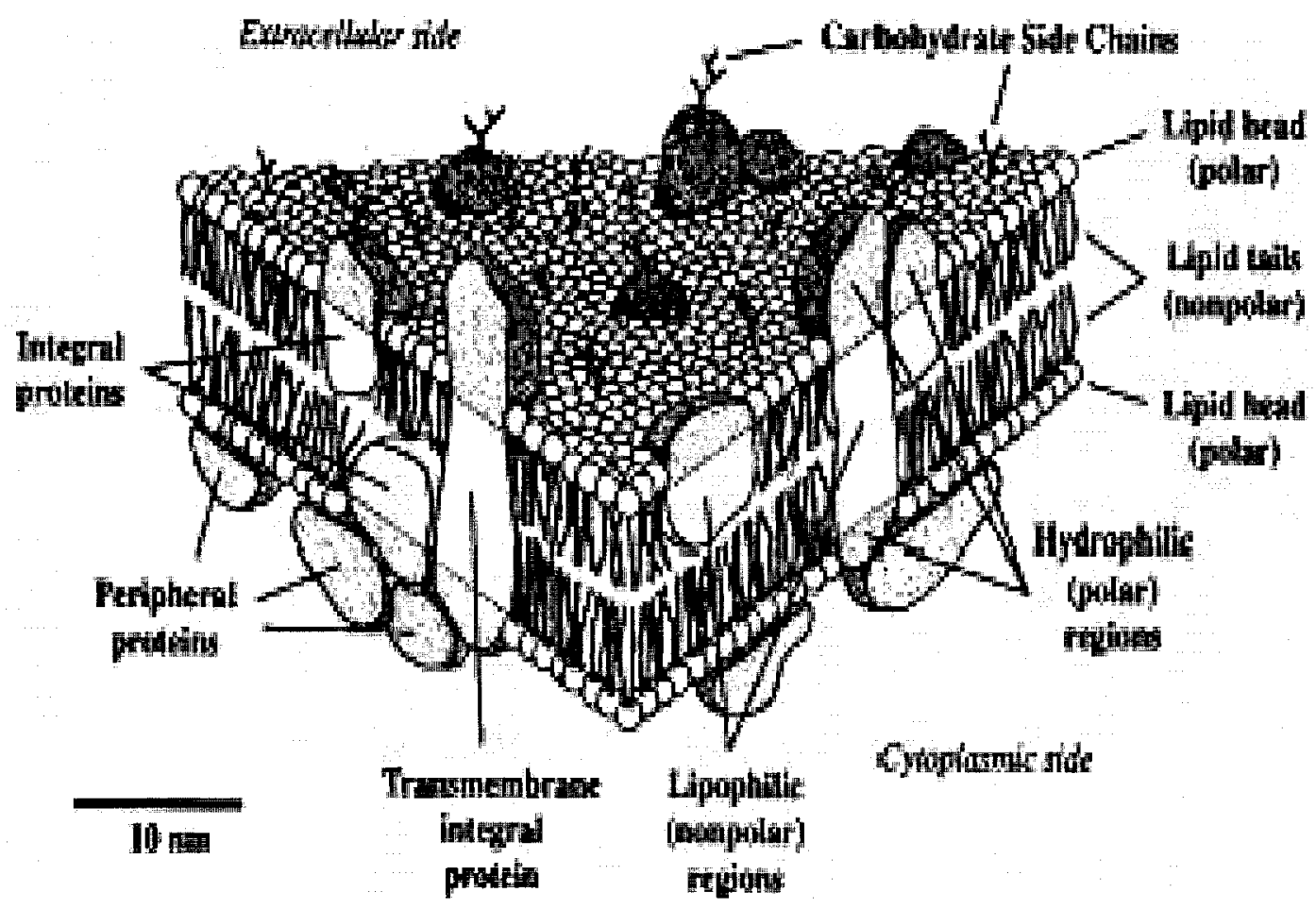

Figure 1.1.5 Fluid Mosaic Model of Biological Membranes (Ref 10) 


\subsection{Cyclopropyl Fatty Acids}

\subsubsection{History, Structure and Nomenclature}

The isolation of a novel cyclopropyl fatty acid from Lactobacillus arabinosus by K. Hoffmann et al in 1950 was an unexpected discovery. This new fatty acid (lactobacillic acid) was shown to be $c i s-11,12-$ methyleneoctadecanoic acid, a cyclopropanated derivative of $c i s$-vaccenic acid. ${ }^{11}$
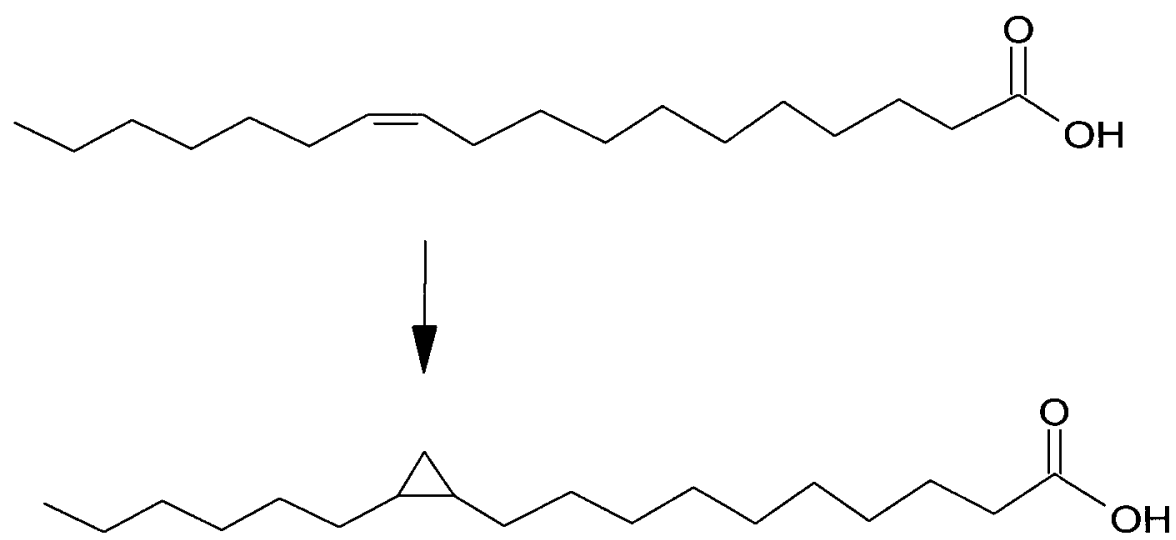

Figure 1.2.1 Cis-vaccenic (unsaturated) and Lactobacillic (cyclopropyl) Acids

The development of gas chromatography soon made the analysis of fatty acids routine, and cyclopropyl fatty acids (CFAs) were observed as a component of the phospholipids of many bacterial species. ${ }^{12}$ Cyclopropanation of fatty acids occurs widely among bacterial species including gram-positive and gram -negative genera ranging from strict anaerobes to obligate aerobes. ${ }^{13}$ CFAs have also been found in eukaryotic species including four genera of trypanosomatid protozoa, the slime mold Physaram polycephalum, the females of some millipedes of the Spirostreptida order, and seed oils of the order Malvales. ${ }^{12}$ The major CFAs found in seed oils are cis-9methylenehexadecanoic acid and cis-9-methyleneoctadecanoic acid (dihydrosterculic acid). $^{14}$ 
Table 2 Bacterial Genera known to produce Cyclopropyl fatty acids*

Gram positive

Arthrobacter

Bfidobacterium

Clostridium

Lactobacillus

Pediococcus

Streptococcus

${ }^{*}$ Table modified from ref 12 .

Alcaligenes

Azobacter

Bordetella

Campylobacter

Caulobacter

Chlorobium

Citrobacter

Enterobacter

Helicobacter

Klebsiella
Gram negative

$$
\begin{gathered}
\text { Nitrobacter } \\
\text { Proteus } \\
\text { Pseudomonas } \\
\text { Rhizobium } \\
\text { Salmonella } \\
\text { Serratia } \\
\text { Thiobacillus } \\
\text { Vibrio } \\
\text { Yersina }
\end{gathered}
$$

The ability to produce CFAs may have previously gone undetected in many microbial species because CFA synthesis is strongly linked to growing conditions. Many species, including Lactobacillus plantarum and E. coli only begin to produce CFAs in the late exponential growth phase or early stationary phase. ${ }^{15}$ Other bacterial species, such as Azotobacter vinelandii, only produce CFAs during encystment with CFAs making up a majority of the fatty acids present in the cystic state. ${ }^{16}$ In plants, cyclopropane fatty acids are often desaturated to form cyclopropenes and only trace amounts of the former species may be present.

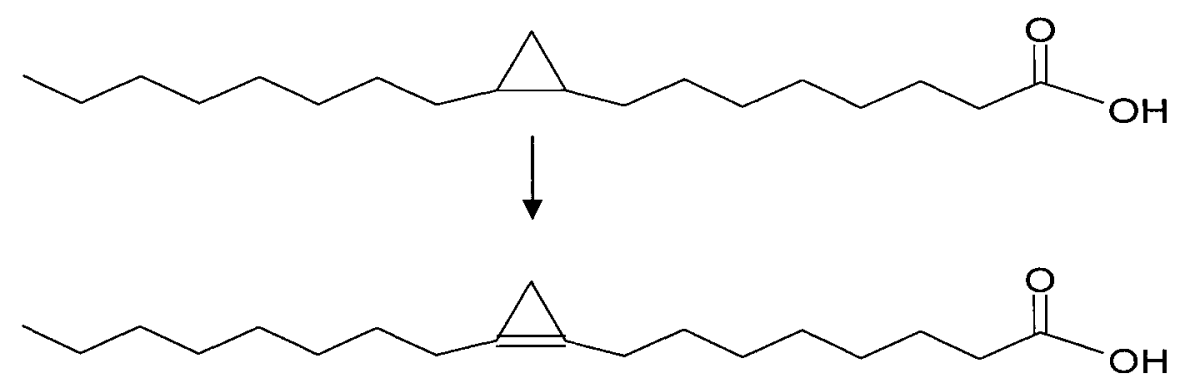

Figure 1.2.2 Desaturation of Dihydrosterculic Acid to Produce Sterculic Acid. 
With advances in the field of genetics, the protein sequences of CFA synthases from different bacterial and one plant species are now known. ${ }^{12,17}$ Since the amino acid sequence of these enzymes appears to be highly conserved in some regions, genomic sequence analysis will aid in the differentiation of CFA producers and non-producers. ${ }^{12}$

\subsubsection{Biosynthesis}

The most commonly occurring CFAs are cis-9,10-methylene hexadecanoic acid, cis-11,12-methylene octadecanoic acid (lactobacillic acid), and cis-9,10-methylene octadecanoic acid (dihydrosterculic acid). With very few exceptions, naturally occurring CFAs have the cis configuration around the cyclopropyl ring. ${ }^{18}$ CFAs only occur in species that produce the analogous unsaturated fatty acids (UFAs), and UFA concentration is seen to decrease upon CFA appearance. These correlations indicate that UFAs are a direct precursor of CFAs, with CFAs being synthesized through modification of the $c i s$-double bond. ${ }^{19,18}$ 
a)

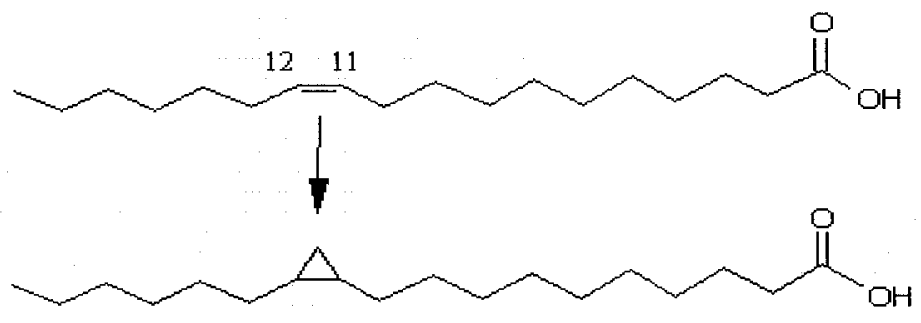

b)

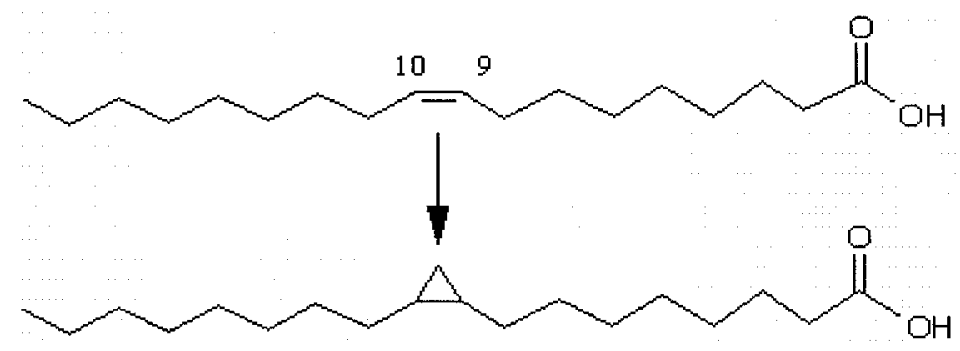

c)

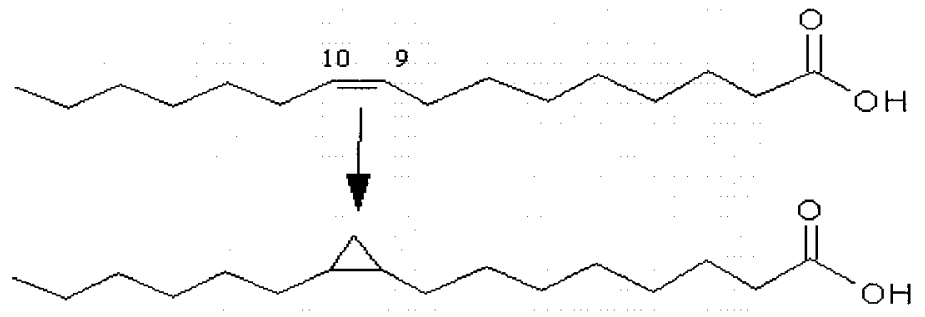

Figure 1.2.3 Olefinic precursors to CFAs: a) cis-vaccenic to lactobacillic acid (LB); b) Oleic to Dihydrosterculic acid(DHS); c) palmitoleic to palmitoyl CFA (PAL).

It is believed that the olefinic substrate must be esterified to phospholipid prior to cyclopropanation. This has been demonstrated through the use of ether-linked fatty acyl phospholipids which cannot be cleaved enzymatically. ${ }^{20}$ In vitro preparations of homogenous CFA synthase only produce cyclopropyl fatty acids in the presence of AdoMet and vesicles of purified phospholipid. ${ }^{21}$

The $\mathrm{C}_{1}$ donor for the methylene unit that forms the cyclopropyl bridge is $S$ adenosylmethionine (AdoMet). This was determined in studies involving AdoMet 
auxotrophic mutants of Enterobacter aerogenes fed [methyl- ${ }^{14} \mathrm{C}$ ]AdoMet. These cultures were seen to produce radiolabeled CFAs and the addition of nonradioactive $L$-methionine did not dilute the isotopic label. ${ }^{22}$ Later research confirmed AdoMet was the $\mathrm{C}_{1}$ donor using $E$. coli transfected with a vector carrying a hydrolase specific to AdoMet. These bacteria were unable to produce CFAs, while other cultures transfected with the same phage lacking only the hydrolase produced CFAs normally. ${ }^{23}$ It has also been shown that cell-free systems used to synthesize CFAs have an absolute requirement for AdoMet and that AdoMet analogs inhibit CFA formation. ${ }^{24}$

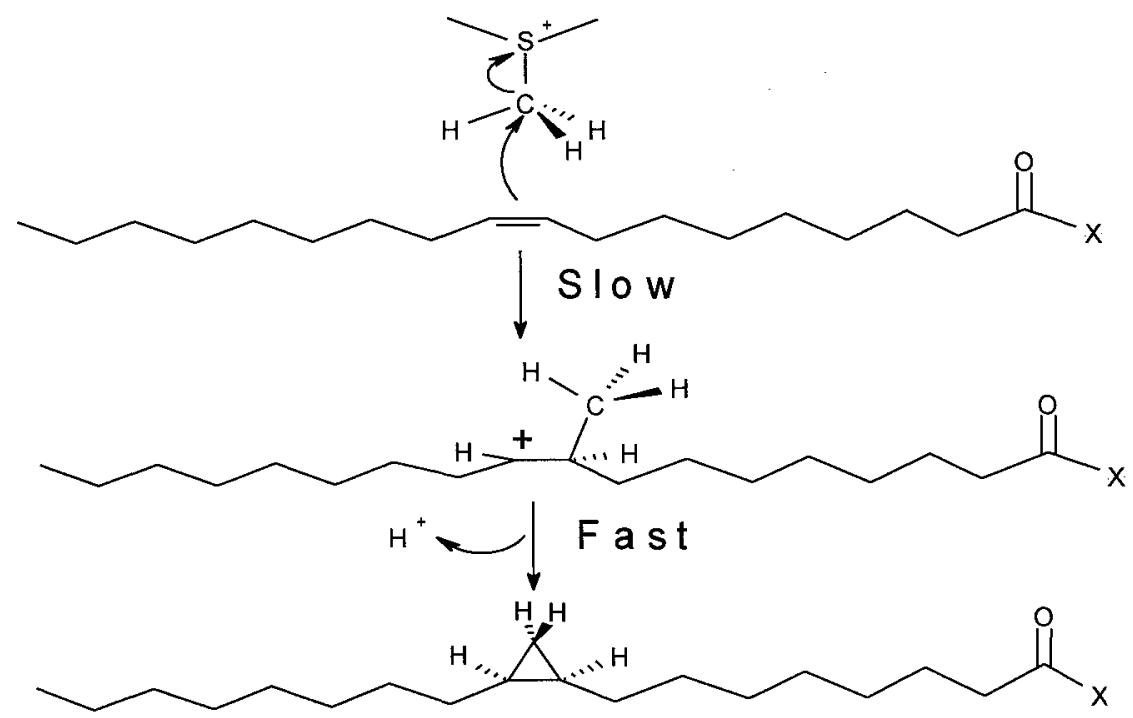

Figure 1.2.4 Methyl Addition to an Olefin to form a Cyclopropyl Ring.

\section{Reaction Mechanism}

Addition of the $\mathrm{C}_{1}$ unit from AdoMet to the double bond of a UFA is thought to occur via a carbocation intermediate which is formed upon methyl transfer. ${ }^{25,26}$ Isotopic labeling studies support this hypothesis. Using Lactobacillus cultures, oleic acid which had been deuterated at vinyl positions and allylic positions was converted to 
dihydrosterculic acid with retention of deuterium at all positions. ${ }^{27}$ These findings make any mechanism involving cyclopropene or other unsaturated intermediates unlikely.

Carbocation formation in the initial step followed by proton loss can also account for formation of other products in other species. ${ }^{25}$

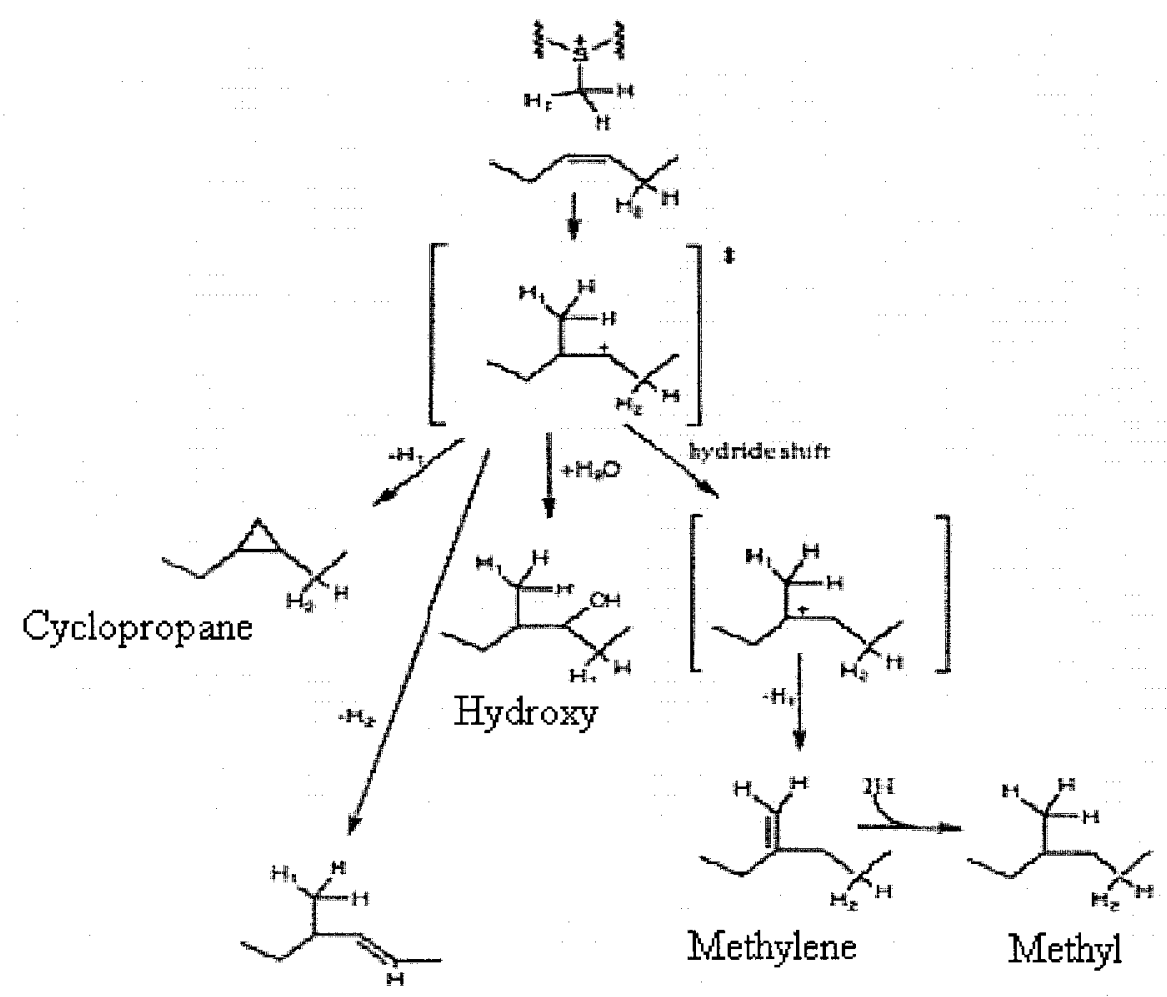

Allylic Methyl Branch

\section{Figure 1.2.5 Formation of various natural products from a common carbocationic intermediate of methyl addition to olefins. ${ }^{25}$}

Detailed mechanistic studies of CFA synthases have been difficult due to the extreme lability of these enzymes and the biochemical characteristics of enzyme and substrates. CFA synthase from $E$. coli has been isolated in an active form with bound phospholipids, and the enzyme is completely inactivated in their absence. ${ }^{24}$ 
Stoichiometric amounts of phosphorus have been detected in the analysis of purified CFA synthase from $E$. coli, suggesting that the enzyme is isolated with fatty acid tails of phospholipids bound to the active site. ${ }^{26}$ It is thought that CFA synthase is a soluble cytoplasmic protein that associates loosely with the inner side of phospholipid bilayers. ${ }^{24}$ The unsaturated portion of the fatty acids is buried deep within the bilayer and AdoMet will be charged at all relevant $\mathrm{pH}$ values, making it difficult to envision how the enzyme brings the two substrates into close proximity. ${ }^{26}$

The results of initial mechanistic experiments involving Lactobacillus cultures incubated with [methyl- $\left.\mathrm{d}_{3}\right]$-methionine suggested that the bacteria incorporated the label into their CFAs, with some isotopic dilution. Using [methyl- $\left.\mathrm{d}_{2}\right]-$ methionine and [methyl- $\left.\mathrm{d}_{1}\right]-$ methionine a substantial, intramolecular primary deuterium kinetic isotope effect of $\sim 3$ was observed. The corresponding intermolecular KIE was $\sim 1$. Taken together, the evidence suggests a slow initial methyl transfer step, followed by rapid and possibly partially reversible ring closure. ${ }^{28}$ The fact that greater than $99 \%$ of all naturally occurring CFAs are of the cis- configuration indicates an extremely rapid collapse of the secondary carbocation intermediate since there is a lack of rotation around the carbon chain. ${ }^{18}$ This mechanistic model was supported by the work of Booker et al. who observed an inverse $\alpha$-secondary deuterium kinetic isotope effect on cyclopropane formation - a result which is consistent with a tight $\mathrm{SN}_{2}$ methyl transfer reaction. ${ }^{26}$ Chiral methyl- methionine has also been used to show that very little racemization accompanies methyl transfer. ${ }^{29}$ 

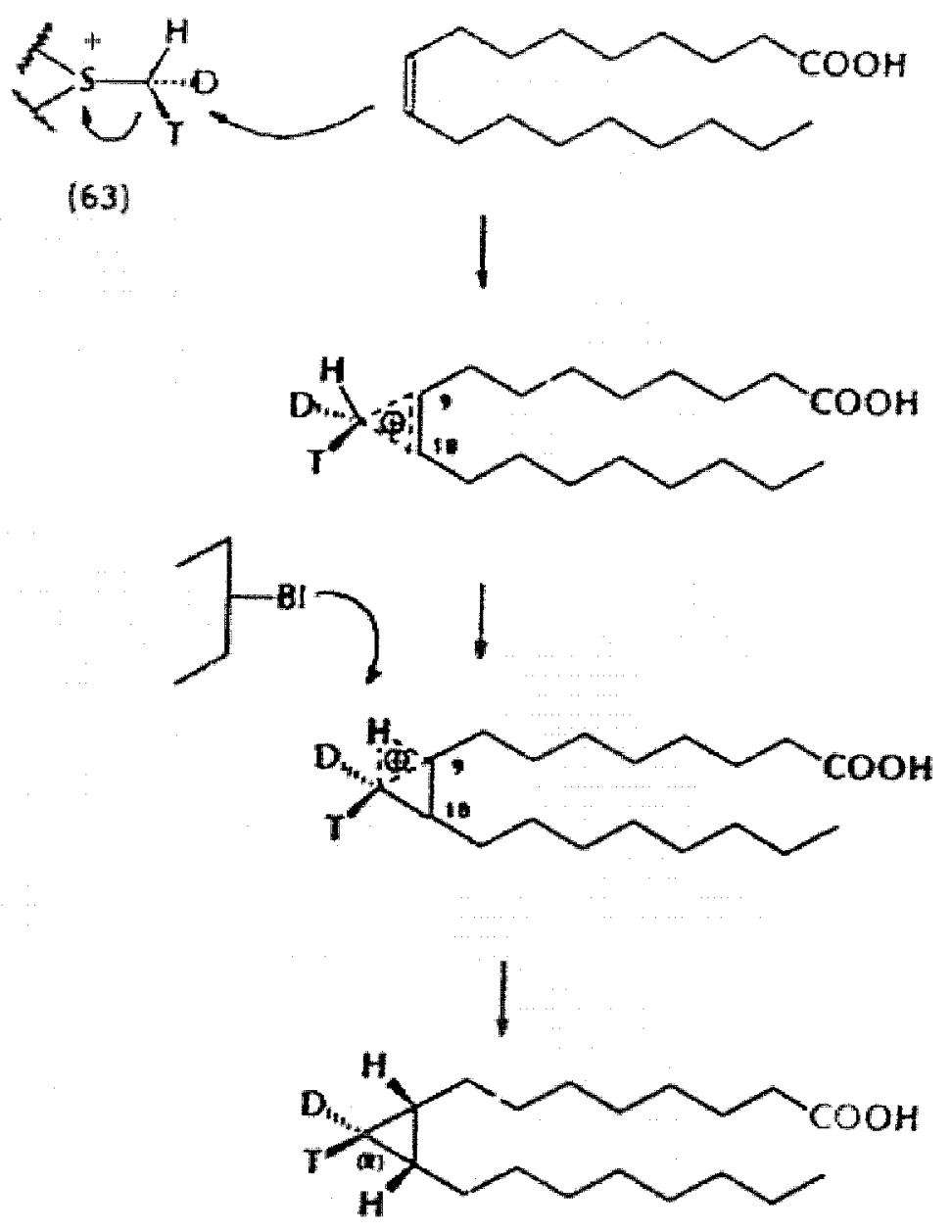

Figure 1.2.6 Chiral-methyl group experiments ${ }^{29}$

CFA synthases seem to have rather strict requirements for the position of the double bond along the hydrocarbon chain of substrate. The results of experiments in which $E$. coli cultures were fed a series of isomeric C18 UFAs with varying double bond position showed that in vivo, only the cis-9, and cis-11 isomers of $\mathrm{C}_{18: 1}$ were converted efficiently to CFAs. ${ }^{30,31}$ Similar findings were obtained using $L$. plantarum incubated with $c i s-9$ and $c i s-11$ octadecenoic acids. ${ }^{32}$ These findings indicated that there may be more than one CFA synthase operating within the bacterial genome or that the active site 
of one CFA synthase has the ability to interact with opposite faces of the double bonds of the two isomers bound in a hairpin conformation.
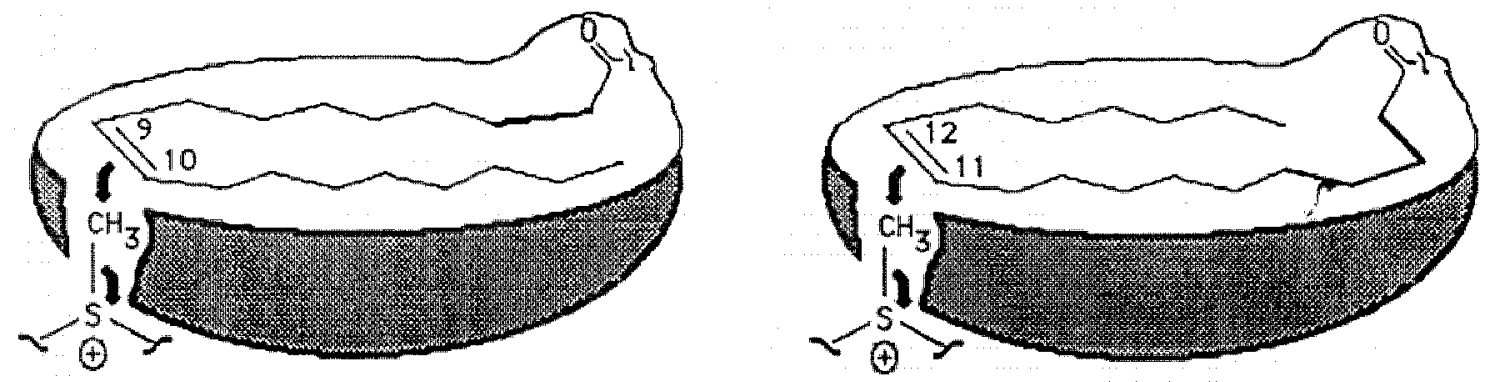

Figure 1.2.7 Model for bimodal binding of a single CFA synthase. ${ }^{29}$

Information about the nature of the active site of CFA synthases could be inferred from previous experiments. One would expect the active site to be hydrophobic and contain at least one basic functional group. Recently, crystal structures of three CFA synthases from $M$. tuberculosis have been published and have helped to shed some light on the operation of these enzymes. The active site is comprised primarily of aromatic amino acids (predominantly tyrosines) providing the hydrophobic pocket required for interaction with UFAs. The authors also suggest that a bicarbonate ion found within the active site may act as a base for the abstraction of a proton from the methylated olefin. ${ }^{33}$

\subsubsection{Purpose of CFAs}

In plants, cyclopropyl fatty acids appear to function as precursors for the corresponding cyclopropenyl fatty acids. The latter are thought to act as molecular defence weapons since cyclopropenyl fatty acids inhibit stearoyl CoA desaturase - an essential mammalian enzyme. ${ }^{34}$ In contrast, the biological purpose of cyclopropyl fatty acids in microorganisms remains a topic of active research. Indeed, their presence would 
seem to provide no specific advantage, given that CFAs are found in so many diverse ecological environments and that they share most chemical and physical properties with UFAs. ${ }^{12}$ CFAs are less easily oxidized by ozonolysis and other mild oxidations, thereby possibly protecting the membrane without dramatically changing the phyiscal properties. ${ }^{20}$ A typical $E$. coli cell contains approximately $2 \times 10^{7}$ UFAs, nearly all of which are cyclopropanated under appropriate conditions at an estimated cost of 3 ATPs per AdoMet used for each CFA formed. ${ }^{35,36}$ With such a high investment in chemical energy, it would be inconceivable to think that CFAs did not serve a specific and important role in the cell.

What is starting to be understood is how UFA cyclopropanation is turned on and how CFA synthases are controlled. In E. coli, CFAs are formed during late log and into early stationary phases and are partially controlled by the $R p o S$ stationary phase sigma factor gene product. $R p o S$ is a $\sigma$ factor required for the translation of proteins present during stationary phase and is also activated during some forms of environmental stress including osmotic strength, cell density and temperature change. ${ }^{37,38}$

Mutant strains of $E$. coli defective in CFA synthesis grow normally under a number of laboratory conditions. ${ }^{39}$ More recent work indicates that CFAs may assist $E$. coli in coping with acid -shock. It has been shown that $E$. coli in the exponential phase are much more sensitive to sudden a drop in $\mathrm{pH}$ then are cells in the stationary phase. If, however, the $\mathrm{pH}$ of exponential phase culture is dropped moderately $(\mathrm{pH} 5)$, then to $\mathrm{pH}$ 3 , survival is greatly increased. ${ }^{40}$ Cultures lacking the CFA gene are also abnormally sensitive to acid-shock, even in the stationary phase. The survival rate of these null mutants increased significantly when the CFA gene is introduced on a plasmid, or when 
CFAs are included in the growth medium. ${ }^{40}$ The mechanism of CFA protection from acid shock is not known, though it has been speculated CFAs would decrease the proton permeability of the membrane. ${ }^{41}$

It is interesting to note that many pathogenic bacterial species contain CFAs as part of their phospholipid membrane including E. coli, Mycobacterium tuberculosis, $M$. leprae, and number of pseudomonad and streptococcal species (see table 2, pp 8).

Given the low $\mathrm{pH}$ encountered in the stomach, acid-shock resistance would be an important factor in pathenogenesis. In fact, studies have shown that pathogenic strains of E. coli have higher acid-shock resistance and higher concentrations of CFAs. ${ }^{42}$ Mycobacteria, including $M$. tuberculosis and M. leprae, produce high molecular weight $\left(\sim \mathrm{C}_{70}-\mathrm{C}_{90}\right) \alpha$-branched and $\beta$-hydroxylated fatty acids, called mycolic acids; these molecules are often cyclopropanated at multiple sites. Interestingly, the non-pathogenic species of mycobacteria have fatty acids with a very low level of cyclopropanation. ${ }^{43,44}$ Further studies showed that a strain of $M$. tuberculosis with a null mutation for the cyclopropane mycolic acid (CMA) synthase, were unable to survive in infected mice. ${ }^{45}$ Cyclopropanation of mycolic acids decreases membrane permeability, a phenomenon that has been associated with resistance to treatment by antibiotics and chemotherapy agents. $^{46,47}$ These findings have led to new research into the treatment of $M$. tuberculosis with drugs designed to inhibit CFA synthesis.<smiles>CCCCCCCC1CC1CC1CC1CC1CC1CC</smiles>

Figure 1.2.8 A Mycolic Acid from M. tuberculosis. 


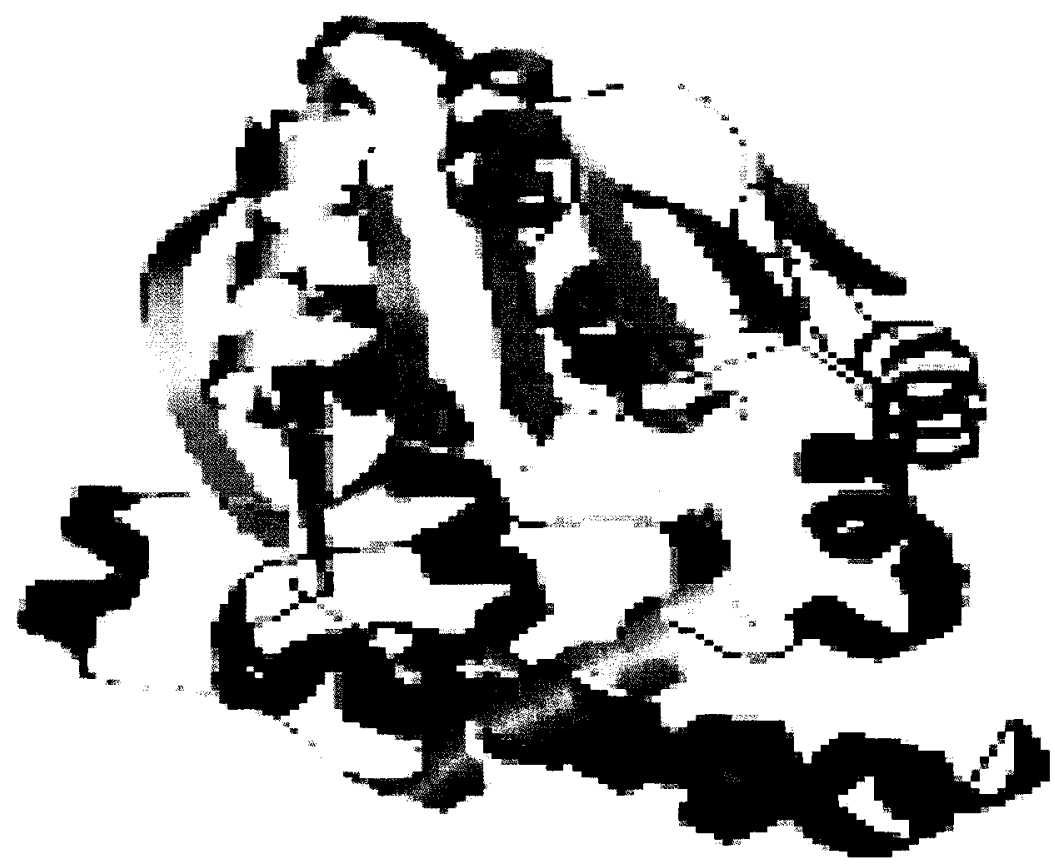

Figure 1.2.9 Mycolic acid CFA synthase M $^{33}$ 


\subsection{Stereochemistry of Cyclopropanation}

Before discussing the stereochemistry of cyclopropanation, a short review of relevant concepts is in order. Stereoisomers are molecules with the same molecular formula and order of atom attachment, but with different orientations in space. ${ }^{48}$ Enantiomers are stereoisomers that are defined as non-superimposable mirror images of each other. Objects that are non-superimposable on their mirror image are said to be chiral. Chirality arises most commonly in organic molecules where four different functional groups attached to a tetrahedral atom called a stereocentre.

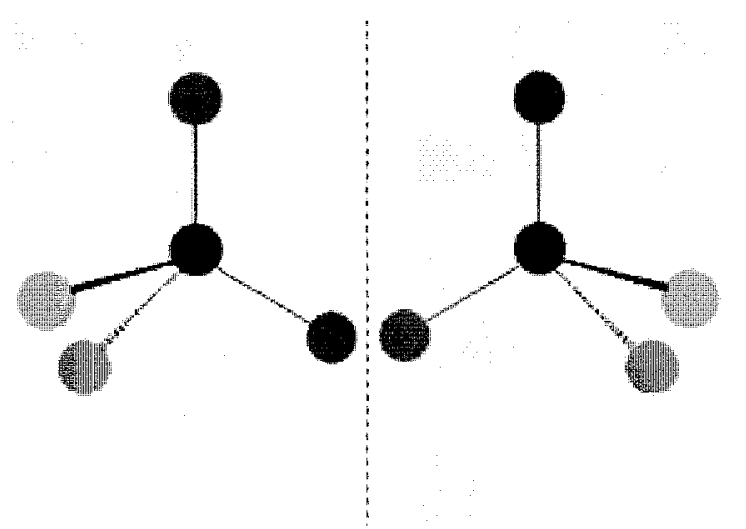

Figure 1.3.1 Ball and Stick Enantiomers ${ }^{49}$

A system for designating the configuration around a stereocentre was developed in the 1950s by R.S. Cahn, C.K. Ingold, and V. Prelog and is known as the R-S convention. Using a set of rules, each substituent around a stereocentre is assigned a priority. The $R$ or $S$ configuration is determined by following the substituents in order of priority around the stereocentre with the lowest priority substituent pointing directly away from the observer. A clockwise rotation is deemed " $R$ ", while a counterclockwise rotation is " $S$ ". 


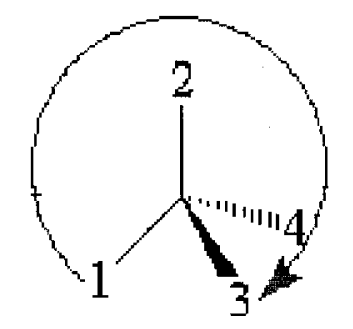

Clocknise R conflguation

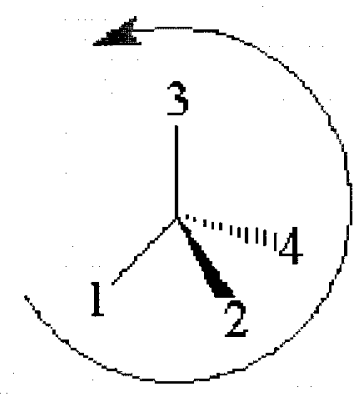

counterclockcuise $S$ configuration

\section{Figure 1.3.2 $R$ and $S$ Convention for Designating Chiral Centres}

A pair of enantiomers have identical physical and chemical properties in an achiral medium. However enantiomers can be distinguished by their "optical activity": the ability of a chiral molecule to rotate the plane of plane-polarized light either clockwise (d (dextrorotatory)/+) or counterclockwise (1 (laevorotatory)/-). Enantiomers will rotate plane-polarized light equally in opposite directions. The observed rotation $\left(\alpha_{D}^{T}\right)$ is measured using a polarimeter, which consists of a light source ( sodium D-line), a polarizing filter and an analyzing filter. A characteristic specific rotation, $[\alpha]_{D}{ }^{T}$, for a molecule can then be calculated. The length of the polarimeter cell (l), concentration (c), and temperature $(\mathrm{T})$ as well as the solvent need to be specified.

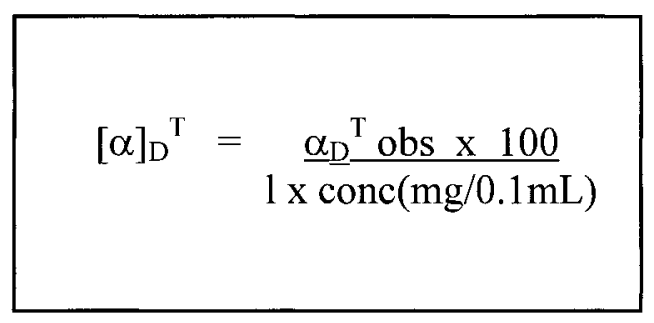


Molar (M= Molecular weight) rotations $[\phi]$ are also sometimes given and are calculated as follows:

$$
[\phi]_{\mathrm{D}}{ }^{\mathrm{T}}=\frac{[\underline{\alpha}]_{\underline{\mathrm{D}}}{ }^{\mathrm{T}} \mathrm{obs} \times \mathrm{M}}{100}
$$

Enzyme-catalyzed reactions are typically stereoselective in the sense that prochiral substrates can be transformed into a single optically active product (enantiomer). This is also the case for biological cyclopropanation reactions as was determined early on by a careful comparison of X-ray data obtained on naturally occurring lactobacillic acid and the corresponding synthetic racemate (1:1 mixture of $d$ and $l$ enantiomers). In addition, a very low but measurable $[\alpha]_{\mathrm{D}}$ of $+0.25\left(\mathrm{c} 0.8, \mathrm{CHCl}_{3}\right)$ was measured for lactobacillic acid isolated from Brucella millitensis. ${ }^{50}$

In order to establish the absolute configuration of lactobacillic acid isolated from Brucella, Tocanne and coworkers took advantage of earlier work originally developed to confirm the position of the cyclopropyl ring. This involved oxidation of the microbial FAMEs with chromium trioxide to produce $\alpha$-cyclopropyl ketones. Mass spectrometry was used to confirm the position of the ring based upon known cleavage patterns of these molecules. ${ }^{51}$ 


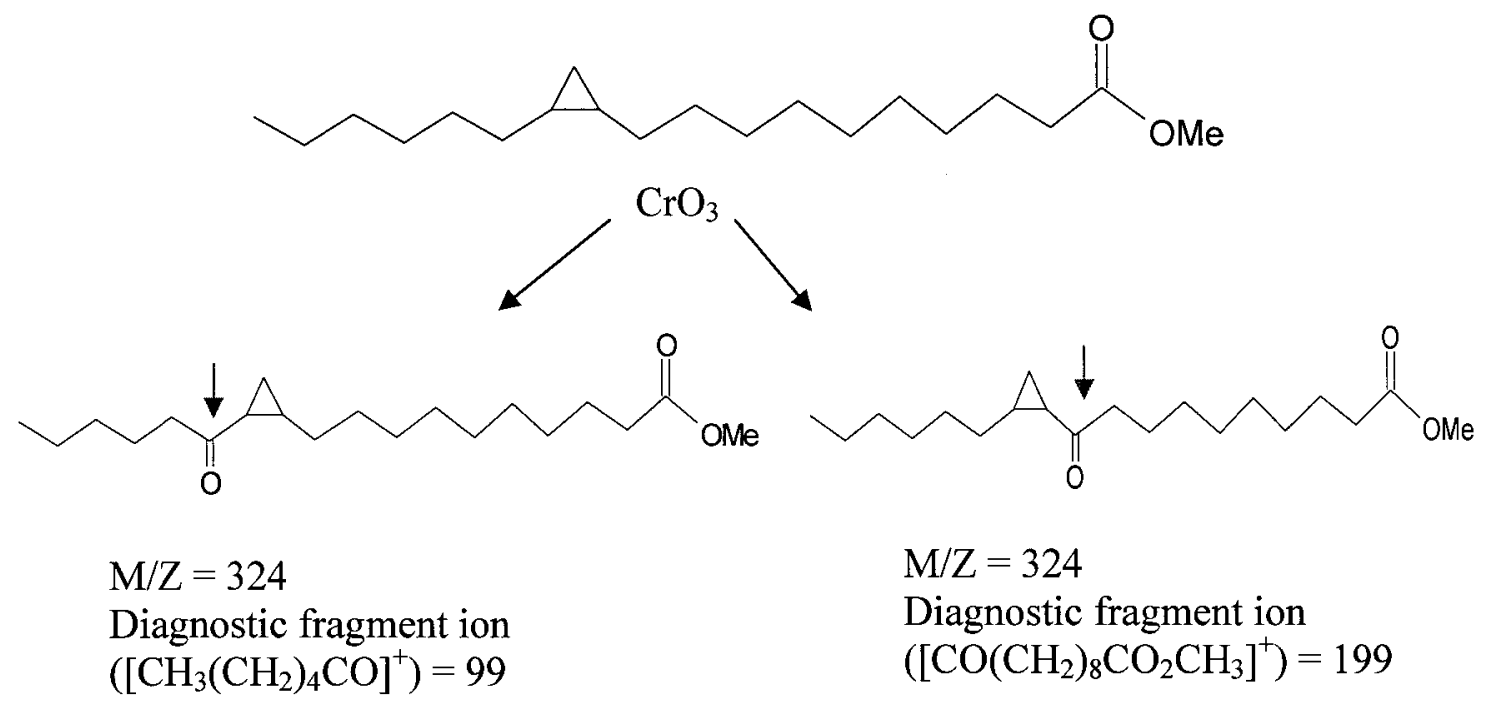

Figure 1.3.3 Oxidation of LB to $\alpha$-cyclopropyl ketones and diagnostic MS peaks.

In 1972, Tocanne and Bergmann developed synthetic routes to a-cyclopropyl keto enantiomers that could be used as reference standards for the corresponding fatty acid keto derivatives. The optical rotation associated with the reference molecules of known absolute configuration was measured and was used to establish the absolute configuration of the lactobacillic acid sample of microbial origin. ${ }^{52}$ 


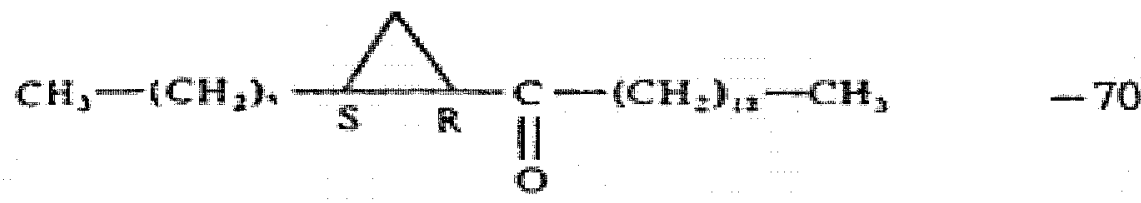

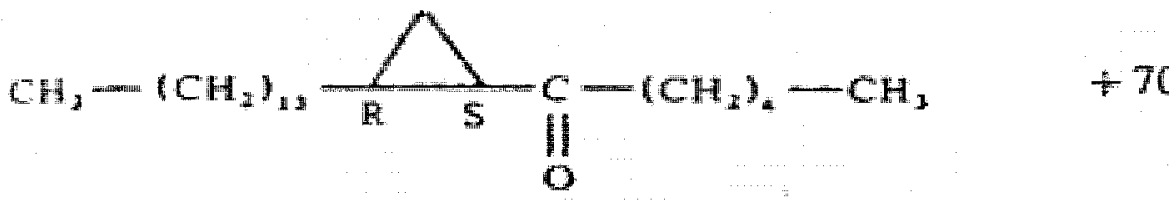

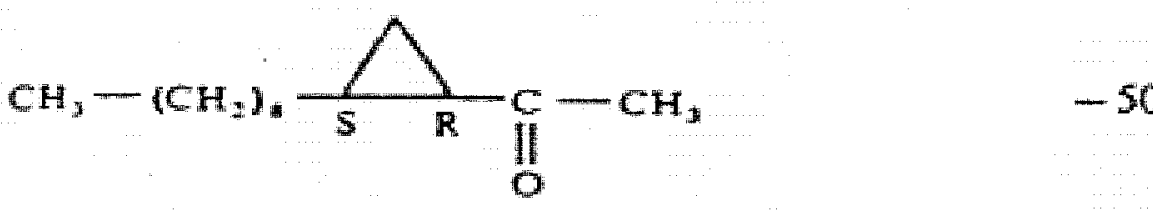
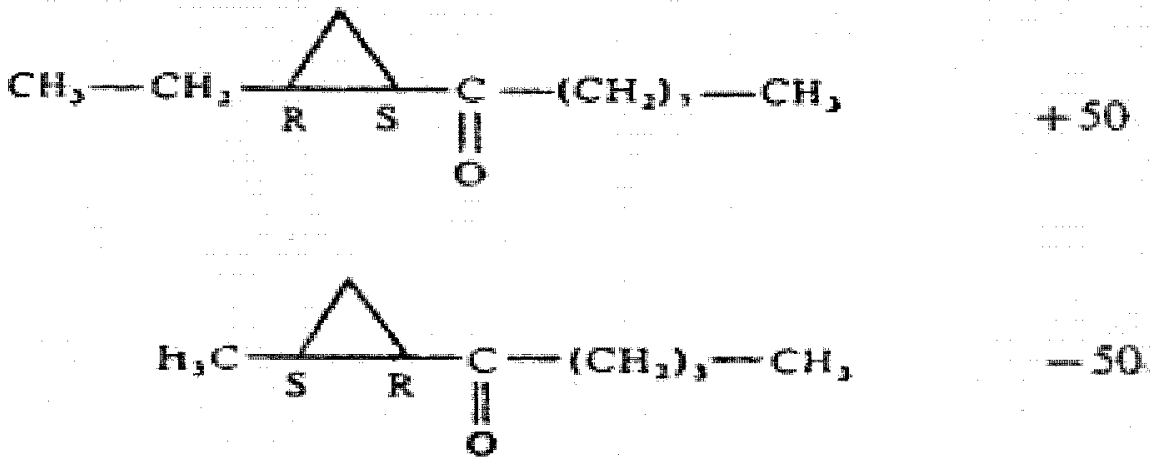

Figure 1.3.4 Comparison of chiroptical propertries of Cyclopropyl Ketones. ${ }^{52}$<smiles>CCCCCC(=O)[C@H]1C[C@H]1CCCCCCCCCC(=O)O</smiles>

(S)

13-keto lactobacillic acid $(+75)$<smiles>CCCCCC[C@H]1C[C@H]1C(=O)CCCCCCCCC(=O)O</smiles>

10-keto lactobacillic acid (-55)

Figure 1.3.5 Chiroptical properties of $\alpha$-keto Cyclopropyl Ketones of lactobacillic acid. ${ }^{52}$ 
From figures 1.3.4 and 1.3.5, it can be seen that for $\alpha$-cyclopropyl ketones of the cis- conformation, a negative molar rotation is obtained for molecules with the ketone next to an $R$-cyclopropyl centre. Ketones next to an $S$-cyclopropyl centre show positive molar rotations. ${ }^{52}$ A comparison of these properties with those of the ketones obtained from methyl lactobacillate established that the absolute configuration at C-11, C12 is $R$ and $S$ - respectively. It should be noted that the presence of the ketone group does not alter the designation of absolute configuration at the cyclopropyl centres (Figure 1.3.5.)
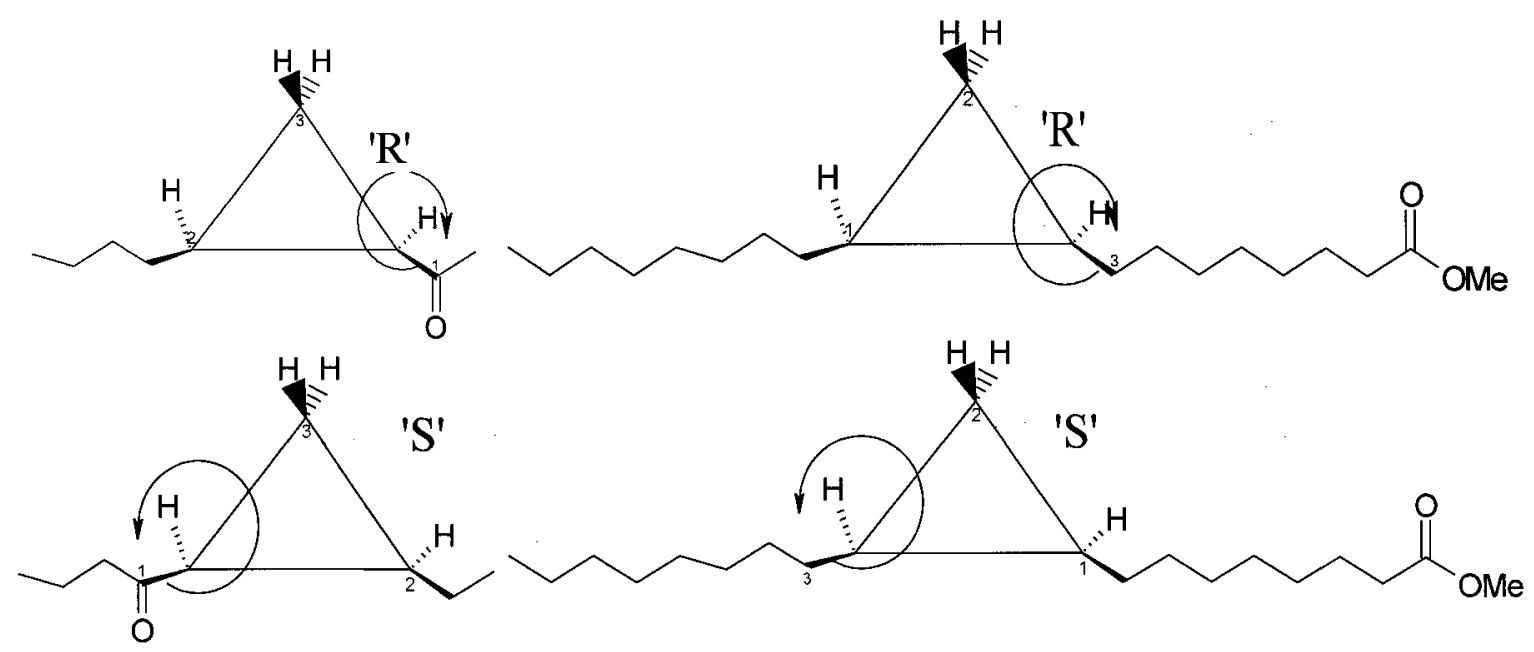

\section{Figure 1.3.6 $R \& S$ Convention for $\alpha$-Cyclopropyl ketones and the Parent Cyclopropanes.}

Apart from Tocanne's work and some unpublished data by the Zurich group of D. Arigoni, ${ }^{29}$ no definitive stereochemical analyses of cyclopropyl fatty acids has appeared in the literature prior to the work described in this thesis. 


\subsection{Project goals}

There are a number of naturally occurring cyclopropyl fatty acids for which the absolute configuration has not yet been determined. Of particular interest to the Buist lab is the stereochemical analysis of dihydrosterculic acid from different sources. This 18 carbon fatty acid bears a cyclopropyl group at the 9,10 position and is thought to be desaturated to sterculic acid in some plant species. The objective of this project was to compare the absolute configuration of methyl dihydrosterculate (DHS) of plant and microbial origin. The seed oil of Litchi chinensis and the lipids of Lactobacillus plantarum represent convenient phyto- and bacterial sources of DHS. The determination of the configuration of the 9,10 - cyclopropyl group will provide further insight into the stereoselectivity of the desaturation of DHS to the highly strained cyclopropenyl fatty acid - sterculic acid.

In addition, given the current interest in microbial cyclopropane synthases in relation to tuberculosis treatment, we wanted to compare the stereochemistry of dihydrosterculic acid from different sources with that of lactobacillic acid - its 11,12 isomer, and a 17 carbon CFA with a cyclopropyl ring at the 9,10 position produced by E. coli. In this manner, valuable information on active site topology could be gained and correlated with ongoing structural studies. 


\section{Chapter 2 Results and Discussion}

\subsection{Synthesis and Trial Oxidation of Racemic Methyl Dihydrosterculate (DHS)}

Direct configurational analysis of quasisymmetrical cyclopropyl fatty acids such as DHS is difficult because the optical rotation of these materials is inherently very low. An oxidation step is required to generate two isomeric, less symmetrical, cyclopropyl ketones which can be separated and analyzed individually. The stereochemistry around the cyclopropyl ring is not changed during this procedure. The absolute configuration of the $\alpha$-cyclopropyl ketones can be determined by comparison to synthetic standards which have been synthesized by Tocanne. ${ }^{52}$<smiles>CCCCCCCC(=O)C1CC1[C@H](C)CCCCCCC(=O)O</smiles>

Figure 2.1.1 Chromium Trioxide Oxidation of CFAs 
A sample of racemic cyclopropyl fatty acid methyl ester was used to optimize the oxidation conditions. Since cyclopropyl fatty acids are not commercially available, a Simmons-Smith reaction $\left(\mathrm{Zn} / \mathrm{Cu}, \mathrm{CH}_{2} \mathrm{I}_{2}\right)$ was used to produce methyl dihydrosterculate from methyl oleate. ${ }^{53}$ In this procedure, iodomethyl zinc iodide reacts with an alkene to give a cyclopropane. The reaction is stereospecific with respect to the alkene, for example, a cis olefin will yield a cis cyclopropyl ring. The mechanism is concerted, meaning that both new carbon-carbon bonds are formed essentially simultaneously.

a)<smiles>[AlH2]CI</smiles><smiles>C/C=C\C</smiles><smiles>C</smiles>
$\mathrm{I}-\mathrm{CH}-\mathrm{ZnI}$<smiles>C/C=C\C</smiles>

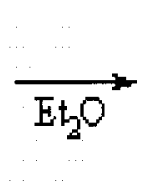<smiles>CC1CC1C</smiles><smiles>CC</smiles>
$\operatorname{Ln} \mathrm{L}_{2}$

b)

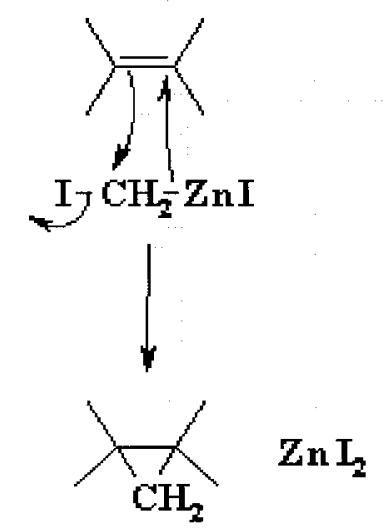

Figure 2.1.2 a) Simmons-Smith Reaction producing Cyclopropanes of the same configuration as the precursor olefin. b) Simmons-Smith Reaction Mechanism. ${ }^{54}$

Unreacted diiodomethane was removed from the crude product by high vacuum bulb-to-bulb distillation and 980mg of impure DHS was obtained as a yellow oil from 900 mg methyl oleate ( $\sim 3$ mmoles). Gas chromatography mass spectrometry (GC-MS) was used to examine the purity of the sample and revealed the presence of unreacted methyl oleate ( $47 \%$ of total). Epoxidation of the remaining methyl oleate was carried out using $m$-chloroperbenzoic acid ( $m$-CPBA) and the polar epoxide so formed was separated from DHS via flash chromatography $\left(10 \% \mathrm{Et}_{2} \mathrm{O}\right.$ in hexanes). 
a)<smiles>O=C(OO)c1cccc(Cl)c1</smiles>

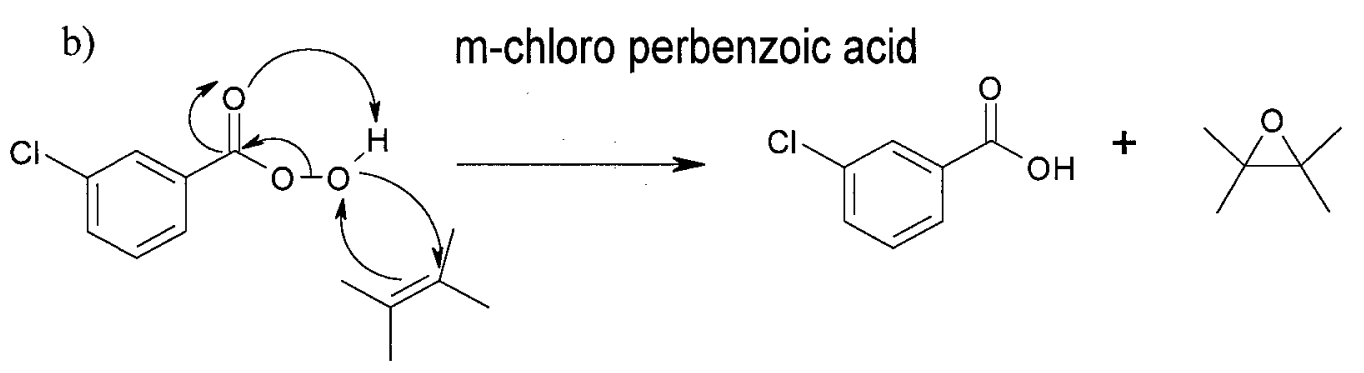

Figure 2.1.3 a) $m$ CPBA b) $m C$ PBA Epoxidation of Double Bonds.

This procedure yielded $260 \mathrm{mg}$ ( $28 \%$ yield from methyl oleate) of racemic methyl dihydrosterculate. The low yields from this reaction can be attributed to the fact that the intermediate zinc carbenoid species generated in situ is very unstable. In addition, the double bond in methyl oleate is reasonably sterically hindered. Recent attempts to increase yields for this reaction, using diethyl zinc and diiodomethane ${ }^{55}$ in the Buist laboratory have been successful.

The presence of the cyclopropyl functional group in the product was confirmed by ${ }^{1} \mathrm{HNMR},{ }^{13} \mathrm{CNMR}$, and GC-MS. For ${ }^{1} \mathrm{HNMR}$, the protons on the carbons making up the ring could be seen as multiplets at -0.3 and $0.6 \mathrm{ppm}$, characteristic peaks for cis cyclopropanes. ${ }^{56}$ The unusual peak at $-0.3 \mathrm{ppm}$ is thought to arise from the proton on the methylene bridging carbon that is out of plane with the hydrogens around it. ${ }^{57}$ The presence of approximately $50 \%$ residual oleate was seen in the $5.3 \mathrm{ppm}$ region, prior to $m$-CPBA oxidation and flash. 


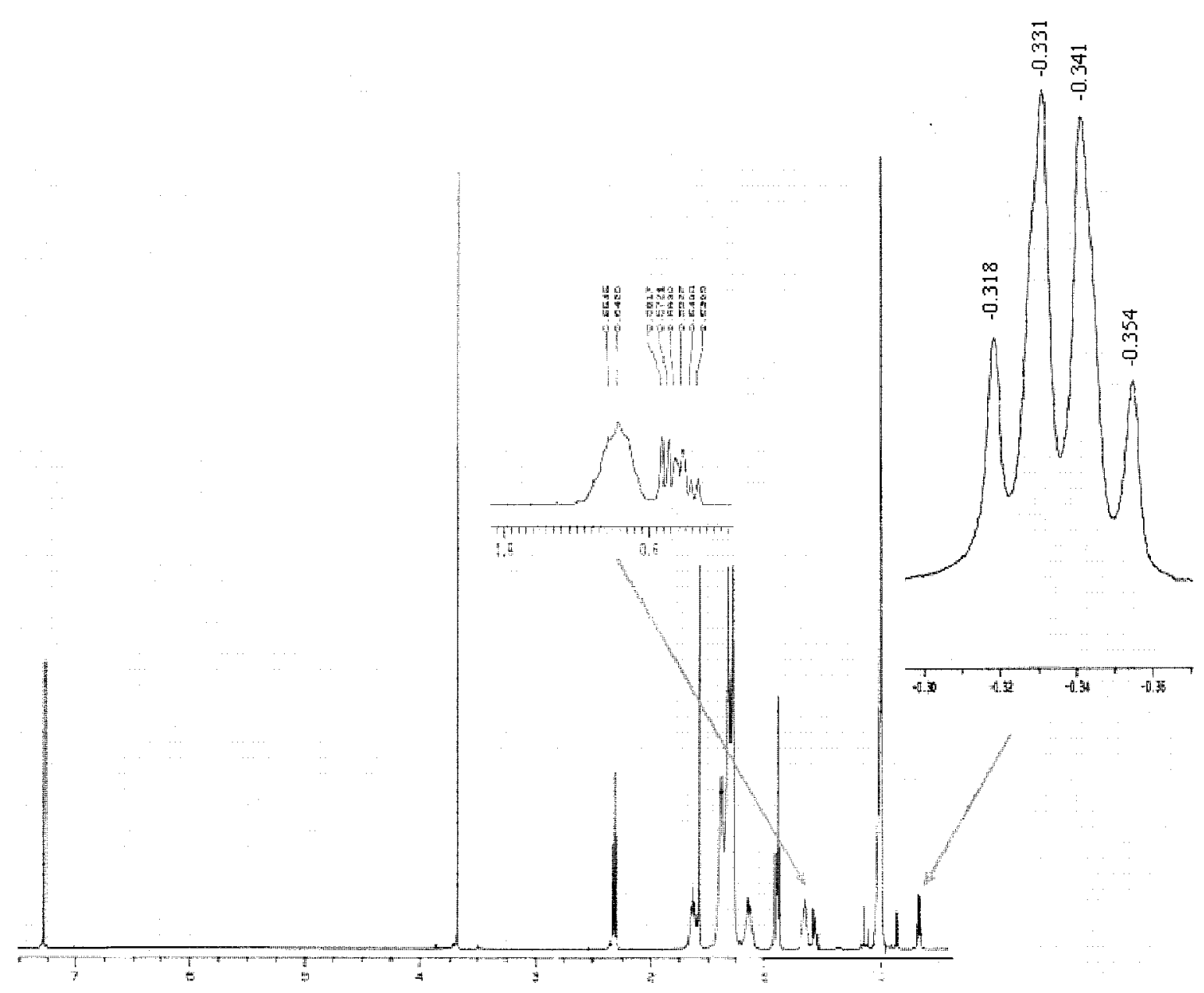

Figure 2.1.4 ${ }^{1}$ H NMR of mCPBA Treated Synthetic Racemic Methyl Dihydrosterculate.

The highly characteristic chemical shifts of cis cyclopropyl rings are clearly visible via ${ }^{1} \mathrm{H}$ NMR, making it a useful tool for rapid analysis of a sample that may contain this unusual functional group.

Carbon NMR provided further information about the structure of the product in three key areas: $\sim 15.7 \mathrm{ppm}(\mathrm{C}-9,10) \sim 28.7 \mathrm{ppm},(\mathrm{C}-8,11)$ and $\sim 30.2 \mathrm{ppm}(\mathrm{C}-7,12)$. For isomerically pure CFAs, these peaks appear as pairs of singlets. In addition, the chemical shift of the bridgehead carbon for DHS appears at $10.93 \mathrm{ppm}$. 


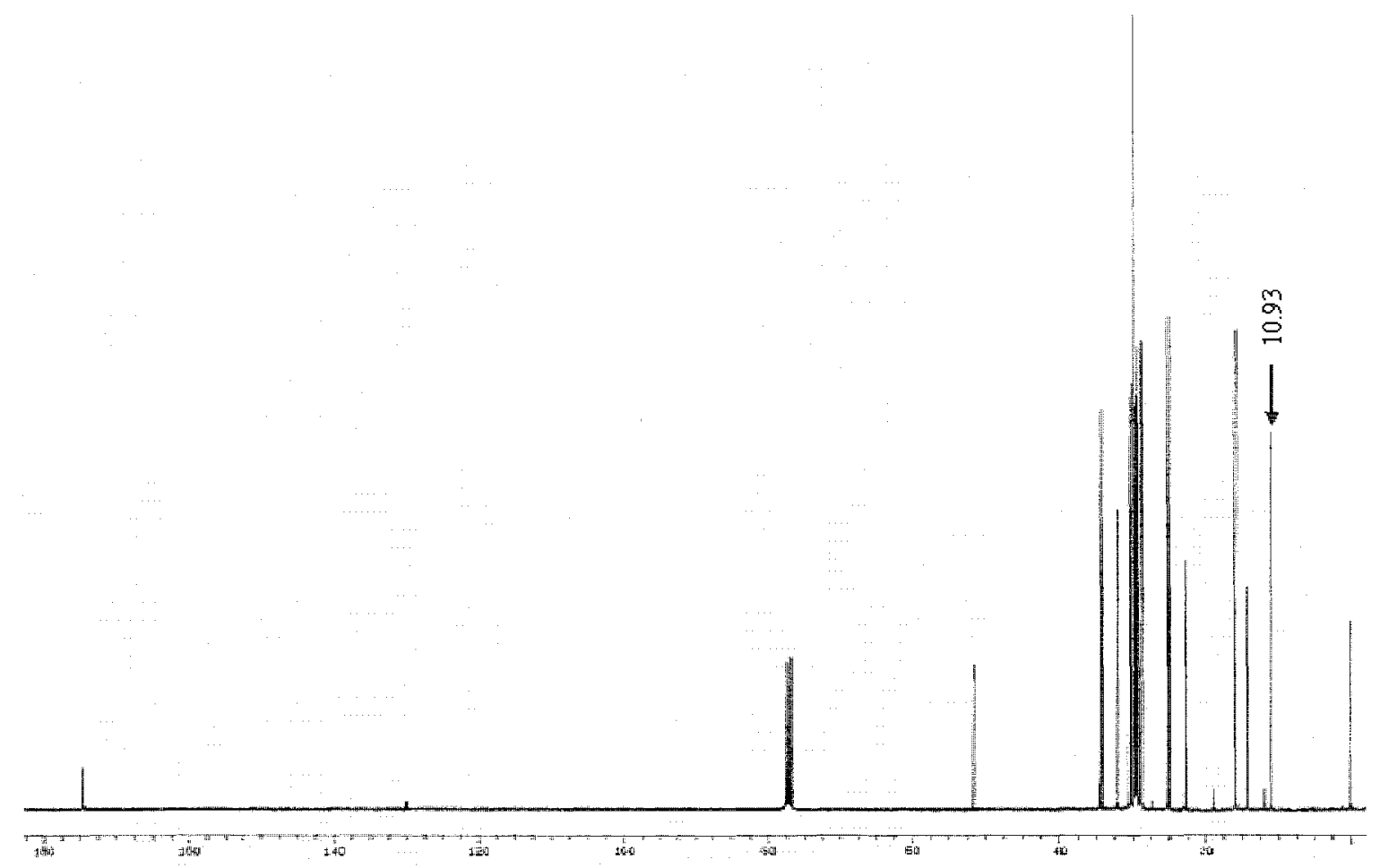

Figure 2.1.5 ${ }^{13}$ C NMR of mCPBA Treated Methyl Dihydrosterculate.
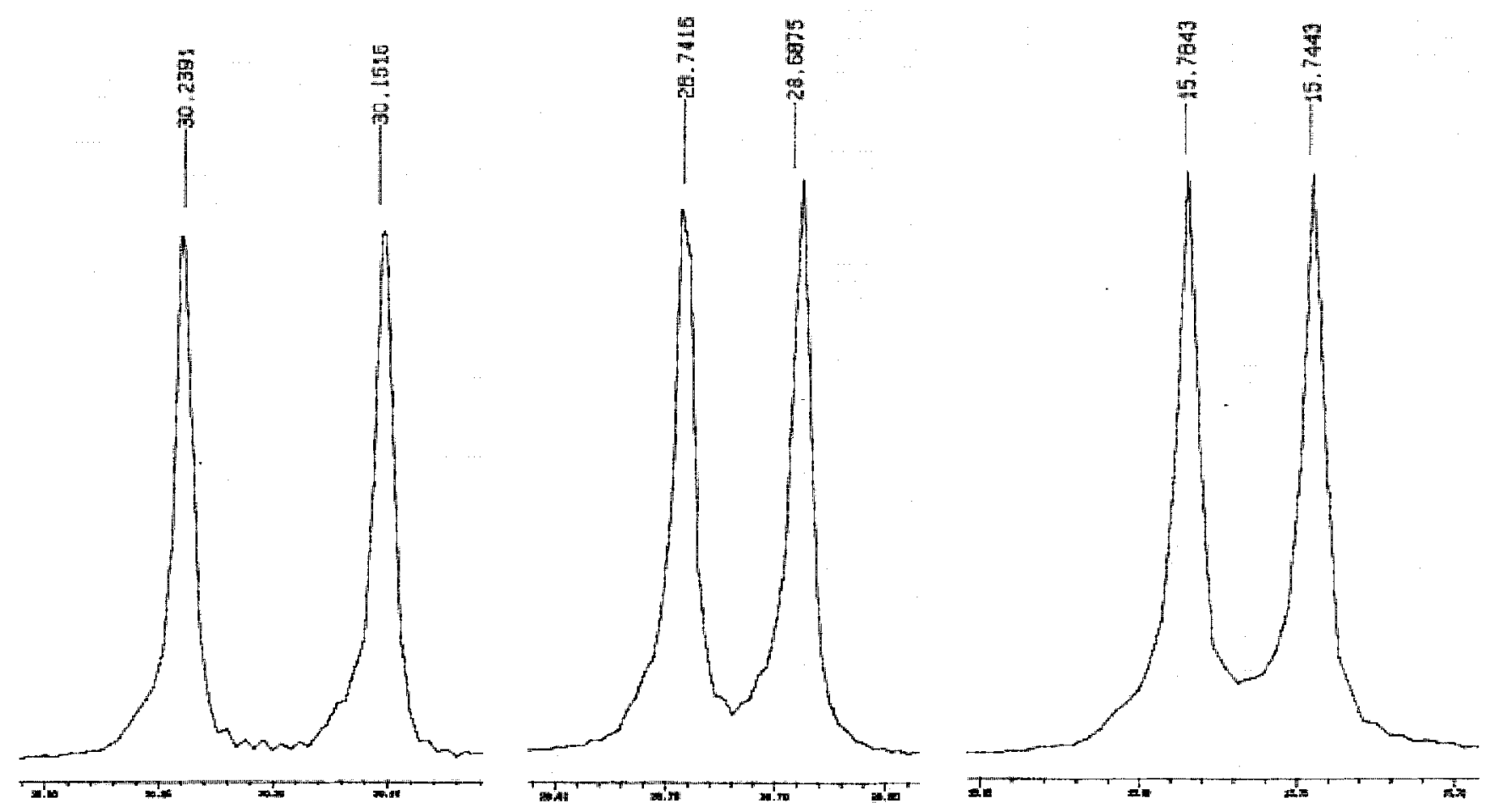

Figure 2.1.6 Key Areas of ${ }^{13} \mathrm{C}$ NMR from Racemic DHS Showing Peaks Representative of a C18 $\triangle 9$ CFA. 
Methyl dihydrosterculate and methyl oleate can clearly be differentiated using GC-MS. DHS has a GC retention time that is $\sim 1$ minute longer than oleate on a nonpolar column allowing for base line resolution between peaks. Though DHS and oleate can be differentiated using GC-MS, isomers of CFAs of the same chain length cannot be separated. Mass spectral data is not helpful in locating the ring position since cyclopropyl functional groups open to give olefins. ${ }^{58}$

The sample of synthetic DHS was of sufficient purity to use for trial oxidation experiments. A cocktail of chromium trioxide, acetic acid and water was added to a 100 mg sample of DHS in $\mathrm{CCl}_{4}$ as had been previously described ${ }^{52}$ and the resultant orange red mixture was diluted with hexanes, washed with ice-water, Satd. $\mathrm{NaHCO}_{3}$, Satd. $\mathrm{NaCl}$, and dried over $\mathrm{Na}_{2} \mathrm{SO}_{4}$. The oil product was assessed by TLC, ${ }^{1} \mathrm{H} \mathrm{NMR}$, and ${ }^{13} \mathrm{C}$ NMR.

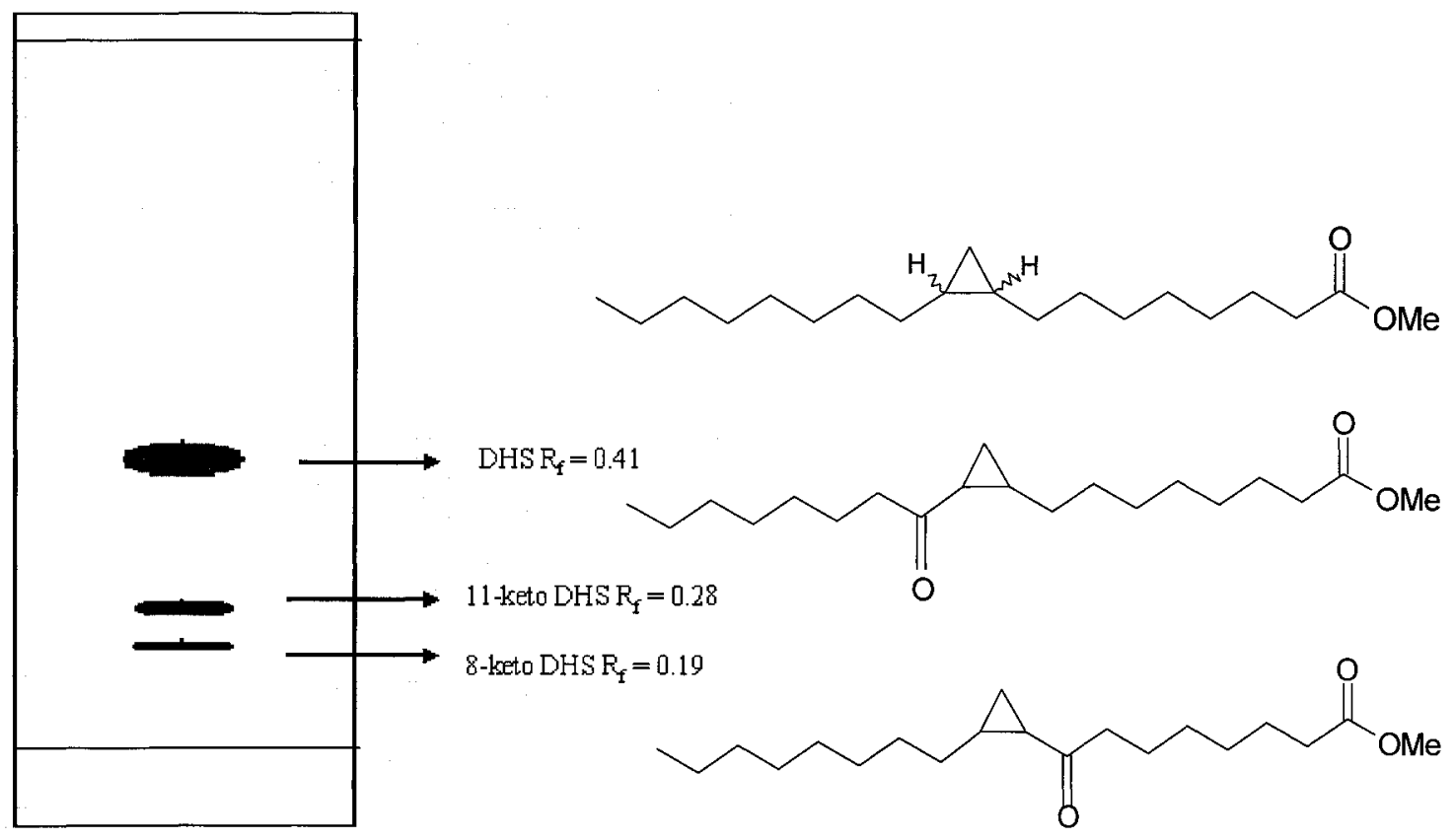

Figure 2.1.7 TLC (10:1 Hex:Et $\left.\mathrm{t}_{2} \mathrm{O}\right)$ of Oxidized Racemic DHS. 
${ }^{1} \mathrm{H}$ NMR of the mixture showed the characteristic peaks for cyclopropyl rings at 0.6 and $-0.3 \mathrm{ppm}$, as well as peaks representing the chemical shifts for the newly formed keto functional group at 2.0 and $2.5 \mathrm{ppm}$. The characteristic shift for the carbon of an $\alpha-$ cyclopropyl ketone was seen at $203 \mathrm{ppm}$ for the ketone, and $44.90 \mathrm{ppm}$ for 11-keto DHS and $44.71 \mathrm{ppm}$ for 8-keto DHS on the ${ }^{13} \mathrm{C}$ NMR.

Since the oxidation sequence described above worked well with the racemic DHS, the same conditions were used for the oxidation of cyclopropyl FAMEs obtained from natural sources. 


\subsection{Absolute configuration of Dihydrosterculate isolated from Litchi chinensis}

The seed oils of "lychee" fruit (Litchi chinensis) represent the most abundant source of plant cyclopropane fatty acids. Lychee fruit from Thailand were purchased from 'Herb and Spice' (1310 Wellington Ave, Ottawa, ON) and ninety-nine seeds were hulled and washed. The dark brown outer layer was removed and the seeds (200g) were ground in a blender, transferred to a round bottomed flask and stirred in 2:1 chloroform:methanol for 24 hours. The dark brown mixture was then suction-filtered on a Buchner funnel to remove solids and the liquid portion was extracted with dichloromethane $(3 \times 100 \mathrm{~mL})$. The organic layer was dried over $\mathrm{MgSO}_{4}$.

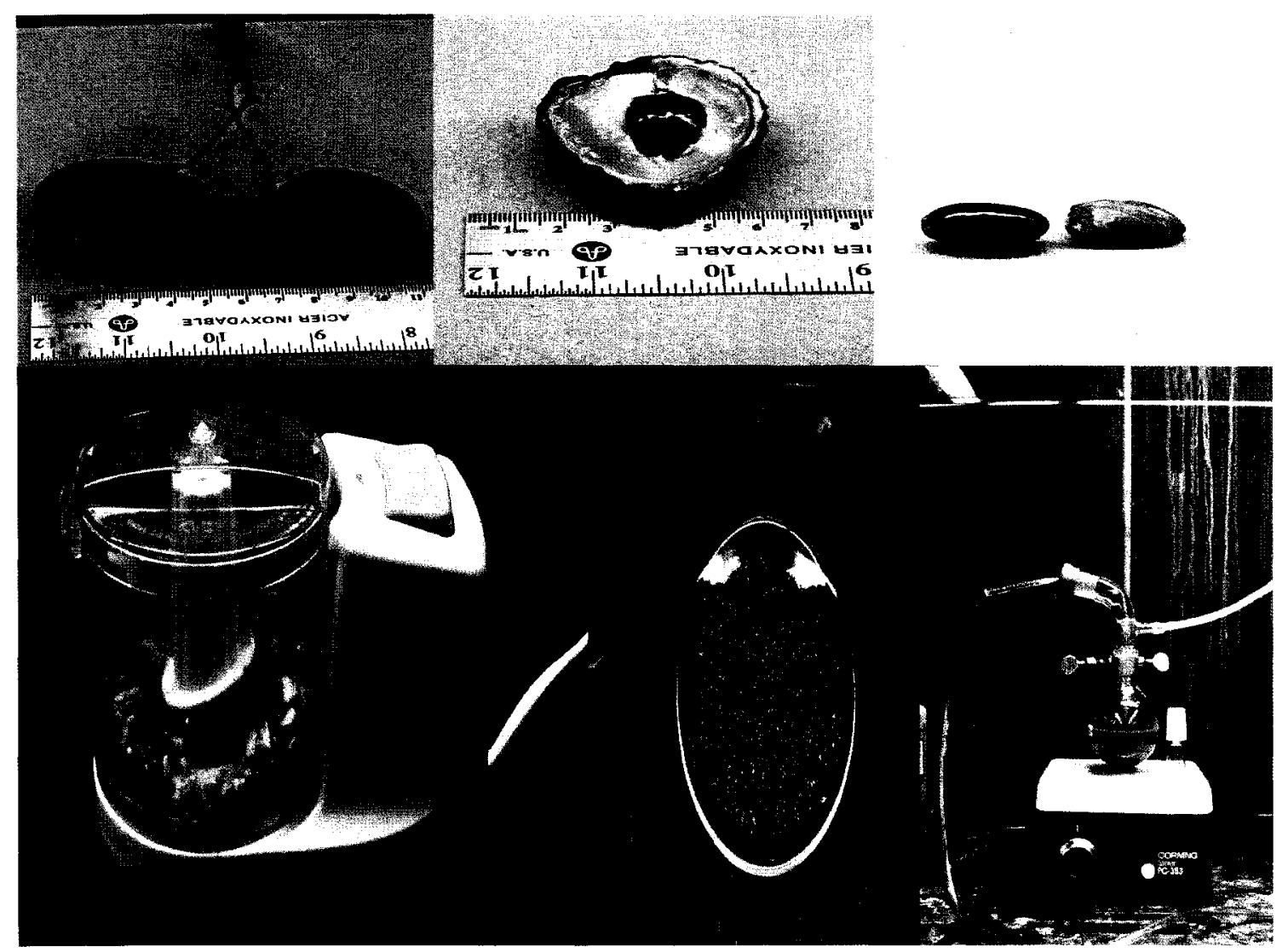

Figure 2.2.1 Processing of Litchi seeds for triglyceride extraction. 
The solvent was removed to give 1.62 grams of a brownish oil. This material, assumed to be chiefly triglycerides and some coloured plant lipids, was transmethylated with sodium methoxide ( $60 \mathrm{~mL}$ dry $\mathrm{MeOH}, 1.4 \mathrm{~g} \mathrm{Na}, 24$ hours) to produce FAMEs (1.0048 $\mathrm{g}$, brown oil) for GC/MS analysis. This analysis indicated a fatty acid distribution as follows: Palmitate $\left(\mathrm{C}_{16: 0}\right) 11 \%$, cyclopropyl $\mathrm{C}_{17}(\mathrm{C} 17$ cyc 9$) 4 \%$, stearate $\left(\mathrm{C}_{18: 0}\right) 4 \%$, oleate $\left(\mathrm{C}_{18: 1} \Delta 9\right) 25 \%$, linoleate $\left(\mathrm{C}_{18: 2} \Delta 9,12\right) 17 \%$, and dihydrosterculate (DHS) ( $\mathrm{C}_{19}$ cyc 9) 39\%. Each peak was identified on the basis of a comparison of characteristic retention times and mass spectra with those of authentic reference standards. That DHS was the major cyclopropyl fatty acid was confirmed in subsequent analyses (see below). These results were encouraging because they matched well with previous studies. ${ }^{59}$ These experiments have since been repeated in the Buist lab with similar results in an attempt to obtain a palmitate-free sample of DHS from $L$. chinensis.

The FAMEs $(1 \mathrm{~g})$ derived from $L$. chinensis seeds were treated with $m$-CPBA ( $3.2 \mathrm{mmol})$ to reduce the large olefinic content prior to oxidation. The more polar epoxy products derived from unsaturated fatty acids was removed by flash chromatography (10:1 hexanes:diethyl ether) to yield crude methyl DHS contaminated with saturated fatty acids $(277 \mathrm{mg})$. GC-MS analysis of this material indicated a distribution as follows: Palmitate $\left(\mathrm{C}_{16: 0}\right) 22 \%$, cyclopropyl $\mathrm{C}_{17}(\mathrm{C} 17$ cyc 9$) 12 \%$, stearate $\left(\mathrm{C}_{18: 0}\right) 7 \%$, oleate $\left(\mathrm{C}_{18: 1}\right.$ $\Delta 9)<1 \%$, linoleate $\left(\mathrm{C}_{18: 2} \Delta 9,12\right)<0.1 \%$, and dihydrosterculate (DHS) $\left(\mathrm{C}_{19}\right.$ cyc 9$) 59 \%$. The high cyclopropane content was confirmed by a comparison of the ${ }^{1} \mathrm{H}$ NMR and IR spectrum of this material with that of synthetic DHS. The presence of DHS as the major cyclopropyl species was confirmed by a peak by peak comparison of the ${ }^{13} \mathrm{C}$ NMR spectrum with that of synthetic DHS (see Table 2.2.1 below). The location of the 
cyclopropane ring along the hydrocarbon chain is given by the mass spectral characteristics of the two keto derivatives (see below).
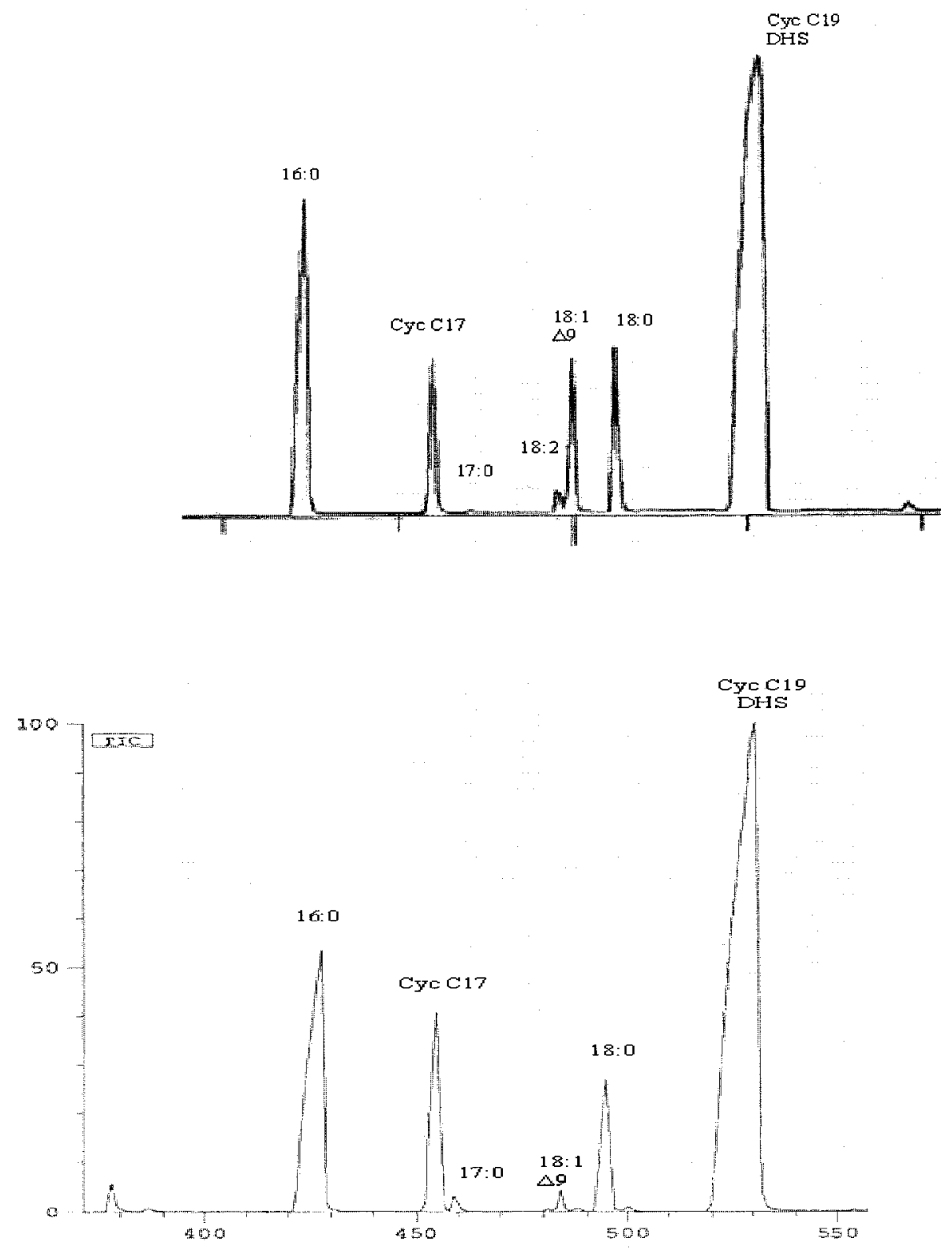

Figure 2.2.2 Gas Chromatographs of FAMEs isolated from $L$. chinensis before and after $m$-CPBA oxidation.

From the GCs, it can be seen that the olefinic content has been reduced from $42 \%$ to nearly $0 \%$. The spectroscopic properties of the collected material matched that of the 
synthetic standard and data previously reported for DHS. ${ }^{27,29}$

The stereochemical analyis of DHS was performed following the procedure of Tocanne. ${ }^{52}$ Crude Litchi DHS (102mg) was oxidized with $\mathrm{CrO}_{3}(220 \mathrm{mg}, 2.2 \mathrm{mmol})$ for 66 hours as described for the oxidation of synthetic DHS (Section 2.1) and the product mixture (64.5mg) chromatographed $\left(\mathrm{SiO}_{2}, \mathrm{Hex}_{\mathrm{Et}} \mathrm{O}(10: 1)\right)$ to give unreacted DHS (27mg), 11-ketoDHS (ketone A, $9.2 \mathrm{mg}$ ) and 8-keto DHS (ketone B, $10.2 \mathrm{mg}$ ). Use of the correct solvent mixture for flash chromatography was very important since the two isomeric $\alpha$-cyclopropyl ketones are of similar polarity. TLC analysis $\left(\mathrm{SiO}_{2}, \mathrm{Hex}: \mathrm{Et}_{2} \mathrm{O}\right.$ (10:1), phosphomolybdic acid visualization) of the crude product revealed three components representing the two ketones $\left(\mathrm{R}_{\mathrm{f}}=0.26\right.$ and 0.18$)$ and the unoxidized starting material $\left(R_{f}=0.4\right)$. The less polar ketone (ketone $A$ ) was found to be the 11-keto derivative of DHS, while the more polar ketone (ketone B) was the 8-keto derivative as would be predicted from the literature. ${ }^{60,29}$ The identity of each fraction was confirmed by TLC, GC-MS and 13C NMR analysis with the help of synthetic standards.

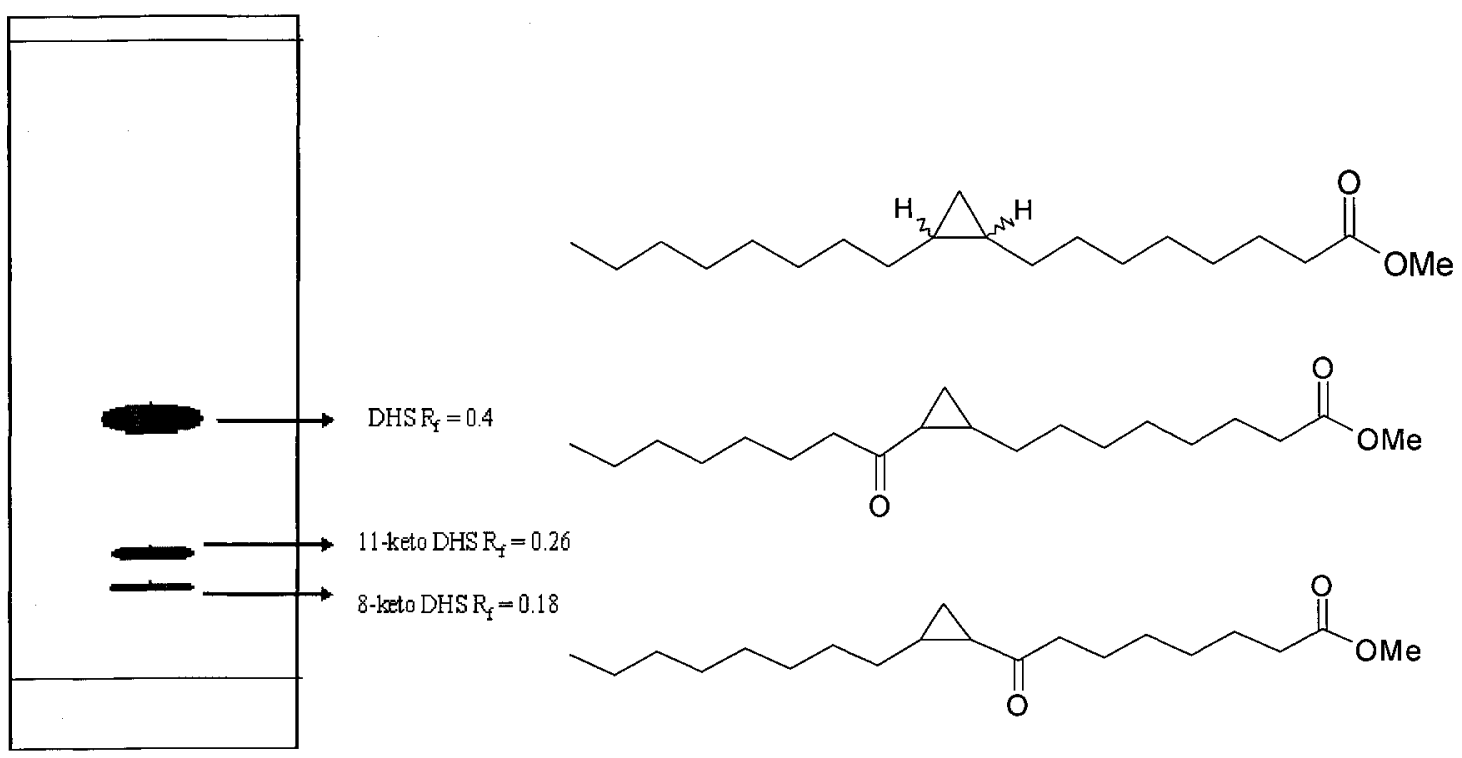

Figure 2.2.3 Thin Layer Chromatography of oxidized DHS mixture. 


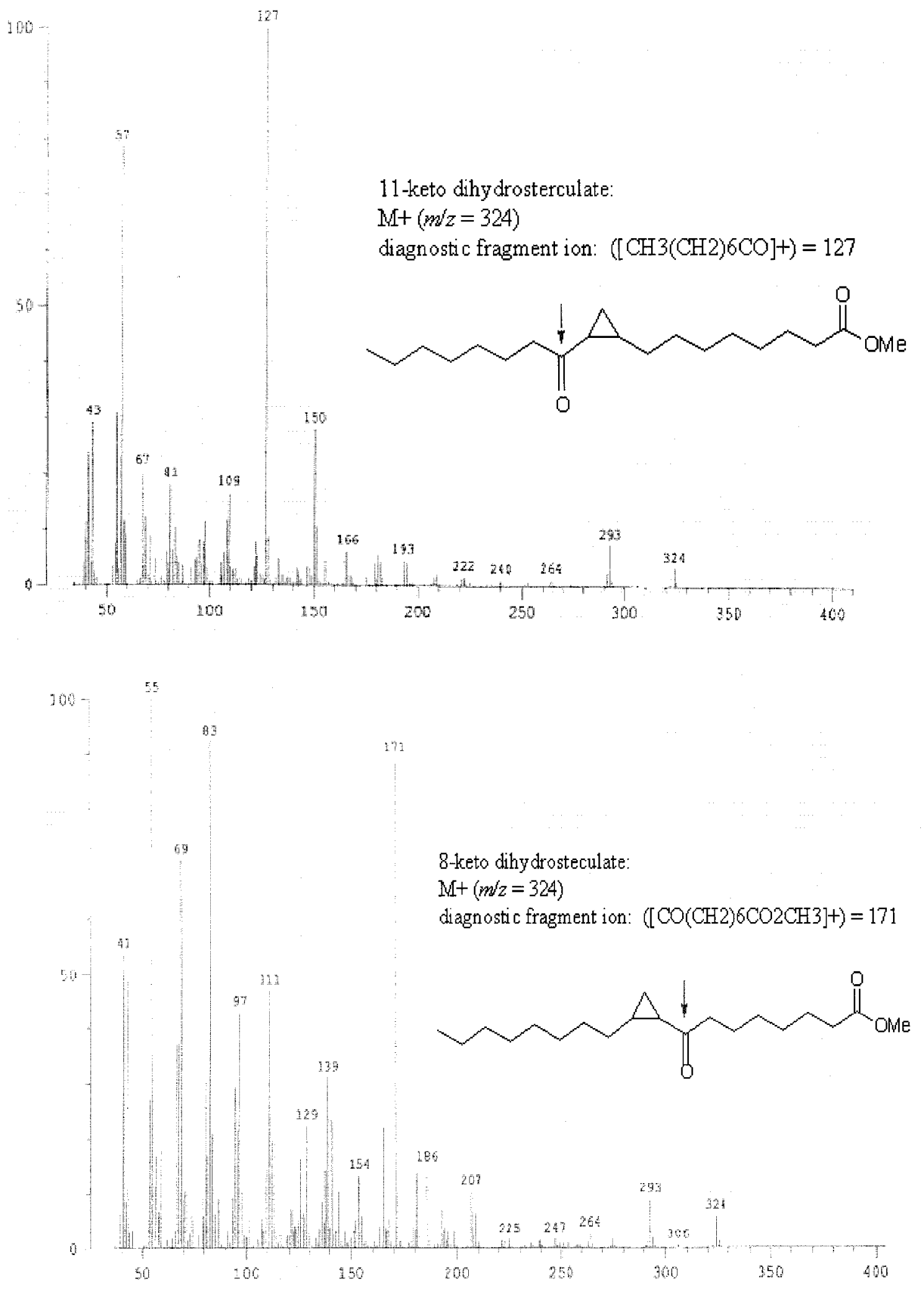

Figure 2.2.4 Mass Spectra of $\alpha$-cyclopropyl ketones of DHS from $L$. chinensis. 
Because the ketones have equivalent molecular weights, they cannot be identified on the basis of retention time by routine gas chromatography. However GC/MS analysis of each of the two oxidized fractions separated by flash chromatography confirmed the identity of the ketones based upon mass spectrometry cleavage patterns.

Table 2.2.1 $\quad{ }^{13}$ C NMR Data for Synthetic and Litchi DHS and keto derivatives

\begin{tabular}{|c|c|c|c|c|}
\hline & Syn & Litchi & Litchi & Litchi \\
\hline & $\Delta 9$ cyc & $\Delta 9$ cyc & 11 -ketoA & 8 -ketoB \\
\hline Ref & 77.0322 & 77.0191 & 77.0239 & 77.0282 \\
\hline 1 & 174.37 & 174.34 & 174.34 & 174.23 \\
\hline 2 & 34.14 & 34.14 & 34.11 & 34.03 \\
\hline 3 & 24.99 & 24.98 & 24.94 & 24.80 \\
\hline 4 & 29.19 & $29.17^{*}$ & $29.14^{*}$ & $28.94^{*}$ \\
\hline 5 & 29.33 & $29.33^{*}$ & $29.12^{*}$ & $28.97^{*}$ \\
\hline 6 & 29.39 & $29.38^{*}$ & $29.22^{*}$ & $23.89^{*}$ \\
\hline 7 & 30.15 & $30.14^{*}$ & $29.87^{*}$ & 44.71 \\
\hline 8 & 28.69 & $28.68^{\mathrm{a}^{*}}$ & $25.41^{*}$ & 209.31 \\
\hline 9 & 15.74 & $15.74^{\mathrm{a}^{*}}$ & $25.68^{*}$ & $26.23^{*}$ \\
\hline 10 & 15.78 & $15.78^{\mathrm{a}^{*}}$ & $26.19 *$ & $25.74^{*}$ \\
\hline 11 & 28.74 & $28.74^{\mathrm{a}^{*}}$ & 209.58 & $25.52^{*}$ \\
\hline 12 & 30.24 & $30.23^{\mathrm{a}^{*}}$ & 44.90 & $29.97^{*}$ \\
\hline 13 & 29.47 & $29.47^{*}$ & $24.16^{*}$ & $29.30^{*}$ \\
\hline 14 & 29.71 & $29.70^{*}$ & $29.14^{*}$ & $29.36^{*}$ \\
\hline 15 & 29.71 & $29.70^{*}$ & $29.31^{*}$ & $29.60^{*}$ \\
\hline 16 & 31.95 & 31.94 & 31.73 & $31.88^{*}$ \\
\hline 17 & 22.72 & 22.71 & 22.64 & 22.69 \\
\hline 18 & 14.14 & 14.13 & 14.09 & 14.12 \\
\hline 19 & 10.93 & 10.92 & 14.30 & 14.32 \\
\hline me & 51.45 & 51.44 & 51.45 & 51.47 \\
\hline
\end{tabular}

* Tentative assignments based on a comparison with Tulloch's rigorous assignments of methyl oleate and methyl stearate. ${ }^{61}$

${ }^{a}$ Based on deuterium labeling data and by analogy with assignments for methyl oleate (quasienantiotopic carbons). ${ }^{62}$

${ }^{13} \mathrm{C}$ NMR data was used to compare the DHS isolated from Litchi chinensis with the DHS synthesized in the lab. There was very strong similarity 
between the DHS from the two sources, as would be expected. Extraneous minor peaks (not shown) could be attributed to saturated fatty acid methyl ester content. The ${ }^{13} \mathrm{C}$ NMR data also confirmed the presence of the ketone functional group in each of the more polar fractions as evidenced by appearance of a characteristic peak at $\sim 209 \mathrm{ppm}$. Appropriate changes in chemical shifts of carbons close to the new carbonyl carbon were also noted.

The polarimetric analysis of 11-keto and 8-keto DHS (diethyl ether solutions) was carried out using plane polarized light of wave length $589 \mathrm{~nm}$ (Sodium D line). Diethyl ether was used as the solvent in these measurements to allow comparison with previously published work..$^{52}$ An optical rotation $\left(\alpha^{21}\right)$ of $+0.190^{\circ}$ and $-0.128^{\circ}$ was measured for 11-keto DHS and 8-keto DHS respectively. To calculate the corresponding specific rotations, the sample purity of each of the two ketone fractions was assessed by ${ }^{13} \mathrm{C}$ NMR, in combination with GC-MS. It was determined that ketone A, 11-keto DHS, was pure while the 8-keto derivative (ketone B) was contaminated with 11-keto DHS (6 $\%)$ and an unknown impurity (4\%). The latter contaminant was assumed to be an unsaturated ketone arising from cyclopropyl ring opening, and thus achiral. The appropriate corrections were applied in the calculation of the specific rotation of 8-keto DHS.

\section{Calculation of Specific Rotation for 11-keto and 8-keto DHS derived from Litchi}

Fraction 1 (9.2 mg): Pure11-keto DHS (ketone A). Optical Rotation $=0.190+/-0.005$

$$
[\alpha]_{\mathrm{D}}^{21}=\frac{\alpha_{\mathrm{D}}{ }^{21} \mathrm{obs} \times 100}{1 \times \operatorname{conc}(\mathrm{mg} / 0.1 \mathrm{~mL})}=\frac{+0.190 \times 100}{1 \times 0.92}=+20.7+/-0.5
$$


Fraction 2 (10.2 mg): $90 \% 8$-keto (B)

$6 \% 11-$ keto (A)

$4 \%$ contaminant assumed to be achiral

Optical Rotation $=-0.128+/-0.005$

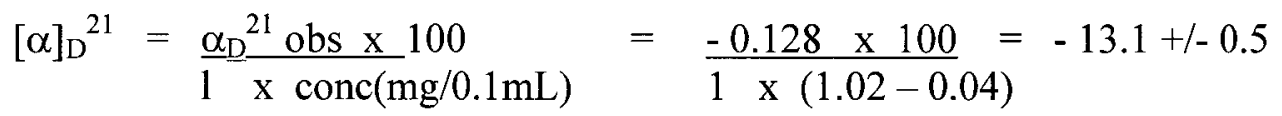

To correct for the presence of minor amounts of ketone $A$ in the sample of ketone $\mathrm{B}$, the value for $[\alpha]_{\mathrm{D}}{ }^{21}$ obtained for ketone $\mathrm{A}$ above was used to solve for $\mathrm{x}$ in the following equation where $\mathrm{x}=[\alpha]_{\mathrm{D}}^{21}$ (8-keto DHS):

$0.94 x+0.06(20.7)=-13.1+/-0.5$

$\mathrm{x}=-15.3+/-0.5$

The values for specific rotations calculated above were converted to molar rotations $\left([\phi]_{\mathrm{D}}\right)$ to allow comparison with the values obtained by Tocanne for comparable compounds.

11-keto DHS (ketone A):

$[\phi]_{\mathrm{D}}=\frac{\mathrm{M}[\alpha]_{\mathrm{D}}^{21}}{100}=\frac{324 \times 20.7}{100}=+67+/-2$

8-keto DHS (ketone B):

$[\phi]_{\mathrm{D}}=\frac{\mathrm{M}[\alpha]_{\mathrm{D}}^{21}}{100}=\frac{324 \times-15.3}{100}=-50+/-2$

Since unbranched, long chain aliphatic $\alpha$-cyclopropyl ketones exhibit characteristic chiroptical activity, reference compounds of known absolute configuration could be used to assess the stereochemistry around the cyclopropyl ring of DHS. The available reference structures described by Tocanne were the 10- and 13- $\alpha$-cyclopropyl ketones of 
lactobacillic acid. As shown in Figure 2.2.5, the pattern of $[\phi]_{D}$ values found for DHS, correlated with the parent cyclopropyl stereogenic centers bearing the ' $11 \mathrm{R}, 12 \mathrm{~S}$ ' configuration.

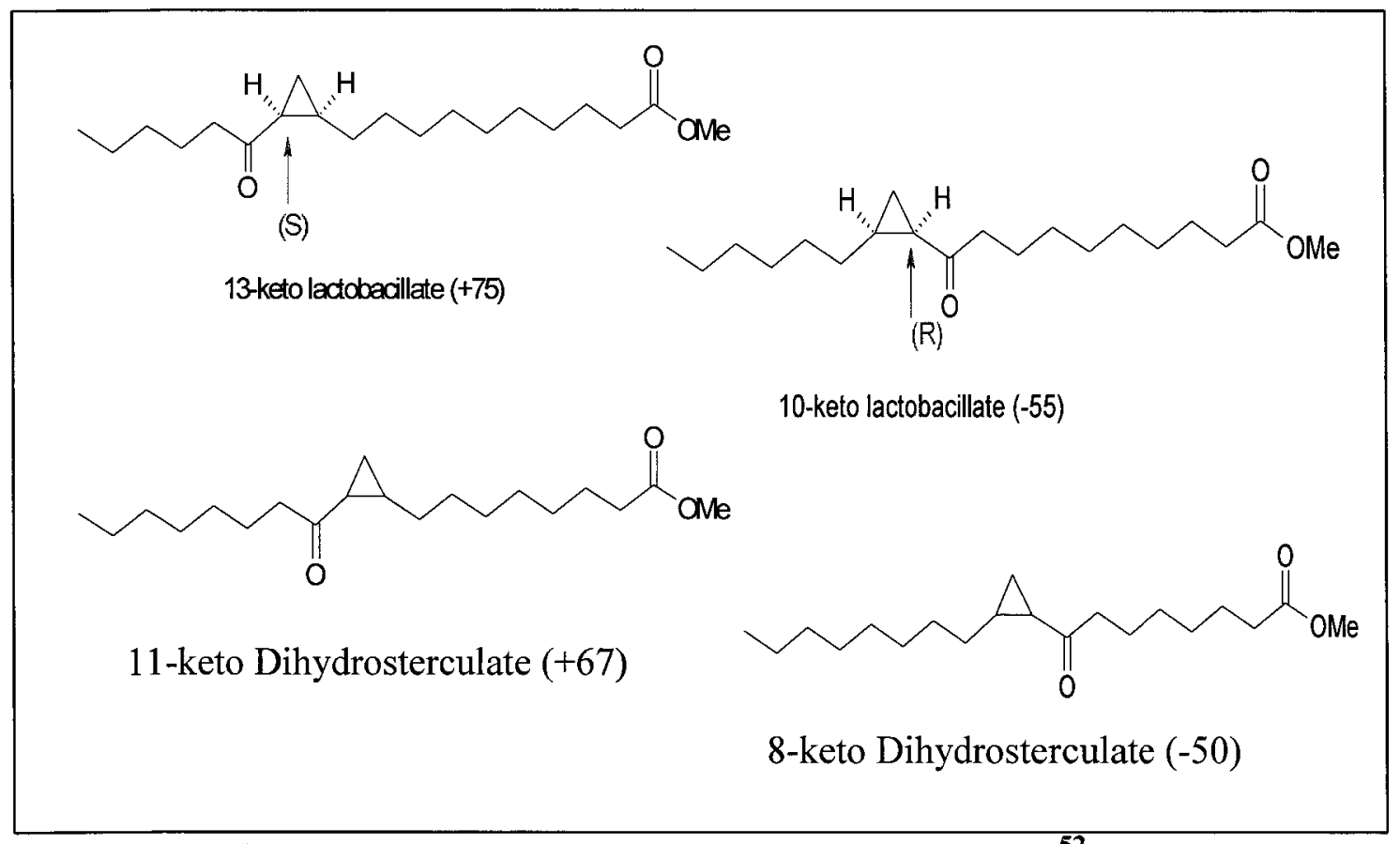

Figure 2.2.5 Methyl Lactobacillate Reference Structures $^{52}$ and $\alpha$-cyclopropyl Ketones of DHS from Litchi chinensis.

Because the 13-ketolactobacillate and 11-keto dihydrosterculate both exhibited positive molar rotations, an $S$-configuration was assigned to C-10 of DHS. Since it is known that the cyclopropyl has the cis-stereochemistry, this automatically means that the configuration at C-9 of DHS is $(R)$. This was confirmed by the finding that 8-keto DHS (and 10-keto lactobacillate) exhibited a negative molar rotation, indicating a stereocentre of the $R$-configuration at C-9. Taken together, these results indicate that the configuration of methyl dihydrosterculate at $\mathrm{C} 9$ and $\mathrm{C} 10$ is $(R)$ and $(S)$ respectively. ${ }^{63}$ 


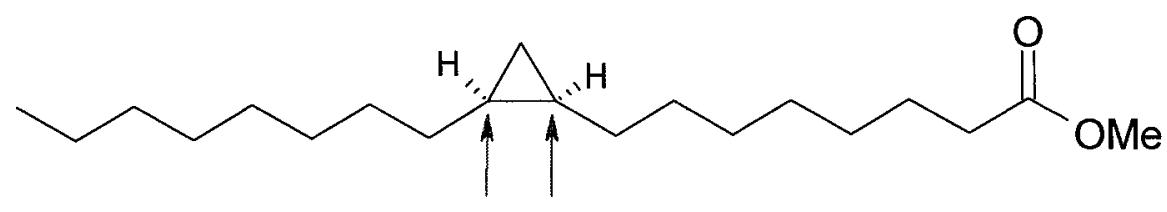

(S) $(\mathrm{R})$

Figure 2.2.6 Methyl Dihydrosterculate from Litchi chinensis.

The residual DHS from Litchi was examined by polarimetry but exhibited an optical rotation of $0^{\circ}$, even at very high concentrations $(345 \mathrm{mg} / \mathrm{ml})$. This result is in contrast with that reported by E . J. Corey (Nobel Laureate, Department of Chemistry, Harvard University) who devised a synthetic strategy to produce enantiomerically enriched dihydrosterculic acid. ${ }^{64}$ DHS produced by the Corey route was reported to have an specific optical rotation of $+0.9\left(c=14.5, \mathrm{CHCl}_{3}\right)$. Attempts to replicate these findings using the naturally occurring fatty acid isolated in the Buist lab have not been successful. Though the Litchi sample was contaminated with optically inactive methyl palmitate, the quantity was adjusted to ensure that the concentration of DHS was comparable to that used by the Corey group. It is possible that our mixture of FAMEs has other chirally active molecules present that are responsible for canceling any signal from DHS, though it seems unlikely that this would result in an overall optical rotation of exactly $0^{\circ}$. It was also surprising that Manabu et al. obtained such a high numerical value for the optical rotation $(+0.9)$ given that the DHS molecule is quasi-symmetrical and that the less symmetrical, methyl lactobacillate has a lower specific optical rotation $(+0.25)$ and which can only be observed at very high concentrations $(0.5 \mathrm{~g} / \mathrm{mL}) .{ }^{64}$ Work is continuing to obtain pure samples of Litchi DHS in order to shed more 
light on the Corey result. It should be noted that this effort is confirmatory in nature and does not affect the overall conclusions of this thesis.

Having confirmed a source for one enantiomer of DHS, the next step in the project was to find either a natural source or a synthetic strategy to obtain the other enantiomer. Once both enantiomers were available, we would be in a position to continue investigating the desaturation of DHS to sterculic acid in some plant species. 


\section{3a Absolute configuration of Dihydrosterculate isolated from Lactobacillus plantarum}

The enantioselectivity of methyl transfer during the cyclopropanation of olefins is given by the absolute configuration of the cyclopropyl product. Of particular interest to the Buist lab is the stereochemical analysis of dihydrosterculic acid from different sources. This fatty acid is thought to be desaturated to sterculic acid in some plant species. ${ }^{65}$ The determination of the configuration of the 9,10 - cyclopropyl group that undergoes this desaturation will provide further insight into the stereoselectivity of this remarkable reaction. Given samples of both enantiomers of DHS, we would have the ability to investigate the stereospecificity of sterculate formation in vivo.

Obtaining stereochemically pure compounds is not an easy task, as many synthetic routes lead to racemization at some point. Naturally occurring molecules, however, normally occur as only one enantiomer as the enzymes that produce them are chiral and often highly stereoselective. It had been previously shown that, under the proper growth conditions, the bacterium, Lactobacillus plantarum could be induced to produce dihydrosterculic acid from oleate (cis-9-octadecenoate) in the medium instead of lactobacillic acid, its 11,12 isomer, from endogenously produced cis-vaccenate (cis11-octadecenoate). ${ }^{19}$ Fluorine-labeled oleates (cis-7-fluoro-9-octadecenoate and cis12-fluoro-9-octadecenoate ) and cis-vaccenate (cis-9-fluoro-11-octadecenoate and cis14-fluoro-11-octadecenoate) were used to probe the location of carbocationic intermediates formed during cyclopropanation. ${ }^{32}$ Remote fluorine substitution is known to retard carbocation formation in a distance dependent manner. Remarkably, it was found that the pattern of observed fluorine-induced rate retardations was reversed for the 
two pairs of fluorinated olefinic fatty acids. That is, oleate appeared to form a carbocation at $\mathrm{C}-10$, the carbon closer to the methyl terminus upon methyl transfer, while $c i s$-vaccenate appeared to be methylated so as to give a carbocation at $\mathrm{C} 11$, closer to the carboxyl end. ${ }^{32}$ These results indicated that if a single enzyme was responsible for CFA production in $L$. plantarum, oleate and vaccenate might be attacked by SAM on opposite faces.

This hypothesis was examined by Rasonyi and Arigoni and they reported that the absolute configuration of DHS and lactobacillate(LB) produced by L. plantarum in a chemically defined medium was $9 S, 10 R$ and $11 R, 12 S$ respectively. ${ }^{29}$ Recall that the absolute configuration of DHS isolated from Litchi was shown to be $9 R, 10 S$ (pp. 40). This situation opens the door to a rigorous investigation of the stereochemistry of DHS desaturation given that both enantiomers are now potentially available. It was decided to determine the practicality of obtaining the $9 S, 10 R$ enantiomer of DHS in sufficient quantities to permit such an investigation.

Lactobacillus plantarum cultures were grown in commercially available De Man, Rogosa and Sharpe (MRS) broth which permitted more luxuriant growth of this organism. This medium (1L) is made up of peptone from casein $10 \mathrm{~g}$; meat extract $8 \mathrm{~g}$; yeast extract $\mathrm{g}$; $\mathrm{D}(+)$-glucose $20 \mathrm{~g}$; dipotassium hydrogen phosphate $2 \mathrm{~g}$; Tween ${ }^{\circledR} 801 \mathrm{~g}$; di-ammonium hydrogen citrate $2 \mathrm{~g}$; sodium acetate $5 \mathrm{~g}$; magnesium sulfate $0.2 \mathrm{~g}$; manganese sulfate $0.04 \mathrm{~g}$, and is highly enriched in oleate from the breakdown of the Tween 80 constituent. ${ }^{66}$ Cells were grown in $13 \times 1 \mathrm{~L}$ of medium for 24 hours at $37^{\circ} \mathrm{C}$ and harvested by centrifugation at 10,000 RPM. Pellet weight (wet) averaged $4 \mathrm{~g}$ per liter of medium. The cells ( $54 \mathrm{~g}$ ) were hydrolyzed with refluxing in $2 \mathrm{~N} \mathrm{KOH}$ in $50 \%$ 
ethanol for 5 hours and the fatty acid fraction (orange oil, 280mg) was methylated using boron- trifluoride/ methanol. ${ }^{29}$ The FAMEs $(137 \mathrm{mg})$ were sent for GC-MS analysis and the following fatty acid profile was obtained: myristate $\left(\mathrm{C}_{14: 0}\right) 5 \%$, palmitate $\left(\mathrm{C}_{16: 0}\right)$ $18 \%$, palmitoleate $\left(\mathrm{C}_{16: 1}\right) 1 \%$, stearate $\left(\mathrm{C}_{18: 0}\right) 4 \%$, oleate/cis-vaccenate $\left(\mathrm{C}_{18: 1}\right) 8 \%$, cyclopropyl fatty acids $\left(\mathrm{C}_{19}\right.$; cyc 9 and 11) $64 \%$.

The FAMEs $(137 \mathrm{mg})$ were treated with $m$-CPBA to reduce the olefinic content. The resultant epoxide fraction was removed by flash chromatography $\left(\mathrm{SiO}_{2}\right.$; hex:Et $\left.{ }_{2} \mathrm{O}, 10: 1\right)$ yielding $70 \mathrm{mg}$ crude DHS (70 mg). GC-MS analysis of Lactobacillate FAMEs after $m$-CPBA treatment indicated a distribution of: myristate $\left(\mathrm{C}_{14: 0}\right) 7 \%$, palmitate $\left(\mathrm{C}_{16: 0}\right) 24 \%$, palmitoleate $\left(\mathrm{C}_{16: 1}\right)<1 \%$, stearate $\left(\mathrm{C}_{18: 0}\right) 4 \%$, oleate/cis-vaccenate $\left(\mathrm{C}_{18: 1}\right)<1 \%$, cyclopropyl fatty acids $\left(\mathrm{C}_{19} ; \operatorname{cyc} 9 \&\right.$ cyc 11$) 65 \%$.

${ }^{13} \mathrm{C}$ NMR analysis of the mCPBA treated FAMES indicated that DHS and lactobacillic acid (LB) were present in an 80:20 ratio. The presence of three peaks in each of the three key diagnostic regions of the carbon NMR spectrum of the FAMEs was evidence of a mixture of CFAs and these peaks were used to determine the relative quantities of LB and DHS. The assignments were based on the hypothesis that for LB, the cyclopropyl and neighboring carbons would be less differentiated due to their increased distance from the perturbing effect of the $\mathrm{C}-1$ carbonyl. In addition the chemical shifts of the major peak corresponded to that of synthetic DHS. 
Table 2.3.1 ${ }^{13} \mathrm{C}$ NMR Shifts for DHS and LB from L. plantarum Grown in MRS Broth.

\begin{tabular}{|c|c|c|}
\hline C\# & MRS & MRS \\
\hline & $\Delta 9$ cyc DHS & D11cyc LB \\
\hline ref & 77.0223 & 174.37 \\
\hline 1 & 174.39 & 34.13 \\
\hline 2 & 34.13 & 24.98 \\
\hline 3 & 24.97 & 29.18 \\
\hline 4 & 29.17 & 29.27 \\
\hline 5 & 29.33 & 29.38 \\
\hline 6 & 29.38 & 29.64 \\
\hline 7 & & 29.64 \\
\hline 8 & & \\
\hline 9 & & \\
\hline 10 & & \\
\hline 11 & & \\
\hline 12 & & \\
\hline 13 & 29.45 & 29.47 \\
\hline 14 & 29.70 & 31.96 \\
\hline 15 & 29.70 & 22.72 \\
\hline 16 & 31.94 & 14.14 \\
\hline 17 & 22.71 & 10.91 \\
\hline 18 & 14.13 & 51.45 \\
\hline$\Delta$ & 10.91 & 29.70 \\
\hline me & 51.46 & \\
\hline pal & & \\
& & \\
\hline & & \\
\hline & & \\
\hline 10.69 \\
\hline
\end{tabular}

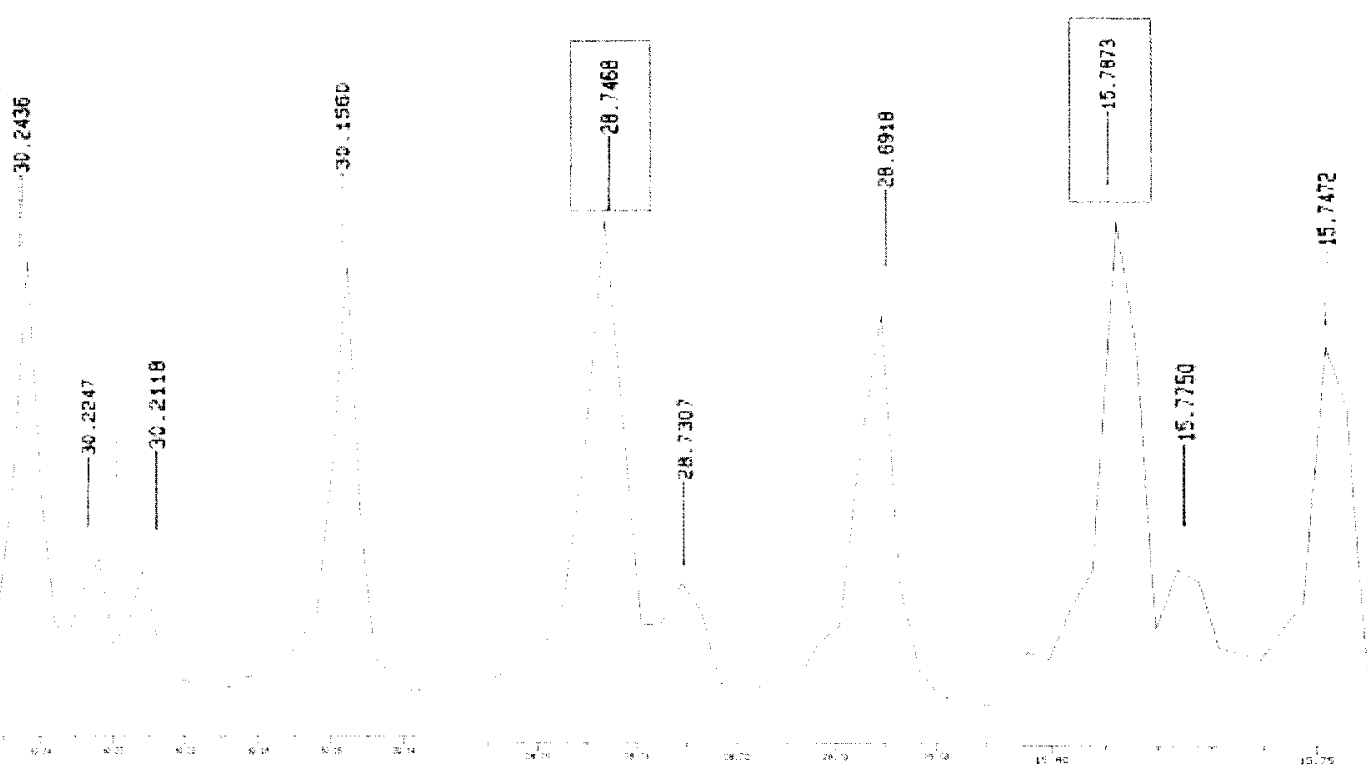

Figure 2.3.1 ${ }^{13} \mathrm{C}$ NMR Showing DHS and LB Isomers of C18 CFAs from L. plantarum 
It was of interest to determine the absolute configuration of the DHS obtained in this manner and to compare our result with the unpublished data of Rasonyi. ${ }^{29}$ Thus the CFA FAMEs (70mg) from L. plantarum was oxidized with $\mathrm{CrO}_{3}(85 \mathrm{mg}, 0.85 \mathrm{mmol})$ for 66 hours. The reaction and extraction conditions used were identical to that employed for the analysis of Litchi cyclopropane fatty acids. Thin layer chromatography analysis of the oxidized mixture $\left(\mathrm{SiO}_{2}, 10: 1\right.$ Hexanes:diethyl ether, $\mathrm{PMA}$ visualization) revealed the presence of three major and two minor spots, as shown in Figure 2.3.2. This was not unexpected because of the mixture CFAs present in the FAMEs from L. plantarum grown in MRS broth, a total of four possible $\alpha$-cyclopropyl isomeric ketones were possible upon oxidation with $\mathrm{CrO}_{3}$. The $\mathrm{R}_{\mathrm{f}}$ values obtained for the two minor spots corresponding to Ketones A (less polar, 13-keto LB) and B (more polar, 10-keto LB) both of LB (0.12 and 0.09) were found to be somewhat lower than that of the corresponding DHS ketones. It was anticipated that Ketones A from DHS (11-keto DHS) and LB would have similar Rf values while Ketones B from DHS (8-keto DHS) and LB would form a second near-unresolvable pair. 


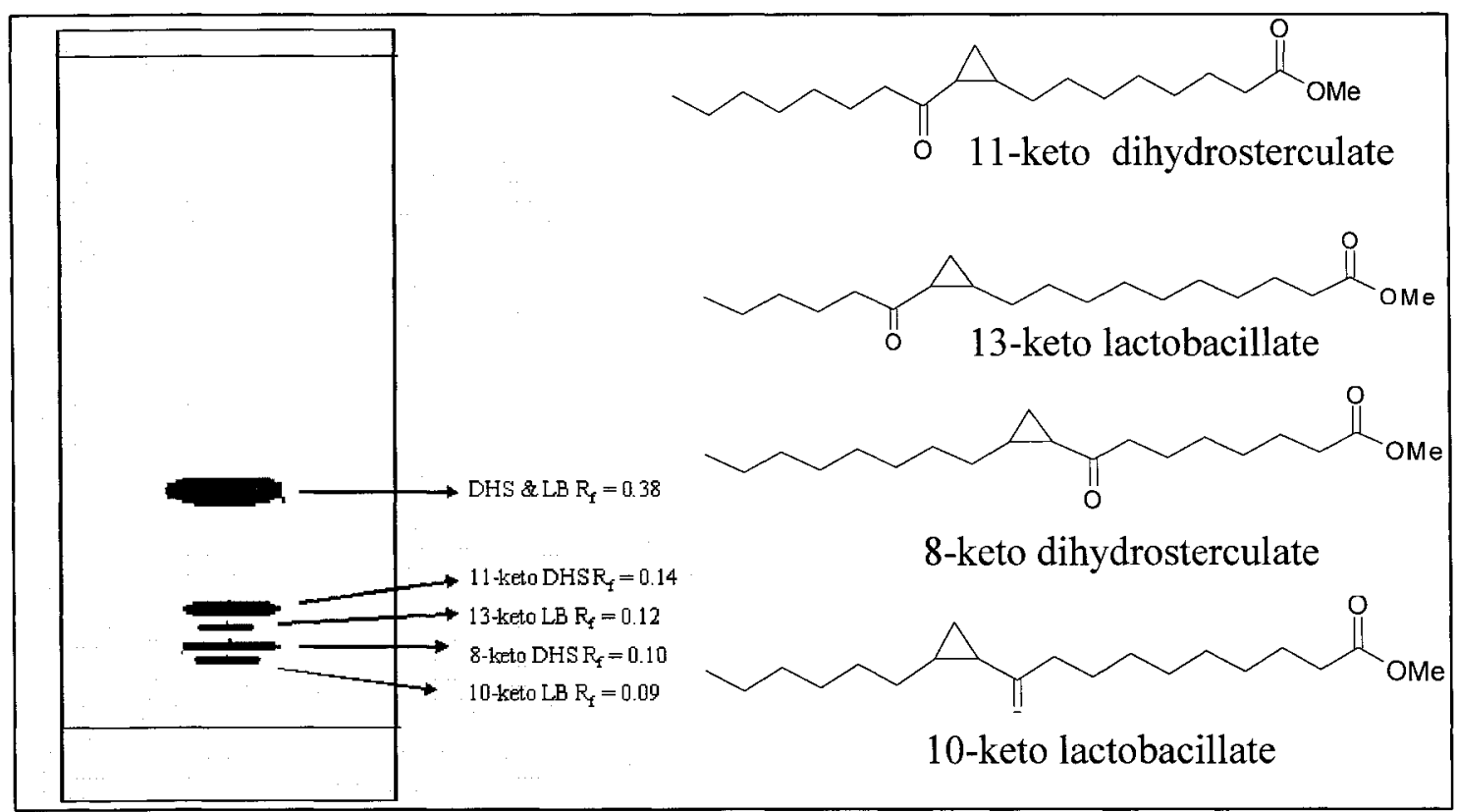

Figure 2.3.2 TLC separation of $\alpha$-cyclopropyl ketones from oxidation of $L$. plantarum.

Flash chromatography $\left(\mathrm{SiO}_{2} 230-400\right.$ mesh, Hexanes/ Diethyl ether: 10:1) was used to isolate the two major ketone fractions of interest as well as the residual CFAs (fraction $1=7.8 \mathrm{mg}$, fraction $2=9.2 \mathrm{mg}, \mathrm{CFA}=34.1 \mathrm{mg}$ ). These fractions were analyzed by GC-MS and ${ }^{13} \mathrm{C}$ NMR. GC-MS of each fraction provided identity of the ketones based upon MS cleavage patterns. 


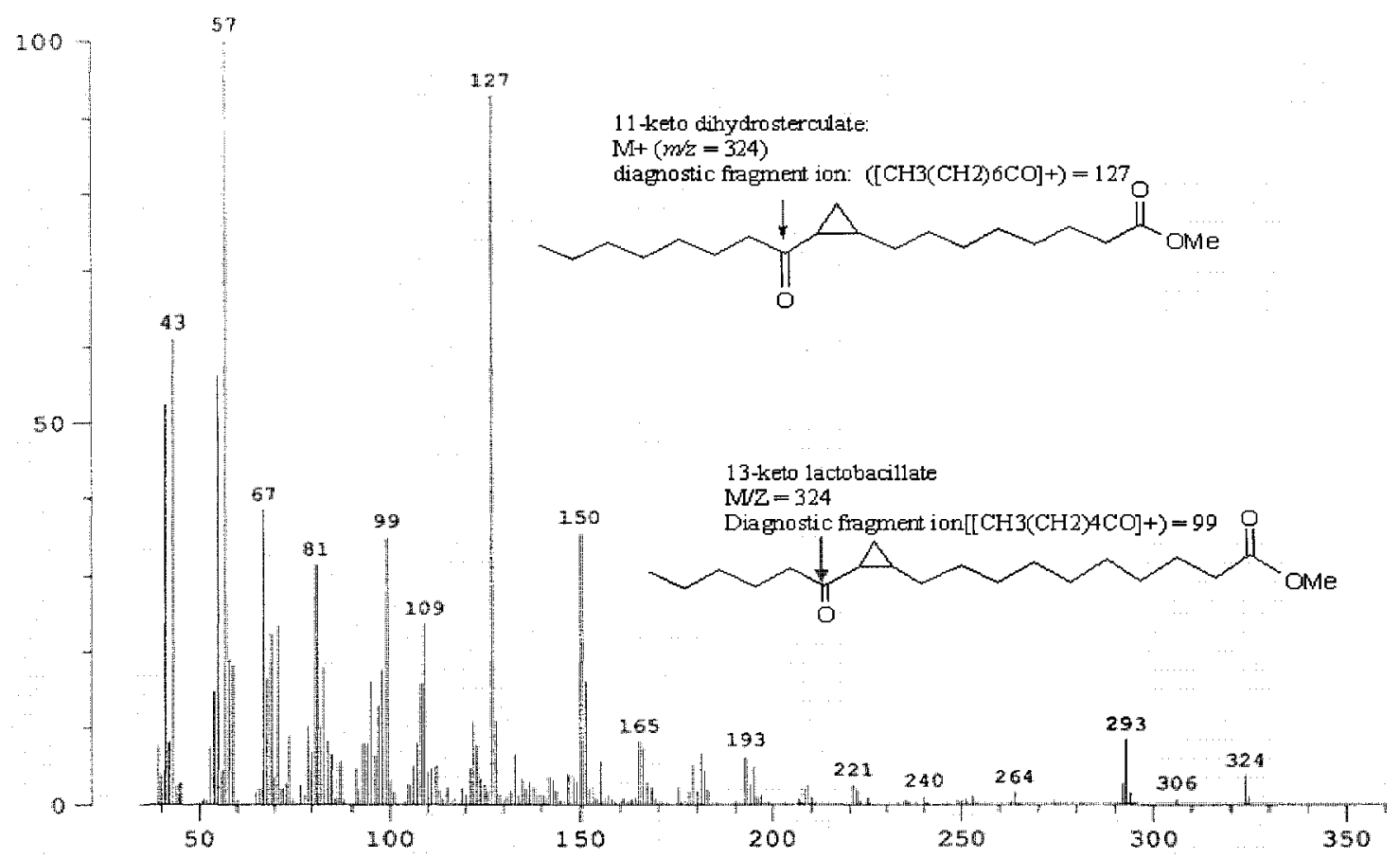

Figure 2.3.3 Mass Spectrum of Ketone Fraction 1 Showing Cleavage Patterns for 11-keto DHS and 13-keto LB.

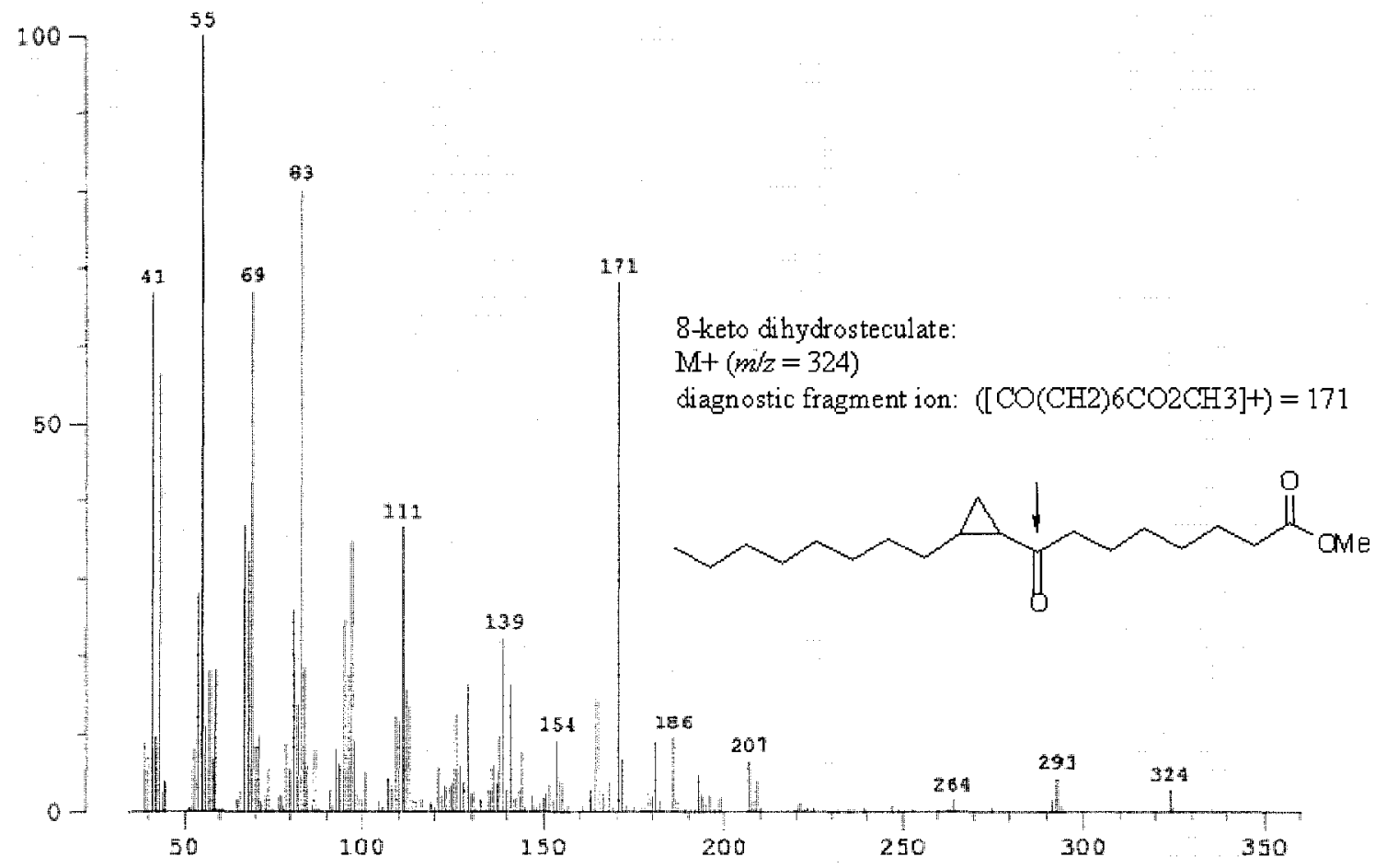

Figure 2.3.4 Mass Spectrum of Ketone Fraction 2 Showing Cleavage Patterns for 8-keto DHS. 
${ }^{13} \mathrm{C}$ NMR data was required to determine additional information on sample and isomeric purity of each of the two ketone fractions. This analysis indicated that Fraction 1 consisted of a 75:25 mixture of 11-keto DHS and 13-keto LB respectively, as was expected from the MS data. Fraction 2 was found to contain $93 \% 8$-keto DHS, $3 \% 11$ keto DHS and $4 \%$ 10-keto LB, though the cleavage peaks were not seen (m/e 99 and $\mathrm{m} / \mathrm{e} 171$, respectively) for these two contaminants in the MS, presumably due their low intensity.

2)

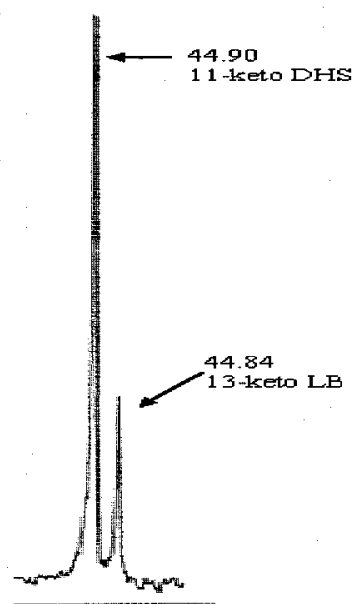

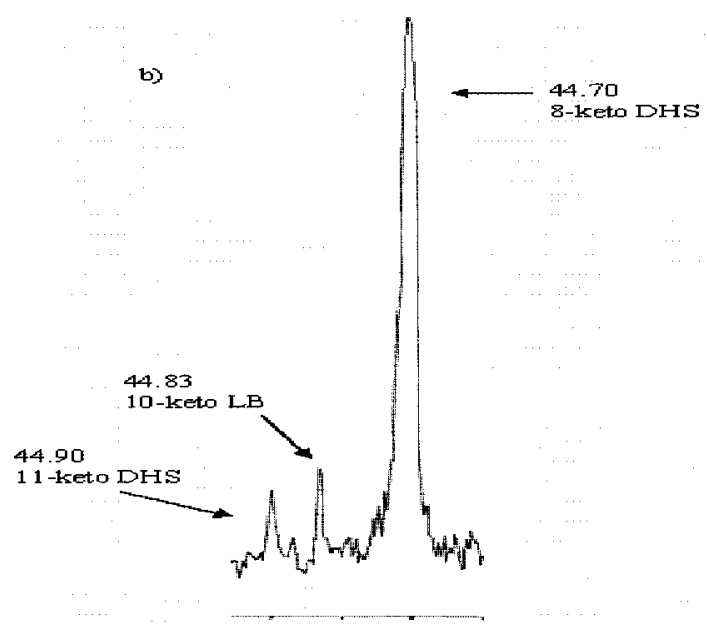

Figure 2.3.5 a) ${ }^{13} \mathrm{C}$ NMR of Ketone Fraction A showing shifts for 11-keto DHS (75\%) and 13-keto

LB contaminant (25\%). b) ${ }^{13} \mathrm{C}$ NMR of Ketone Fraction B showing shifts for 8-keto DHS (93\%) and 11-keto DHS (3\%) and 10-keto LB contaminants (4\%). 
Table 2.3.2 ${ }^{13} \mathrm{C}$ NMR Shifts for $\alpha$-cyclopropyl ketones of DHS and LB from L. plantarum Grown in MRS Broth.

\begin{tabular}{|c|c|c|c|c|c|c|}
\hline $\mathrm{C \#}$ & MRS & MRS & MRS & MRS & MRS & MRS \\
\hline & $\begin{array}{l}\Delta 9 \text { cyc } \\
\text { DHS }\end{array}$ & $\begin{array}{c}\Delta 11 \text { cyc } \\
\text { LB }\end{array}$ & $\begin{array}{c}\text { 11-ketA } \\
\text { DHS }\end{array}$ & $\begin{array}{c}\text { 13-ketA } \\
\text { LB }\end{array}$ & $\begin{array}{c}\text { 8-ketB } \\
\text { DHS }\end{array}$ & $\begin{array}{c}\text { 10-ketB } \\
\text { LB }\end{array}$ \\
\hline ref & 77.0223 & 77.0223 & 77.0196 & 77.0196 & 77.0218 & 77.0218 \\
\hline 1 & 174.39 & 174.37 & 174.33 & 174.36 & 174.22 & ND \\
\hline 2 & 34.13 & 34.13 & 34.11 & 34.12 & 34.03 & 34.05 \\
\hline 3 & 24.97 & 24.98 & 24.94 & 24.96 & 24.80 & 24.89 \\
\hline 4 & 29.17 & 29.18 & 29.145 & 29.15 & 28.94 & ND \\
\hline 5 & 29.33 & 29.27 & 29.11 & 29.32 & 28.97 & $\mathrm{ND}$ \\
\hline 6 & 29.38 & 29.38 & 29.22 & 29.41 & 23.89 & 24.08 \\
\hline 7 & 30.14 & 29.64 & 29.87 & 29.55 & 4.70 & ND \\
\hline 8 & 28.67 & 29.64 & 25.41 & 29.24 & 200,30 & ND \\
\hline 9 & 1573 & 30.22 & 2368 & 29.94 & 2623 & 44.83 \\
\hline 10 & 15.77 & 28.72 & 26.9 & 25.46 & 357 & ND \\
\hline 11 & 28.73 & 15.76 & 20953 & 23,70 & 835 & 25,50 \\
\hline 12 & 30.23 & 15.78 & 445 & 26.22 & 29.97 & 29.93 \\
\hline 13 & 29.45 & 28.73 & 24.15 & 209.55 & 29.30 & ND \\
\hline 14 & 29.70 & 30.20 & 29.15 & 44.84 & 29.36 & ND \\
\hline 15 & 29.70 & 29.47 & 29.31 & 23.82 & 29.60 & ND \\
\hline 16 & 31.94 & 31.96 & 31.73 & 31.52 & 31.88 & 31.85 \\
\hline 17 & 22.71 & 22.72 & 22.64 & 22.52 & 22.69 & 22.64 \\
\hline 18 & 14.13 & 14.14 & 14.69 & 13.97 & 14.13 & 14.09 \\
\hline$\Delta$ & 10.91 & 10.91 & 142 & 14.280 & 8.72 & ND \\
\hline me & 51.46 & 51.45 & 51.45 & 51.45 & 51.47 & ND \\
\hline
\end{tabular}

Polarimetry was conducted on both ketone fractions, yielding optical rotation measurements $\left(\alpha_{D}{ }^{21}\right.$ observed $)$ of $-0.105+/-0.005$ and $+0.138+/-0.005$ for fractions 1 and 2, respectively. The apparent specific optical rotation of Ketone A derived from DHS (Fraction 1) was calculated to be:

$$
[\alpha]_{\mathrm{D}}^{21}=\frac{\alpha_{\mathrm{D}}{ }^{21} \mathrm{obs} \times 100}{1 \times \mathrm{c}(\mathrm{mg} / 0.1 \mathrm{~mL})}=\frac{-0.105 \times 100}{1 \times 0.78}=-13.5+/-0.6
$$

To correct for the $25 \%$ contamination by 13 -ketolactobacillate, the $[\alpha]_{D}$ for this molecule obtained by Rasonyi (+21.6) was used to solve for $\mathrm{x}$, where $\mathrm{x}$ represents the 
true value for the specific rotation of Ketone A (DHS):

$0.75 \mathrm{x}+(0.25) 21.6=-13.5 ; \mathrm{x}=-25.2+/-0.9$

The molar rotation for Ketone $\mathrm{A}$ is therefore

$[\phi]_{\mathrm{D}}=\frac{\mathrm{M}}{100} \underline{\mathrm{L}}_{\underline{\mathrm{D}}}^{21}=\frac{324 \mathrm{x}-25.2}{100}=-82+/-3$

This result correlates reasonably well with Rasonyi's work who obtained

$[\phi]_{\mathrm{D}}=-77$ for Ketone A, indicating that DHS produced by Lactobacillus plantarum is indeed enantiomeric to DHS isolated from Litchi chinensis. Our result also supports Rasonyi's finding that LB biosynthesized by L. plantarum is a quasienantiomer of DHS produced by this organism. If LB and DHS found in L. plantarum were of the same relative configuration, then the calculated specific (and molecular) rotation of pure ketone A derived from DHS would have been too low:

$0.75 \times-(0.25) 21.6=-13.7 ; x=-11.1+/-0.9$

The molar rotation for Ketone A would have been estimated to be $[\phi]_{\mathrm{D}}=\frac{\mathrm{M}[\alpha]_{\mathrm{D}}^{21}}{100}=\frac{324 \times-11.1}{100}=-35.9+/-3$

This value is far too low when compared to all other literature values for Ketone A of similar structure. ${ }^{52,29}$

The apparent specific optical rotation of Ketone B derived from DHS (Fraction 2, $9.2 \mathrm{mg}$ ) was calculated to be:

Fraction $2(9.2 \mathrm{mg}): \quad 93 \%$ ketone B (DHS) $3 \%$ ketone A (DHS) $4 \%$ ketone $\mathrm{B}$ (LB)

$[\alpha]_{\mathrm{D}}^{21}$ (apparent) $=\frac{\alpha_{\mathrm{D}}{ }^{21} \mathrm{obs} \times 100}{1 \times \mathrm{c}(\mathrm{mg} / 0.1 \mathrm{~mL})}=\frac{+0.138 \times 100}{1 \times(0.92)}=+15.0+/-0.6$ 
To correct for presence of DHS ketone A and LB ketone B, the specific rotation calculated for ketone A (DHS) obtained above (-25.2) and the literature value for the specific rotation for ketone $\mathrm{B}$ (LB) $(-0.13$, Rasoni) were used to solve for $\mathrm{x}$.

$0.93 \times-(0.03) 25.2-(0.04) 12.96=+15.09+/-0.6$

$\mathrm{x}=15.09 / .93=17.5+/-0.7$

The corresponding molar rotation for ketone B derived from DHS can then be calculated as follows:

$[\phi]_{\mathrm{D}}=\frac{\mathrm{M}[\alpha]_{\mathrm{D}}^{\underline{2}}}{100}=\frac{324 \mathrm{x}+17.5}{100}=+57+/-02$

This value compares well with that obtained by Rasonyi ${ }^{29}$ for ketone B (DHS): +54 and therefore confirms the configurational assignment of $9 S, 10 R$ to methyl dihydrosterculate isolated from $L$. plantarum, the enantiomer of DHS isolated from $L$. chinensis.

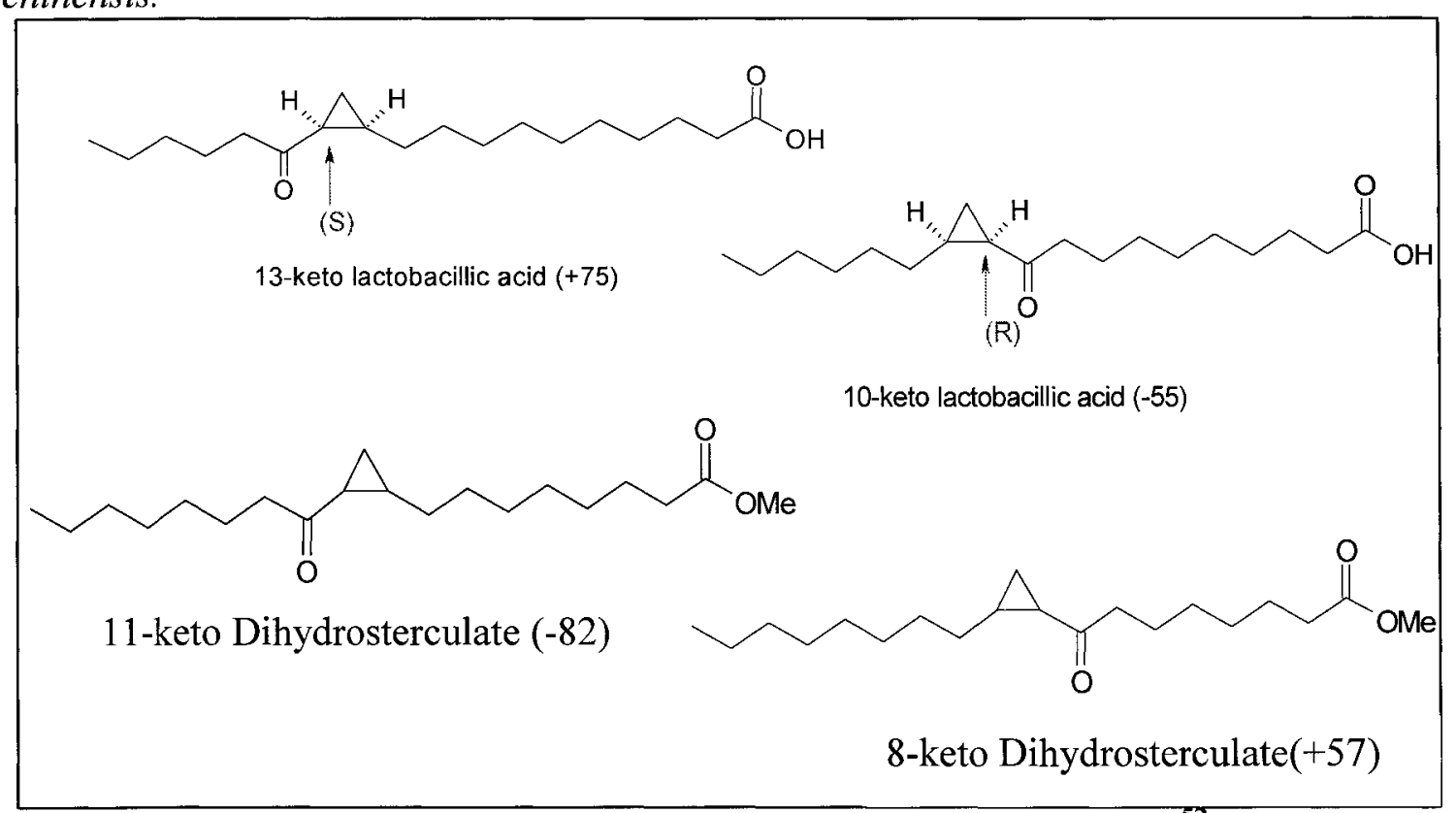

Figure 2.3.6 Lactobacillic acid Reference Structures ${ }^{52}$ and a-cyclopropyl Ketones of DHS from Lactobacillus plantarum. 
In Table 2.3.3, we summarize the chiroptical data which emphasizes that DHS obtained from microbial and phyto sources are enantiomers.

Table 2.3.3 Molar Rotations of 8-keto and 11-keto DHS from $L$. chinensis and $L$. plantarum.

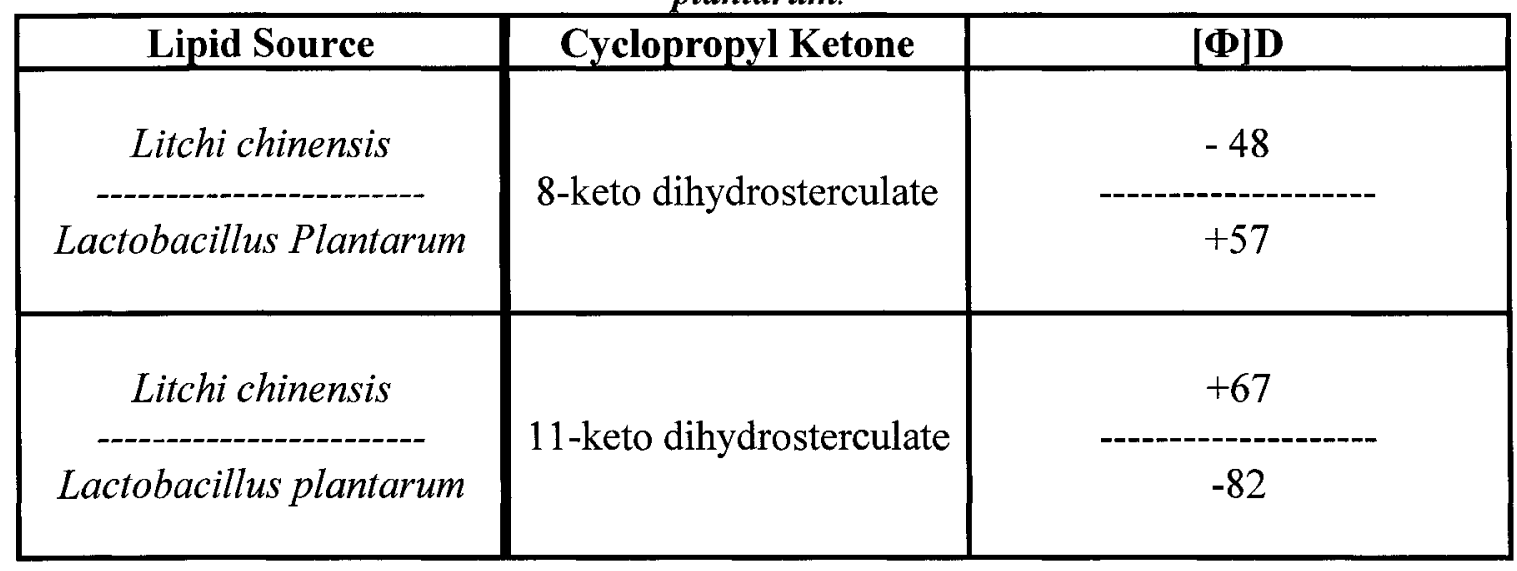<smiles>CCCCCCCC[C@]1(C)C[C@@]1(C)CCCCCCCC(=O)OC</smiles>

(S) $(R)$

Figure 2.3.7 DHS from Litchi chinensis.

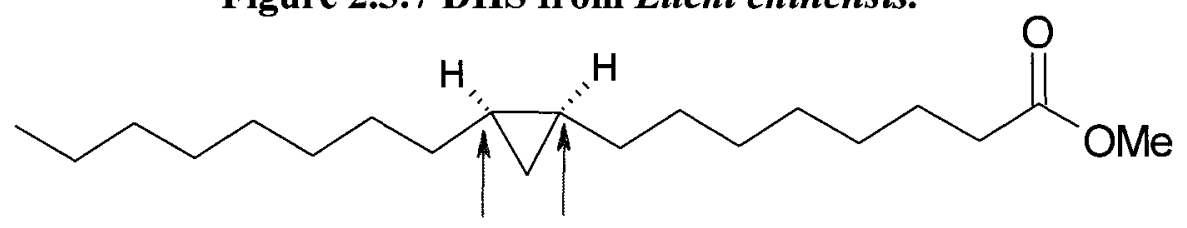

(R) (S)

Figure 2.3.8 DHS from Lactobacillus plantarum.

These results indicate that $L$. plantarum is a viable source of DHS enantiomeric to the DHS from Litchi. The contamination of the DHS with LB remains problematic; however, if it is found that LB is not a substrate or an inhibitor of DHS desaturase, then removal of LB content should not be an issue. 


\section{3b Attempted configurational analysis of Lactobacillic acidisolated from Lactobacillus plantarum.}

In an attempt to further confirm the absolute configuration of lactobacillic acid produced by L. plantarum, this organism was grown in commercially available Biotin assay medium, a synthetic medium free of oleate. Cultures were grown in $1 \mathrm{~L}$ of medium which was prepared by combining $37 \mathrm{~g}$ dry biotin assay medium with $1 \mathrm{~L}$ of deionized distilled water. This solution was boiled and allowed to cool before $50 \mathrm{~mL}$ casein hydroly sate and $1 \mathrm{~mL}$ biotin stock solution $(10 \mathrm{mg} / \mathrm{L})$ were added. According to the literature, L. plantarum cultures become increasingly acidic as the cells enter the stationary phase, reaching a final $\mathrm{pH}$ of $\sim 4.0{ }^{67}$ The measurement of culture $\mathrm{pH}$ is therefore a convenient measure of microbial growth. Cells were grown for 40 hours at $37^{\circ} \mathrm{C}$, at which point the $\mathrm{pH}$ had reached 4.2 and was not observed to decrease with longer incubation time. The cells were harvested by centrifugation at 10,000 RPM and the final pellet weight (wet) averaged $2.5 \mathrm{~g}$ per liter of medium. The pellets were hydrolyzed with $2 \mathrm{~N} \mathrm{KOH}$ in $50 \%$ ethanol for 5 hours and the fatty acids extracted as for the MRS grown cells. A yellow coloured fatty acid fraction was obtained after extraction ( $\sim 15 \mathrm{mg} / \mathrm{L}$ culture). The fatty acids were methylated with $\mathrm{BF}_{3} / \mathrm{MeOH}$ to give a final yield of $187 \mathrm{mg}$ FAMEs from 13L of culture. GC/MS analysis of the FAMEs indicated a fatty acid profile as follows: myristate $\left(\mathrm{C}_{14: 0}\right) 3 \%$, palmitate $\left(\mathrm{C}_{16: 0}\right) 19 \%$, palmitoleate $\left(\mathrm{C}_{16: 1}\right) 1 \%$, stearate $\left(\mathrm{C}_{18: 0}\right) 5 \%$, oleate/cis-vaccenate $\left(\mathrm{C}_{18: 1}\right) 28 \%$, cyclopropyl fatty acids $\left(\mathrm{C}_{19}\right.$; cyc 9 and 11) $38 \%$. Comparing these results to the FAME profile obtained for MRS grown- $L$. plantarum indicated that the CFA content was much lower and the olefins were still a large part of the phospholipid makeup. Since it is known that the 
olefin to CFA transition occurs predominantly in late exponential to early stationary phases, it is possible that the cells were harvested too early. Longer incubation times did not decrease the $\mathrm{pH}$ of the medium, and after 48 hours, the optical density $\left(\mathrm{O}_{\mathrm{D}} 360\right)$ was seen to decrease slightly. It is also possible that when grown in a less rich medium, this species is not functioning optimally, causing decreased activity of the CFA synthase. This decrease in function would also explain lower pellet weights, even though these cultures were grown almost twice as long as the MRS cultured cells.

The FAMEs were treated with $m$-CPBA to reduce the high olefinic content. The epoxidized mixture was cleaned up by flash chromatography $\left(\mathrm{SiO}_{2} ;\right.$ hex: $\left.\mathrm{Et}_{2} \mathrm{O} 10: 1\right)$ yielding $127.1 \mathrm{mg}$ crude CFA, which was expected to be a mixture of LB contaminated with DHS and saturated FAMEs. GC-MS analysis of Lactobacillate FAMEs after MCPA treatment indicated a distribution of: mistyrate $\left(\mathrm{C}_{14: 0}\right) 3 \%$, palmitate $\left(\mathrm{C}_{16: 0}\right)$ $32 \%$, palmitoleate $\left(\mathrm{C}_{16: 1}\right)<1 \%$, stearate $\left(\mathrm{C}_{18: 0}\right) 5 \%$, oleate/cis-vaccenate $\left(\mathrm{C}_{18: 1}\right)<1 \%$, cyclopropyl fatty acids $\left(\mathrm{C}_{19} ;\right.$ cyc9 \& cyc11) $60 \%$.

Because the isomeric CFAs present in the FAME mixture have identical mass spectra due to a ring-opening process, GC/MS did not provide information on the ratio of LB:DHS. To determine this, ${ }^{13} \mathrm{C}$ NMR analysis of the mCPBA treated FAMEs was used. This indicated that DHS and lactobacillic acid (LB) were present in a ratio of $43 \%$ DHS to $57 \%$ LB.

This was a surprising result, as oleate, the precursor to DHS, is not endogenous to L. plantarum. As mentioned above, Biotin assay medium is oleate free, so the only oleate that would be present would have to have been introduced from the $10 \mathrm{~mL}$ MRS broth started cultures used to inoculate the $1 \mathrm{~L}$ cultures. Though we were aware of the 
oleate content of MRS broth, its use as an inoculum medium was selected in order to encourage enough growth in the biotin assay medium. We are capable of resolving mixtures of isomers using ${ }^{13} \mathrm{C}$ NMR, so we felt that the incorporation of some oleate would be acceptable. It was not thought possible that the oleate present in the inoculum would cause such a large incorporation of oleate into the membranes. Though we were still able to determine the isomeric ratio of the CFAs, problems were encountered after chromic acid oxidation when no fractions could be obtained that were enriched in either ketone of LB. This led to problems obtaining optical rotations and in doing the calculations required to determine the molecular rotations of these molecules.

\section{Observed Optical Rotations for $\alpha$-cyclopropyl ketone mixtures from $L$. plantarum grown in Biotin Assay Medium.}

Fraction 1 (9.1 mg): (analyzed by GC/MS only)

ketone A DHS (major)

ketone B DHS and Ketone A LB (minor)

Optical Rotation $=-0.062+/-0.005$

Fraction 2 (18.3 mg):

ketone A DHS $31 \%$

ketone B DHS $40 \%$

ketone A/B LB 29\%

Optical Rotation $=+0.032+/-0.005$

Fraction 3 (12.2 $\mathrm{mg})$ :

(similar to Fraction 2)

Optical Rotation $=+0.020+/-0.005$

These results, while qualitatively consistent with the previous data (ketone A

DHS -ve optical rotation, ketone B DHS (+ve optical rotation), were impossible to

evaluate on a quantitative basis. This forced us to abandon this section of the project

until a means of obtaining higher purity lactobacillic acid became available. Currently, 
the best way to accomplish this is to grow L. plantarum cultures on Biotin assay medium with strictly no oleate present. This, however is problematic in that in order to obtain enough FAMEs for oxidation and isolation of the ketones, large volumes of cultures would have to be grown in order to compensate for the meagre growth of $L$. plantarum on a defined medium. An estimate based upon FAME yields from other experiments indicate that a minimum of $30 \mathrm{~L}$ of culture would need to be grown to acquire enough FAMEs to complete the analysis. Due to our limited microbiological facilities, this was deemed unrealistic.

The results obtained were still of value, even though the absolute configuration of lactobacillate was not determined. The low optical rotations seen for the ketone fractions are indicative of canceling due to the presence of enantiomers, or quasienantiomers in this case since the $\Delta 9$ and $\Delta 11$ CFAs have stereocentres in different positions. This was also consistent with the results obtained for lactobacillate by Rasonyi. ${ }^{29}$

That the two CFAs produced by Lactobacillus plantarum are in all probability quasienatiomeric led us to question whether this species has one CFA synthase responsible for bimodal selectivity, or if this species has a second enzyme for the cyclopropanation of oleate when the bacteria obtains this compound from its natural environment. Precedence for bimodal binding has been seen in lipoxygenases from some plant species and cytochrome $\mathrm{P}_{450}$ from mammals, which can interact with a number of different substrates. ${ }^{68}$ CFA synthase from $E$. coli is also known to be able to cyclopropanate both palmitoleate $(\mathrm{C} 16: 1, \Delta 9)$ and oleate $(\mathrm{C} 18: 1, \Delta 9) .^{12}$ In 1995 , Arigoni proposed a possible model for bimodal activity of CFA synthase from L. plantarum. This model suggested that opposite faces of the double bond of oleate and cis-vaccenate 
would interact with the active site of the single enzyme if the fatty acids entered the hydrophobic pocket from opposite sides (Figure 2.3.8). ${ }^{29}$ A hairpin binding mode is also possible (Figure 1.2.7, Introduction).
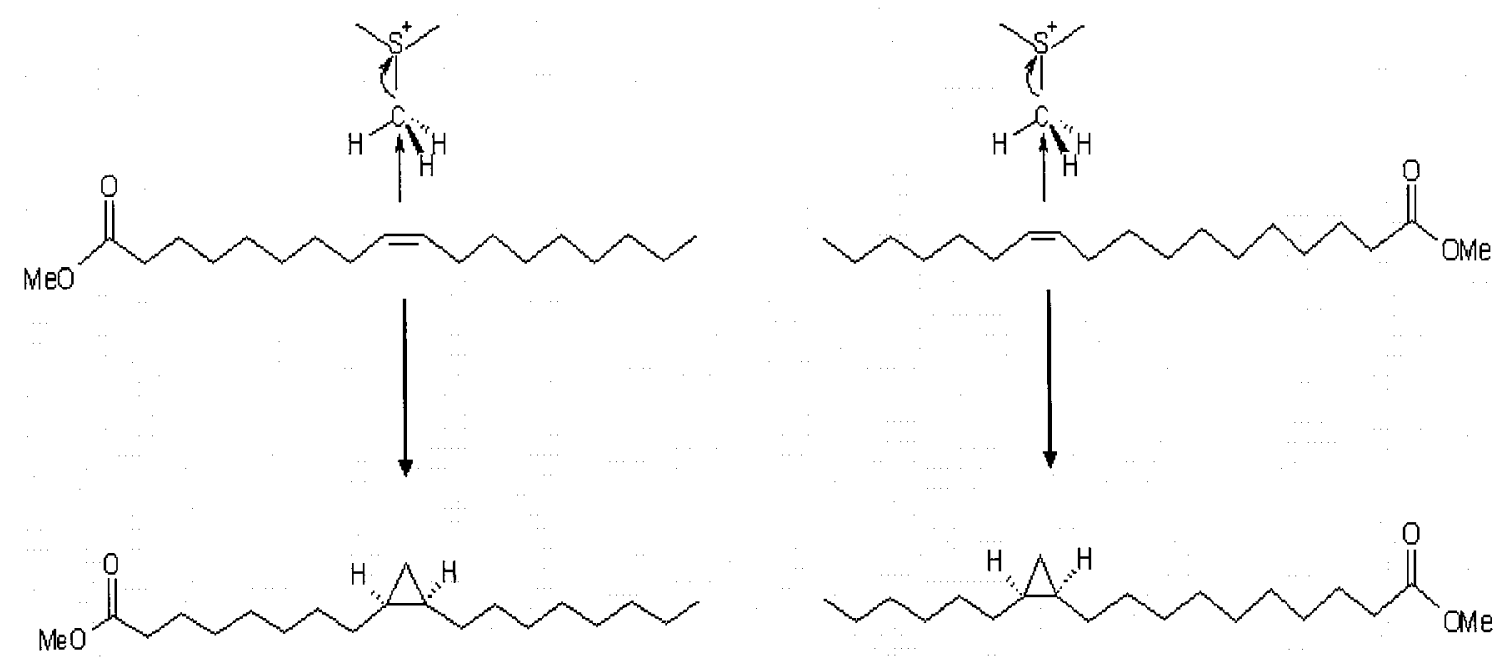

Figure 2.3.9 Proposed Interaction of CFA Synthase Active Site with Oleate (left) and $\mathrm{Cis}$-vaccenate (right).

To further explore the ability of L. plantarum to produce two CFAs, a search of the recently completed genome for CFA synthases was pursued. The CFA synthase from E. coli has been recently characterized and compared to known synthases from Mycobacterium tuberculosis. One putative sequence of 9 amino acids common to S.A.M. methyl transferases was highly conserved among all of the CFA synthases examined. $^{41}$ The full genomic sequence for L. plantarium was searched for this sequence using the NCBI BLAST program. This program found two separate proteins containing the search parameters. These two proteins were then lined up with the known CFA synthase from E. coli and Brucella militensis, a bacterial species that produces CFAs, to examine similarities between the proteins from different species (Figure 2.3.9).

The results showed strong homology between all of the enzymes, indicating that 
L. plantarum may have two isozymes of the CFA synthase with opposite facial selectivity. Isolation and assays of each of these enzymes will need to be completed to confirm this hypothesis. The bimodal activity of $E$. coli CFA synthase was also of interest, so it was decided that it would be useful to determine the absolute configuration of the C16 $\triangle 9$ CFA (PAL). 
S.A.M. binding site

Escherichia coli CFT073 Brucella melitensis $16 \mathrm{M}$ Lactobacillus plantarum WCFS1 A Lactobacillus plantarum WCFS1 B

S.A.M. binding site Escherichia coli CETO73 Brucella melitensis $16 \mathrm{M}$ Lactobacillus plantarum WCFS1 A Lactobacillus plantarum WCES1 B

S.A.M. binding site Escherichia coli CFTO73 Brucella melitensis $16 \mathrm{M}$ Lactobacillus plantarum WCFS1 A Lactobacillus plantarum WCFS1 B

S.A.M. binding site Escherichia coli CFT073 Brucella melitensis $16 \mathrm{M}$ Lactobacillus plantarum WCFSI A Lactobacillus plantarum WCFS1 B

S.A.M. binding site Escherichia coli CFT073 Brucella melitensis 16M Lactobacillus plantarum WCFS1 A Lactobacillus plantarum WCFS1 B

S.A.M. binding site Escherichia coli CFT073 Brucella melitensis $16 \mathrm{M}$ Lactobacillus plantarum WCFSI A Lactobacillus plantarum WCFSI B

S.A.M. binding site Escherichia coli CFT073 Brucella melitensis $16 \mathrm{M}$ Lactobacillus plantarum WCFS1 A Lactobacillus plantarum WCFS1 B

S.A.M. binding site Escherichia coli CFT073 Brucella melitensis $16 \mathrm{M}$ Lactobacillus plantarum WCFS 1 A Lactobacillus plantarum WCFS1 B

S.A.M. binding site Escherichia coli CFT073 Brucella melitensis $16 \mathrm{M}$ Lactobacillus plantarum WCFS1 A Lactobacillus plantarum WCFS1 B

S.A.M. binding site Escherichia coli CFT073 Brucella melitensis $16 \mathrm{M}$ Lactobacillus plantarum WCFS1 A Lactobacillus plantarum WCFS1 B
(1)

(1) - - - - MSSSCIEEVSVPDNWYRIANELLSRAGIAI (1) MDVCTCFVPKEEMGP YGMLRTVLTHMIKTGDLTVTDADGSKTRFGD

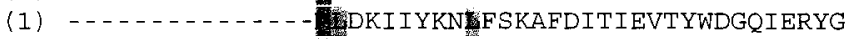

(1) - . - . - EKTFYHT LSHSFNMPVTVNYWDGSSETYG 48

(1)

(32) N

(48) RTGTP H HFTTAHAQA

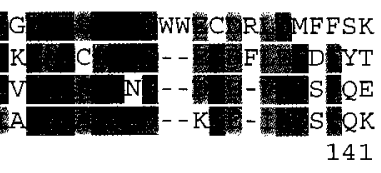

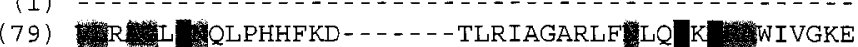

(77) A R RDSFLTHN-...-.-SFLKHLPKISH E STKD $\mathrm{Q}$

(77) ESAESFFNNS - - - - - K- - FKKFMPKSH E QQD 142 188

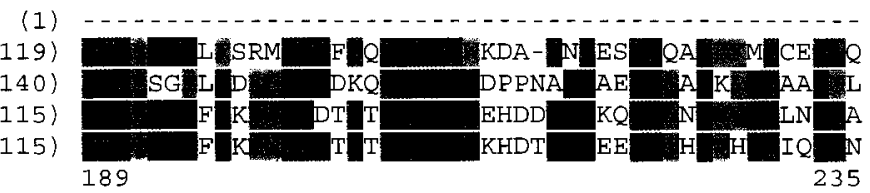

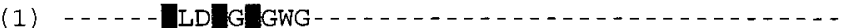

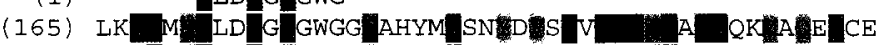
(187) VKE D LD G GWGGGLYL RHLKAN T A A A A A (162) TQ K LDEGSGWGT LFMA DEGG DAT D DYTAOI

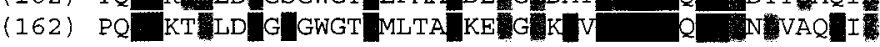
236 282

(10)

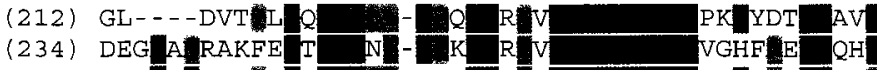

(209) $\mathrm{QRH} \mathrm{E}$ KVH $\mathrm{O}$

(209) DEG SEVAER 283

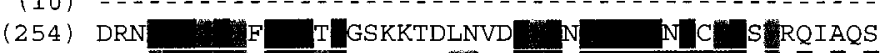

(280) ARL

(255) QAFVGRA

(256) $\mathrm{NHY}$ A 330

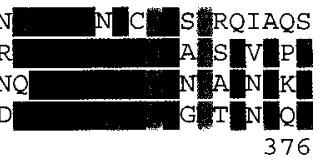

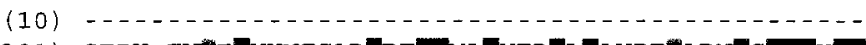

(301) SEPH-FV E WHNFGAD DT MA YER L AWPEVADN

(327) $\mathrm{EK}$ G YTT I L AE KA REA L NRDKAKAL D

TD G O A T $T$ QR TEI DKN N KRA 377

(10)

(347)

(374)

(349)

(349)

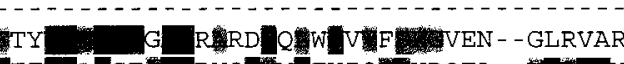

EF A SE

QL 424

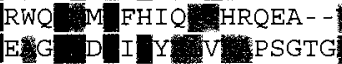

10) 446

(383) (19.-

(419) KRLDSAPKGANSETRSVKKSINA

(391)

(396) KA

\section{Figure 2.3.10 CLUSTAL W Results of Protein Alignment of CFA Synthases}

from Different Bacterial Species.

(yellow: conserved, blue: hydrophobic, green: conservatively substituted). 


\subsection{Absolute Configuration of Cyclopropyl Fatty Acids isolated from $E$. coli}

It was decided that the stereochemistry of $E$. coli cyclopropyl fatty acids would be interesting to examine since the cyclopropane synthase in $E$. coli is well characterized biochemically and exhibits the same bimodal regioselectivity as observed in $L$.

plantarum. ${ }^{41}$ That is, E. coli produces two endogenous CFAs: lactobacillic acid (LB) the 11,12- analogue of dihydrosterculate, and a seventeen carbon CFA with a cyclopropyl ring at C9, C10 (PAL) (Figure 2.4.1). Since palmitoleate is also a good substrate of E. coli cyclopropane synthase it was of interest to determine whether LB and PAL are quasienantiomeric as was found for the DHS/LB pair found in $L$. plantarum. $^{30}$

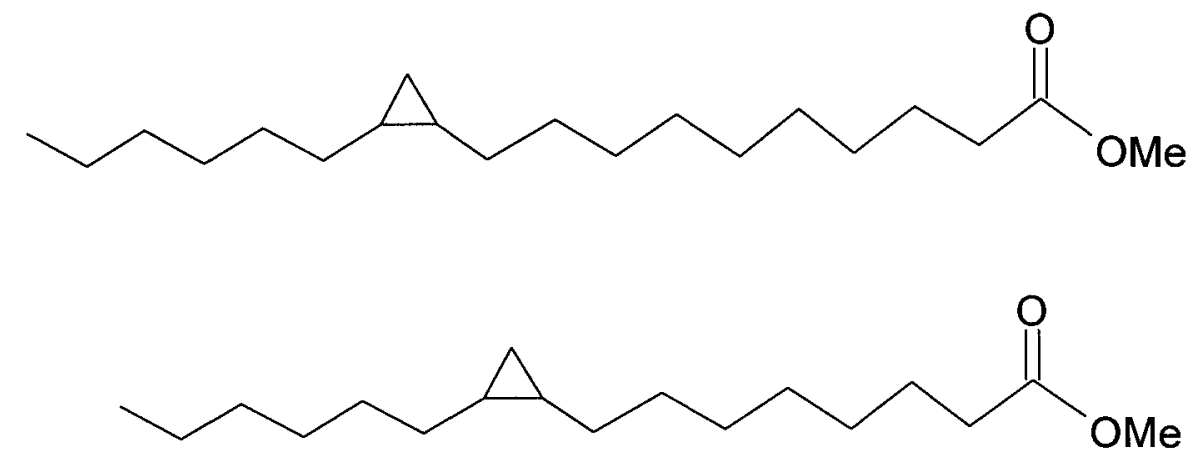

Figure 2.4.1 Lactobacillate (C18 $\Delta 11)$ and the CFA (C16 $\Delta 9)$ Produced by $E$. coli (PAL).

Fortunately, E. coli phospholipids are readily available from Avanti Lipids thereby eliminating the expensive and time consuming step of culturing and harvesting enough cells to examine the CFAs. The cyclopropyl content of the Avanti E. coli lipids was examined prior to saponification using ${ }^{1} \mathrm{H}$ NMR and was determined to be quite high ( $48 \%$ of total fatty acid content). 


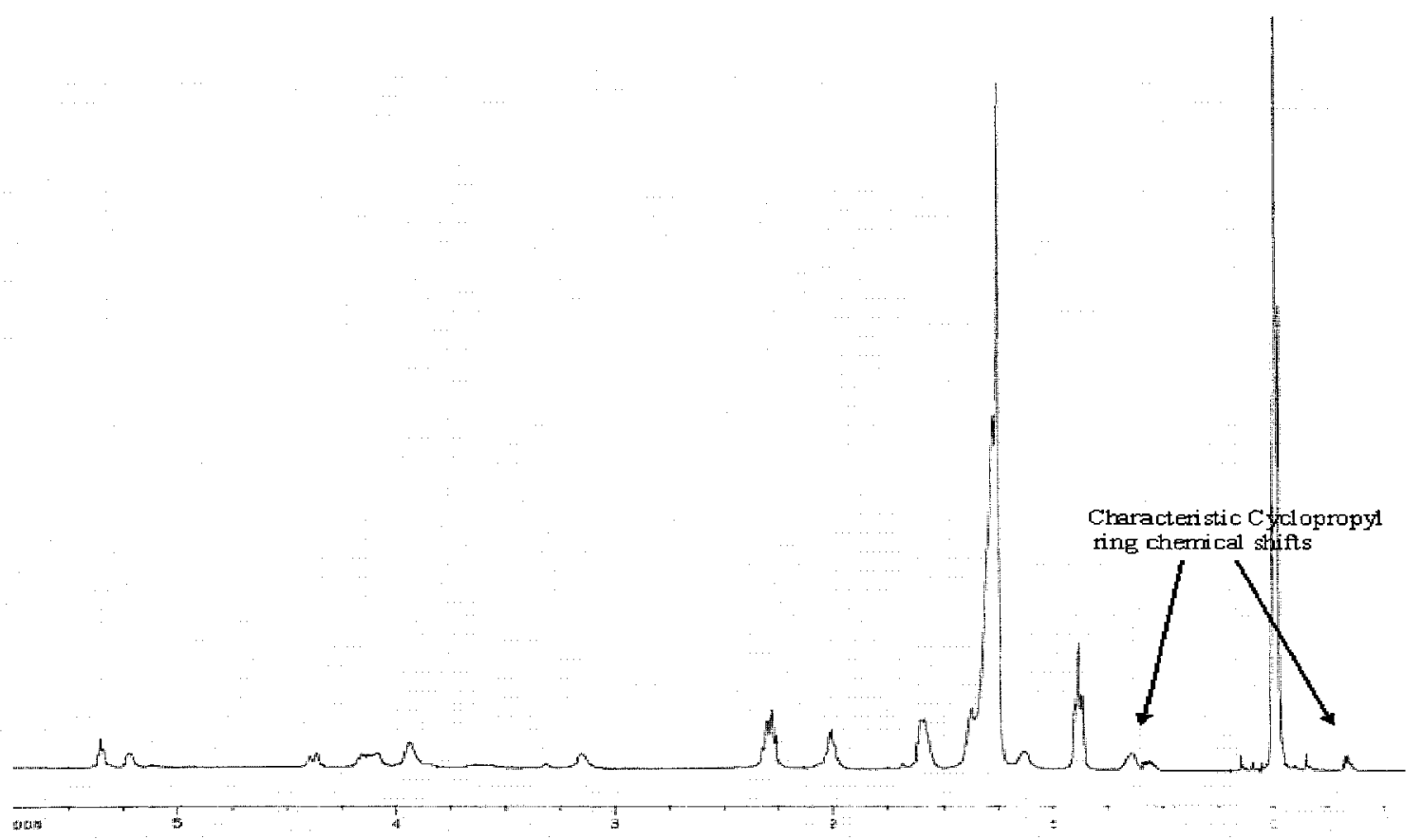

Figure 2.4.2 Proton NMR Spectrum of $E$. coli Phospholipids.

The $E$. coli lipids (1g) were saponified using $50 \%$ aqueous ethanolic $2 \mathrm{~N} \mathrm{KOH}$ solution. The isolated fatty acids were then methylated using $\mathrm{BF}_{3}$ :Methanol to yield a total of $598 \mathrm{mg}$ of FAMEs. The composition of the pale yellow oil was assessed using GC/MS, ${ }^{1} \mathrm{H}$ NMR, and ${ }^{13} \mathrm{C}$ NMR. Because the CFAs isolated from $E$. coli are of different chain lengths as well as different ring position, gas chromatography was useful in determining the ratio of CFAs present. This analysis indicated a fatty acid distribution as follows: Myristate $\left(\mathrm{C}_{14: 0}\right) 0.7 \%$, Palmitate $\left(\mathrm{C}_{16: 0}\right) 36 \%$, Palmitoleate $\left(\mathrm{C}_{16: 1}\right) 2.3 \%$, Cyclopropyl $\mathrm{C}_{17}$ (PAL),(C17 cyc 9$) 20 \%$, Stearate $\left(\mathrm{C}_{18: 0}\right)$ 0.5\%, cis-vaccenate $\left(\mathrm{C}_{18: 1}\right.$ $\Delta 11) 28.3 \%$, and Lactobacillate (LB) $\left(\mathrm{C}_{19}\right.$ cyc 11$) 12.2 \%$.

FAMEs (462mg) derived from $E$. coli lipids were treated with $m$-CPBA (100 mg, $0.6 \mathrm{mmol}$ ) and the resultant polar epoxides removed by flash chromatography (silica 230400 mesh, 10:1 hex:Et ${ }_{2} \mathrm{O}$ ). The clear oil $(205 \mathrm{mg})$ collected was assessed by GC-MS 
which indicated a distribution as follows: Myristate $\left(\mathrm{C}_{14: 0}\right) 1.7 \%$, Palmitate $\left(\mathrm{C}_{16: 0}\right)$ $44.1 \%$, Palmitoleate $\left(\mathrm{C}_{16: 1}\right)$

$<1 \%$, Cyclopropyl $\mathrm{C}_{17}(\mathrm{PAL})(\mathrm{C} 17$ cyc 9$) 34.0 \%$, Stearate $\left(\mathrm{C}_{18: 0}\right) 1.2 \%$, Cis-vaccenate $\left(\mathrm{C}_{18: 1} \Delta 11\right)<1 \%$, and Lactobacillate $(\mathrm{LB})\left(\mathrm{C}_{19}\right.$ cyc 11$) 19.0 \%$.

a)

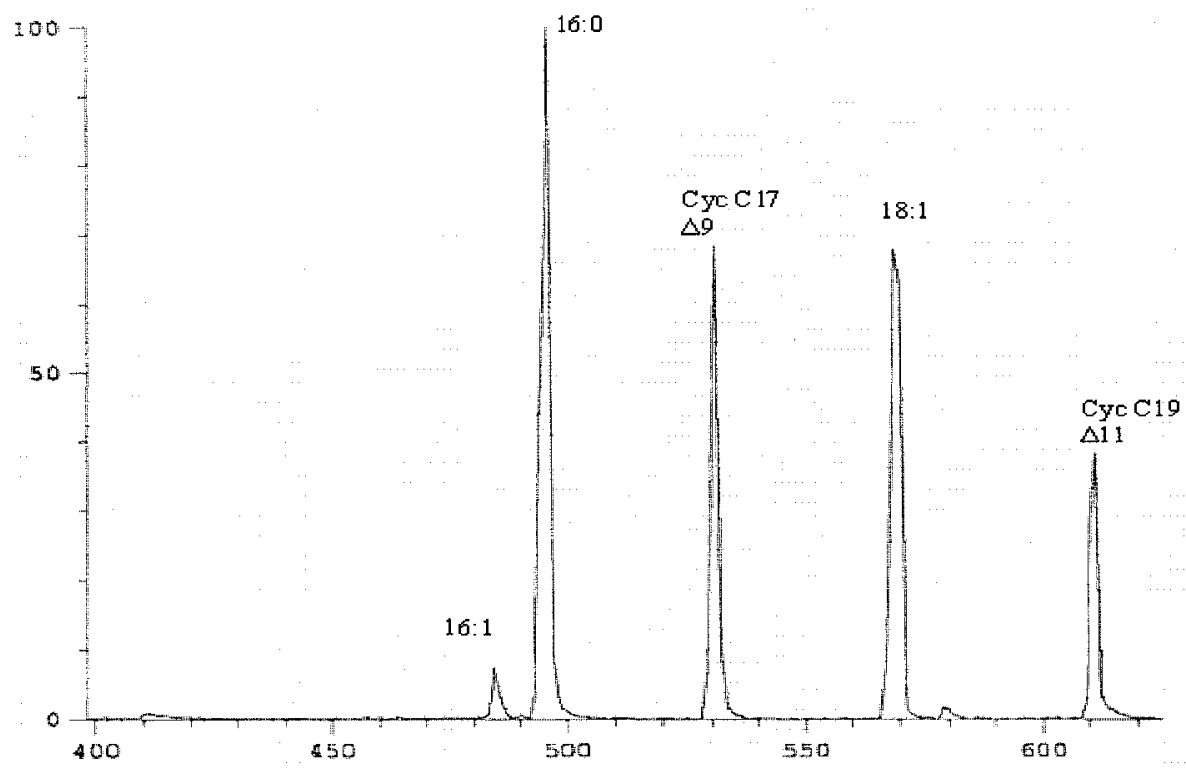

b)

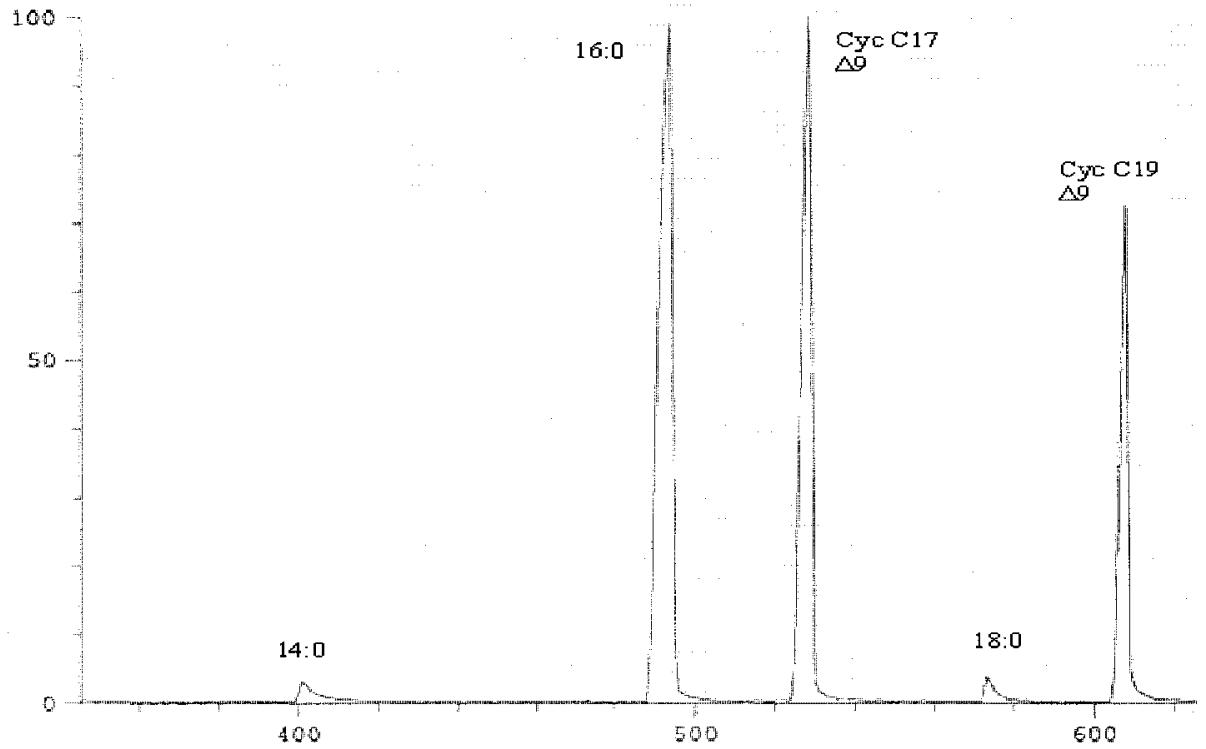

Figure 2.4.3 a) Extracted $E$. coli FAMEs b) $E$. coli FAMEs after mCPBA Treatment. 


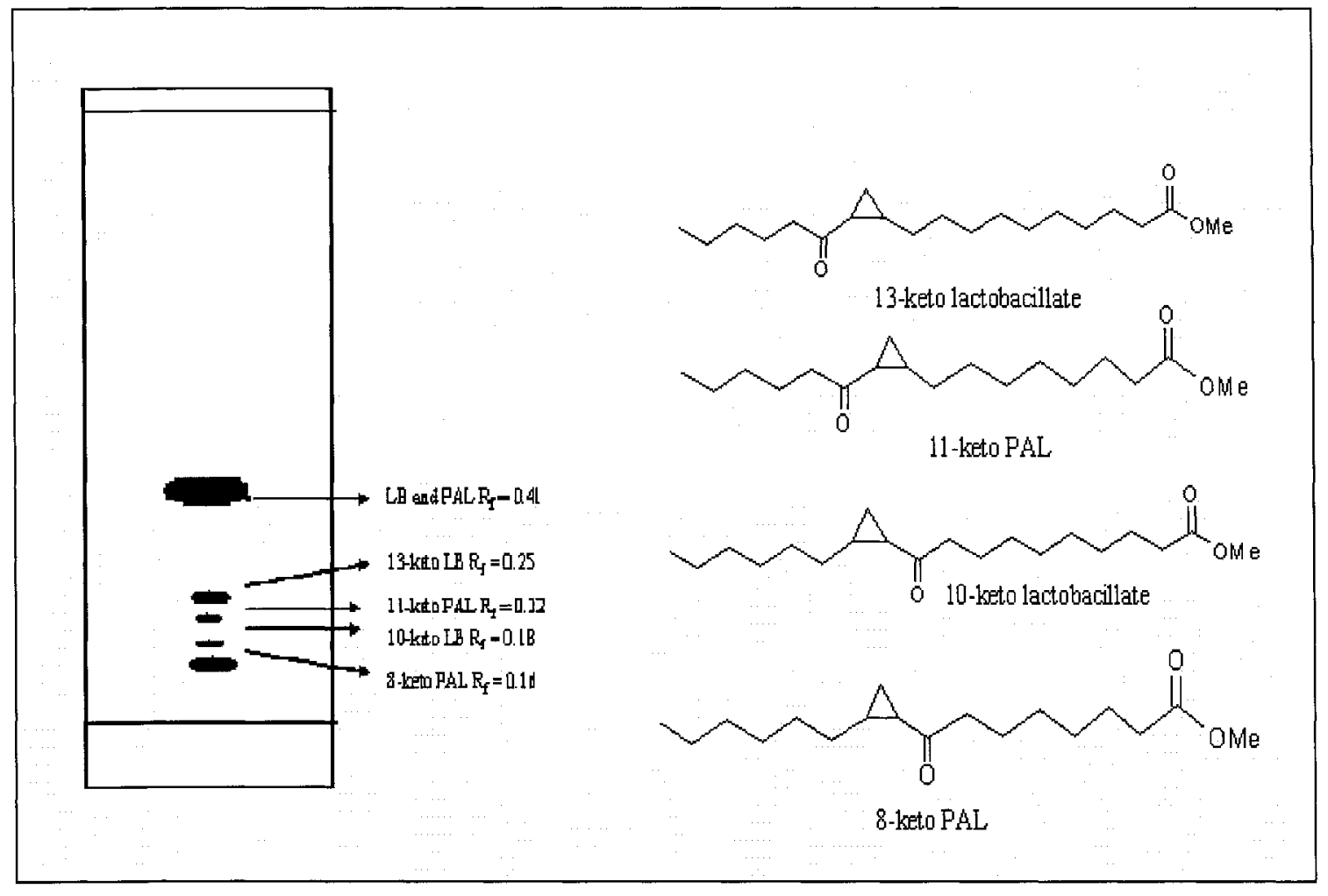

Figure 2.4.4 TLC separation of a-cyclopropyl ketones derived from oxidation of $E$. coli Fames. Minor spots (not shown) are not thought to be ketones of interest.

The ratio of $\mathrm{C} 17: \mathrm{C} 19 \mathrm{CFAs}$ was calculated to be roughly 1.8 , indicating that, although the different chain length CFAs are difficult to separate due to their similar polarity, it would still be possible to determine the absolute configuration of the major and minor components. Thus, the purified E. coli FAMEs $(205 \mathrm{mg})$ were oxidized with $\mathrm{CrO}_{3}(126 \mathrm{mg} ; 1.3 \mathrm{mmol})$ for 66 hours. The oxidized FAMEs were extracted into hexanes and the solvent evaporated to give a yellow oil (134 mg.) TLC was used to examine the product composition and to determine the best solvent mixture for product separation. The TLC plates showed a number of spots in the range $\left(\mathrm{R}_{\mathrm{f}}=0.25-0.16\right)$, as well as a very large spot where the unoxidized CFAs and saturated fatty acids would be expected $\left(R_{\mathrm{f}}=0.4\right)$. The best separation occurred using 10:1 hexane:diethyl ether. 
Flash chromatography $\left(\mathrm{SiO}_{2} 230-40\right.$ mesh, 10:1 Hex:Et ${ }_{2} \mathrm{O}, 4$ psi) was used to separate the oxidized products. Five mililitre fractions were collected in an attempt to get the best separation of products. Along with a fraction containing $106 \mathrm{mg}$ of unoxidized CFAs and saturated fatty acids, three ketone fractions were isolated and analyzed by TLC, GC-MS, ${ }^{13} \mathrm{C}$ NMR and polarimetry.

Gas chromatography was useful in examining the ratio of $\mathrm{C} 17$ to $\mathrm{C} 19$ ketones since they have different molecular weights, while ${ }^{13} \mathrm{C}$ NMR was used to obtain additional information on individual ketone species of each fraction. The latter technique could only be used in a limited fashion due to the complexity of the mixtures obtained in this experiment.

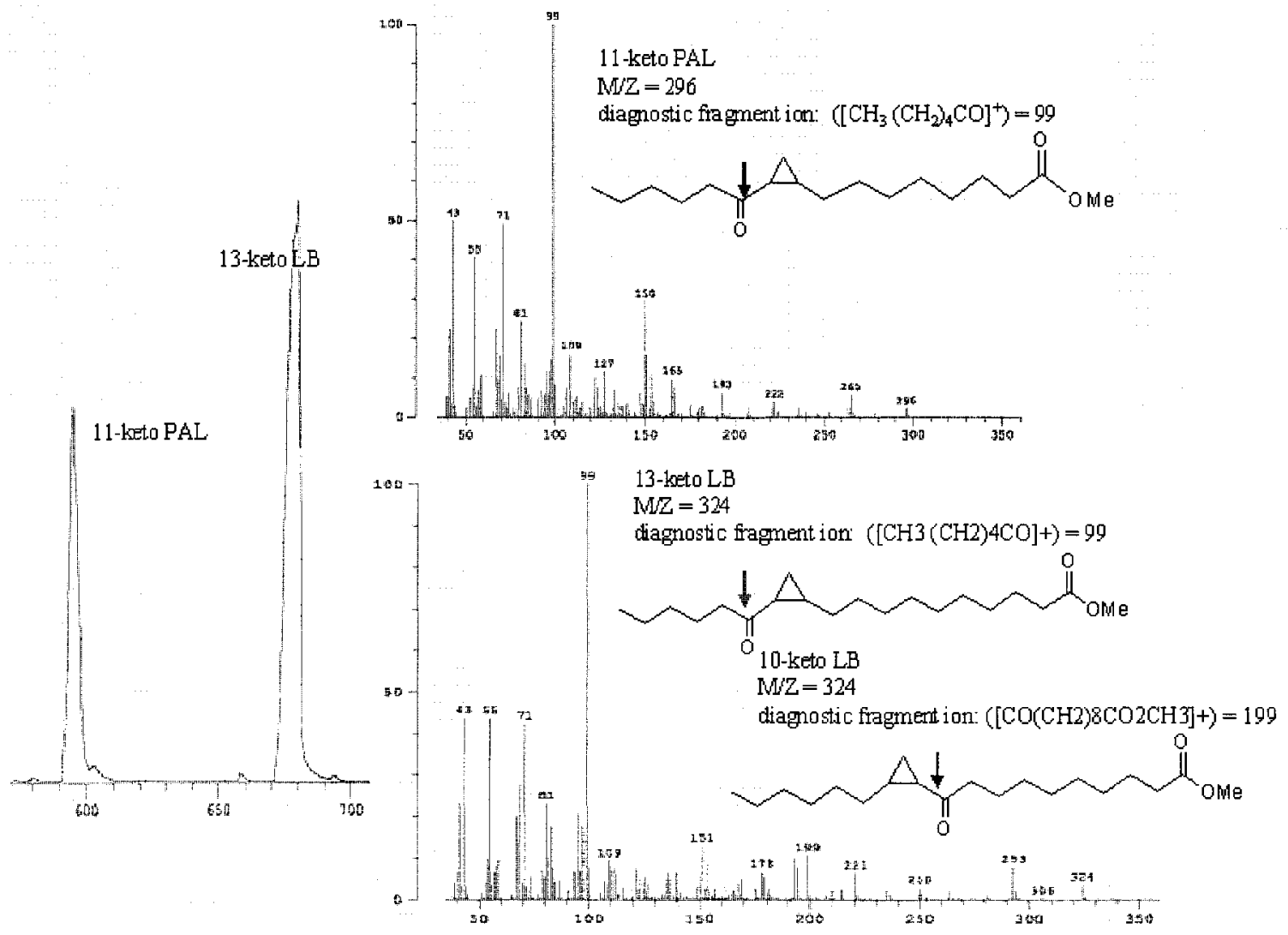

Figure 2.4.5 GC/MS Data for Ketone Fraction 1 from $E$. coli. 


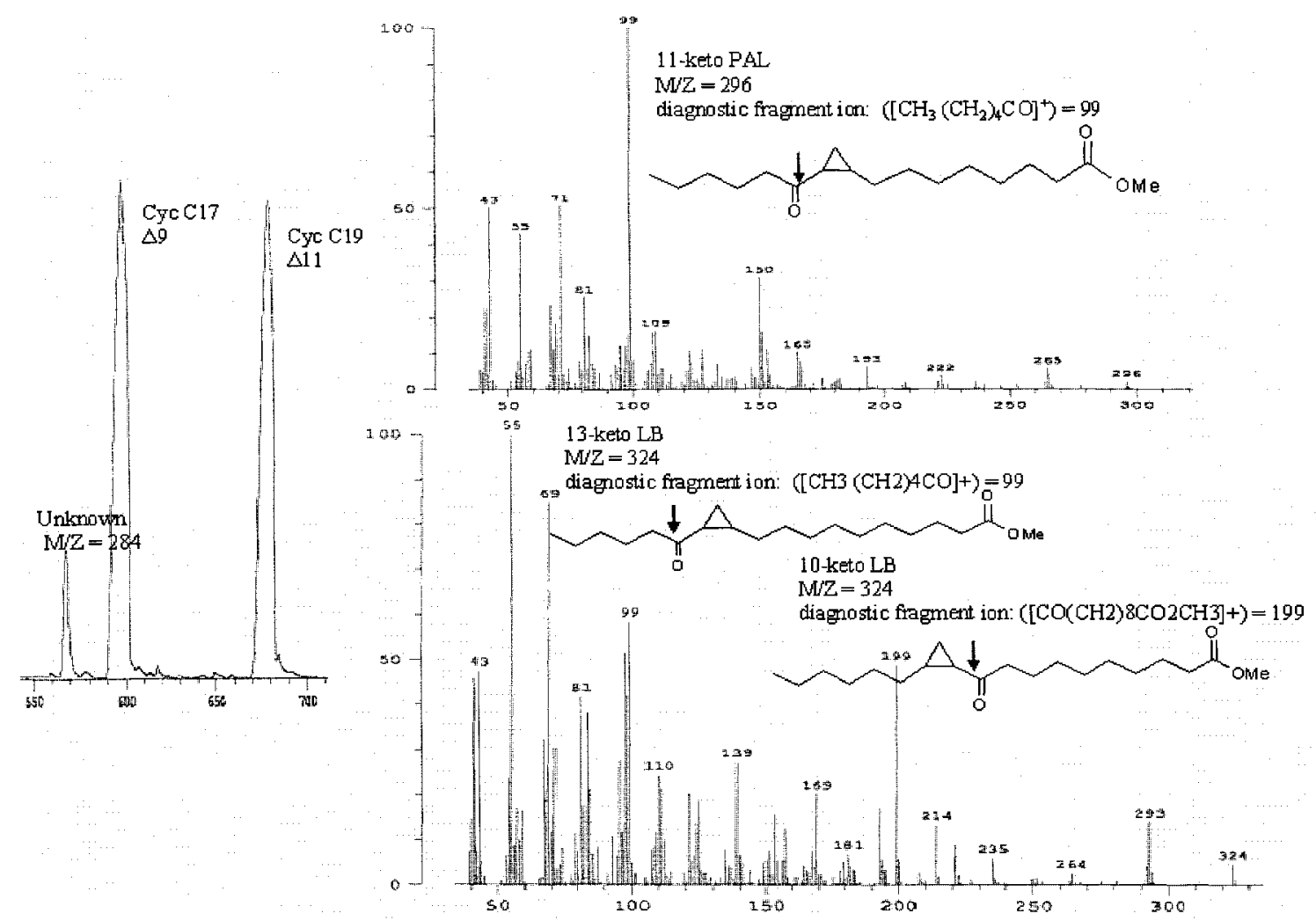

Figure 2.4.6 GC/MS Data for Ketone Fraction 2 from $E$. coli.
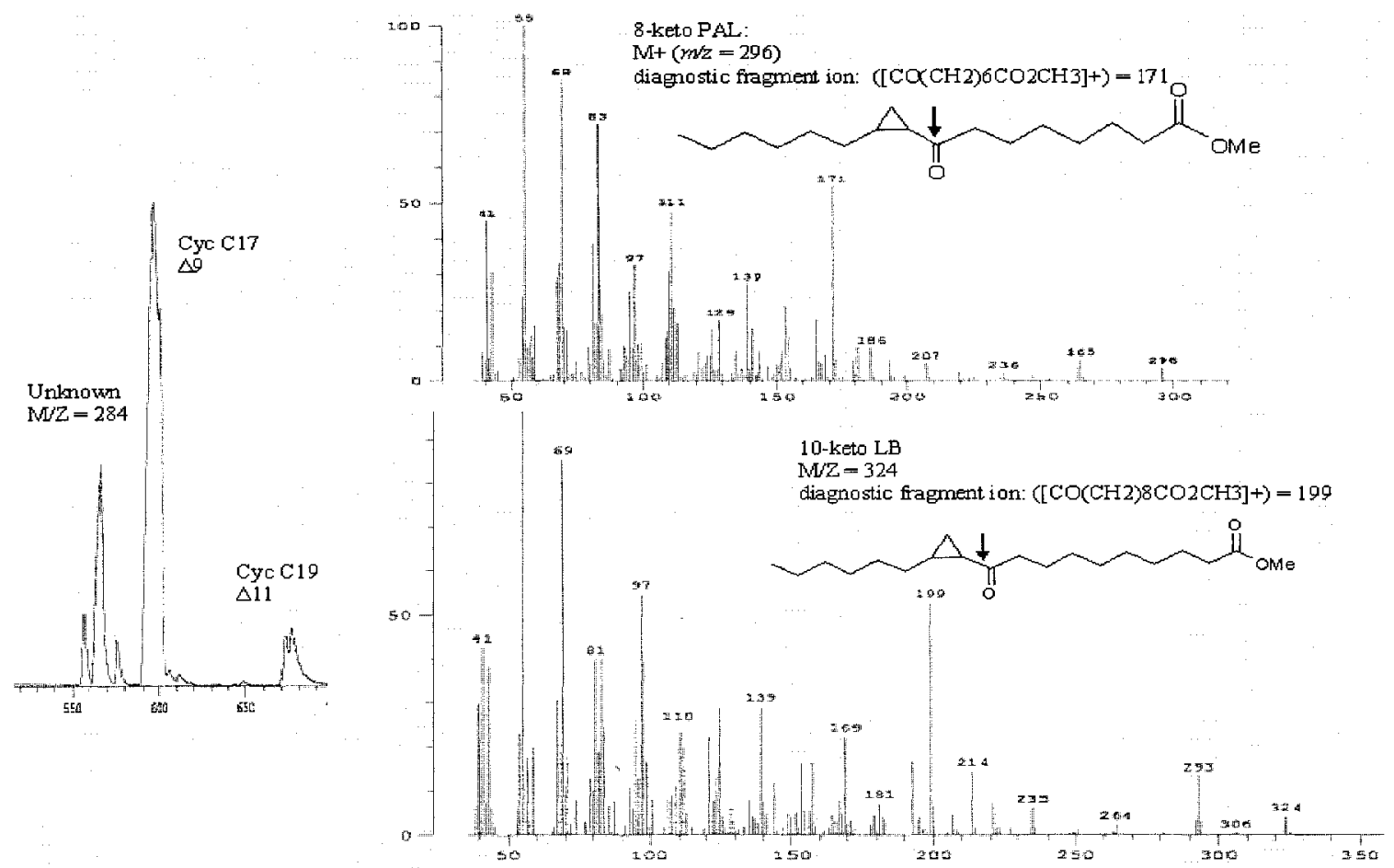

Figure 2.4.7 GC/MS Data for Ketone Fraction 3 from $E$. coli. 
Table 2.4.1 ${ }^{13} \mathrm{C}$ NMR Shifts for Ecoli CFAs and $\alpha$-cyclopropyl ketones.

\begin{tabular}{|c|c|c|c|c|c|c|}
\hline$\#$ & Ecoli & Ecoli & Ecoli & Ecoli & Ecoli & Ecoli \\
\hline & $\begin{array}{l}\Delta 9 \text { cyc } \\
\text { PAL }\end{array}$ & $\begin{array}{c}\Delta 11 \text { cyc } \\
\text { LB }\end{array}$ & $\begin{array}{c}11 \mathrm{ket} A \\
\text { PAL }\end{array}$ & $\begin{array}{c}13- \\
\text { ketA } \\
\text { LB }\end{array}$ & $\begin{array}{l}8 \mathrm{ketB} \\
\text { PAL }\end{array}$ & $\begin{array}{c}10 \mathrm{ketB} \\
\text { LB }\end{array}$ \\
\hline & 77.0367 & 7.0223 & 77.0200 & 77.0200 & 77.0241 & 77.0241 \\
\hline 1 & 174.38 & 174.37 & ND & $\mathrm{ND}$ & 174.23 & ND \\
\hline 2 & 34.14 & 34.13 & $\mathrm{ND}$ & $\mathrm{ND}$ & 34.04 & 34.06 \\
\hline 3 & 24.99 & 24.98 & $\mathrm{ND}$ & $\mathrm{ND}$ & 24.81 & 24.89 \\
\hline 4 & 29.19 & 29.18 & ND & $\mathrm{ND}$ & 28.94 & ND \\
\hline 5 & 29.33 & 29.33 & ND & ND & 28.97 & $\mathrm{ND}$ \\
\hline 6 & 29.38 & 29.38 & ND & ND & 23.89 & $\mathrm{ND}$ \\
\hline 7 & 30.15 & 29.64 & ND & $\mathrm{ND}$ & 44.70 & 44.85 \\
\hline 8 & 28.69 & 29.64 & ND & ND & 209.32 & $\mathrm{ND}$ \\
\hline 9 & 15.75 & 30.22 & 209.55 & ND & 26.24 & $\mathrm{ND}$ \\
\hline 10 & 15.79 & 28.72 & ND & $\mathrm{ND}$ & 25.74 & ND \\
\hline 11 & 28.75 & 15.76 & ND & $\mathrm{ND}$ & 25.53 & $\mathrm{ND}$ \\
\hline 12 & 30.20 & 15.78 & $\mathrm{ND}$ & $\mathrm{ND}$ & 29.93 & ND \\
\hline 13 & 29.47 & 28.73 & $\mathrm{ND}$ & $\mathrm{ND}$ & 29.02 & $\mathrm{ND}$ \\
\hline 14 & 31.97 & 30.20 & ND & ND & 31.85 & ND \\
\hline 15 & 22.72 & 29.47 & ND & ND & 22.64 & ND \\
\hline 16 & 14.14 & 31.96 & 14.08 & $\mathrm{ND}$ & 14.09 & $\mathrm{ND}$ \\
\hline 17 & & 22.72 & & ND & & ND \\
\hline 18 & & 14.14 & & 13.96 & & 14.09 \\
\hline$\Delta$ & 10.93 & 10.92 & & & 14.32 & 14.30 \\
\hline me & 51.45 & $\mathrm{ND}$ & 51.44 & $\mathrm{ND}$ & 51.47 & $\mathrm{ND}$ \\
\hline
\end{tabular}

Calculations of Molar Rotation of $\alpha$-cyclopropyl ketones obtained by oxidation of $E$. coli CFAs (PAL and LB).

Fraction 1 (6.9 mg): $32 \%$ PAL ketone A only; $48 \%$ LB ketone $\mathrm{A}$

$20 \%$ LB ketone B

Observed optical rotation: $+0.112^{\circ}+/-0.005^{\circ}$

Step 1:

$[\alpha]_{D}^{21}=\frac{\alpha_{D}^{21}}{1 \times c(\mathrm{mg} / 0.1 \mathrm{~mL})}=\frac{+0.112 \times 100}{1 \times 0.69}=+16.2+/-0.7$ 
Step 2: Assume that all species have similar molecular weights (within $10 \%$ ).

Assume that LB in E. coli has the same absolute configuration as that determined in

Lactobacillus by Rasonyi, ie $11 R, 12 S .{ }^{29}$ This in turn would mean that the $[\alpha]_{\mathrm{D}}{ }^{21}$ for LB

ketone $\mathrm{A}$ and $\mathrm{B}$ are +22 and -13 and solve for $\mathrm{x}\left([\alpha]_{\mathrm{D}}{ }^{21}\right.$ for PAL ketone $\left.\mathrm{A}\right)$ :

$(0.32) \mathrm{x}+(0.48) 22-(0.2) 13=+16.2+/-0.7$

$[\alpha]_{\mathrm{D}}^{21}$ PAL ketone $\mathrm{A}(\mathrm{x})=+26+/-2$

Step 3. The corresponding molar rotation of PAL ketone A is given by

$$
[\phi]_{\mathrm{D}}=\frac{\mathrm{M}[\alpha]_{\mathrm{D}}{ }^{21}-}{100}=\frac{296 \times 26}{100}=+77+/-6
$$

This value compares favorably with the absolute value of $[\phi]_{D}$ for DHS ketone A formed by L. plantarum ( -82 , this work; -77 Rasonyi) and the value for $[\phi]_{D} L B$ ketone A $(+70$, Rasonyi, +75 Tocanne $)$. Note that exact agreement is not expected since it is reasonable to assume that the absolute value $[\phi]_{D}$ for ketone A would not be identical for ketones with different pendant chain lengths. Thus based on this polarimetric measurement alone, the absolute configuration of the $E$. coli cyclopropyl fatty acids (PAL and $\mathrm{LB})$ are found to be $(9 R, 10 S)$ and $(11 R$ and $12 S)$ respectively This preliminary conclusion was substantiated by an analysis of the other ketone mixtures.

The assumption that the absolute configuration of LB isolated from $E$. coli is the same relative to PAL can be examined by working out a value for $[\phi]_{D}$ PAL ketone A assuming the opposite case ie. LB and PAL are quasienantiomeric. This would mean that the $[\alpha]_{D}^{21}$ for LB ketone A and B would be -22 and +13 . Solving for $x\left([\alpha]_{D}{ }^{21}\right.$ for PAL ketone A) in this case would give: 
$(0.32) \mathrm{x}-(0.48) 22+(0.2) 13=+16.2+/-0.7$

$\mathrm{x}\left([\alpha]_{\mathrm{D}}^{21}\right.$ PAL ketone $\left.\mathrm{A}\right)=76+/-2$ and consequently

$[\phi]_{D}=\frac{M}{100}[\alpha]_{D}^{21-}=\frac{296 \times 76}{100}=+223+/-6$

Clearly this would give an impossibly high value for $[\phi]_{\mathrm{D}}$ PAL ketone $A$, thus

confirming our original conclusion, namely that PAL and LB from E. coli have the same relative configuration at the cyclopropyl centres.

Fraction 2: $(5.7 \mathrm{mg}): 50 \%$ PAL ketone A $22 \%$ LB ketone A $23 \%$ LB ketone B

$5 \%$ impurity ( $\mathrm{MW}=284$, assume not optically active).

Observed optical rotation: $+0.058+/-0.005^{\circ}$

Step 1: Calculate a specific rotation for the mixture compensating for a $5 \%$ impurity of similar molecular weight.

$$
[\alpha]_{\mathrm{D}}^{21}=\frac{\alpha_{\mathrm{D}}{ }^{21} \mathrm{obs} \times 100}{1 \times \mathrm{c}(\mathrm{mg} / 0.1 \mathrm{~mL})}=\frac{+0.058 \times 100}{1 \times(0.57-0.03)}=10.74+/-0.9
$$

Step 2: Assume that all species have similar molecular weights (within 10\%).

Assume that $[\alpha]_{D}^{21}$ for LB ketone A and B are the same as that determined for LB ketone $\mathrm{A}$ and $\mathrm{B}$ found in Lactobacillus $\left(+22,-13\right.$ respectively ${ }^{29}$ and solve for $\mathrm{x}$ $\left([\alpha]_{\mathrm{D}}^{21}\right.$ PAL ketone $\left.\mathrm{A}\right)$

$(0.50) \mathrm{x}+(0.22) 22-(0.23) 13=+10.74+/-0.9$

$\mathrm{x}=+18+/-2$

Step 3. The corresponding molar rotation of ketone A PAL is given by:

$[\phi]_{\mathrm{D}}=\frac{\mathrm{M}[\alpha]_{\mathrm{D}}^{21}}{100}=\frac{296 \times 18}{100}=+53+/-6$ 
This is somewhat lower than the value calculated above based on the data obtained for Fraction 1 and can be contributed to possible errors in calculating the \% composition of this mixture as well as the presence of optically active impurities.

Fraction 3: $(7.1 \mathrm{mg}) \quad 75 \%$ pure PAL Ketone B.

$7 \% \quad$ LB Ketone B.

$18 \%$ impurity ( $\mathrm{MW}=284$, assume not optically active).

Observed optical rotation: $-0.097^{\circ}+/-0.005^{\circ}$

Step 1: Calculate a specific rotation for the mixture compensating for an $18 \%$ impurity of similar molecular weight.

$[\alpha]_{\mathrm{D}}^{21}=\frac{\alpha_{D}{ }^{21} \mathrm{obs} \times 100}{1 \times \mathrm{c}(\mathrm{mg} / 0.1 \mathrm{~mL})}=\frac{-0.097 \times 100}{1 \times(0.71-.13)}=-16.7+/-0.9$

Step 2: Assume that all species have similar molecular weights (within 10\%).

Assume that $[\alpha]_{D}^{21}$ for LB ketone B is the same as that determined for LB ketone B found in Lactobacillus $(-13)^{29}$ and solve for $[\alpha]_{\mathrm{D}}{ }^{21}$ for PAL ketone $\mathrm{B}=\mathrm{x}$.

$(0.92) \mathrm{x}-(0.08) 13=-16.7$

$\mathbf{x}=-17+/-1$

Step 3. The corresponding molar rotation of PAL ketone A is given by:

$[\phi]_{\mathrm{D}}=\frac{\mathrm{M}[\alpha]_{\mathrm{D}}}{100}=\frac{296 \times-17}{100}=-50+/-3$ 


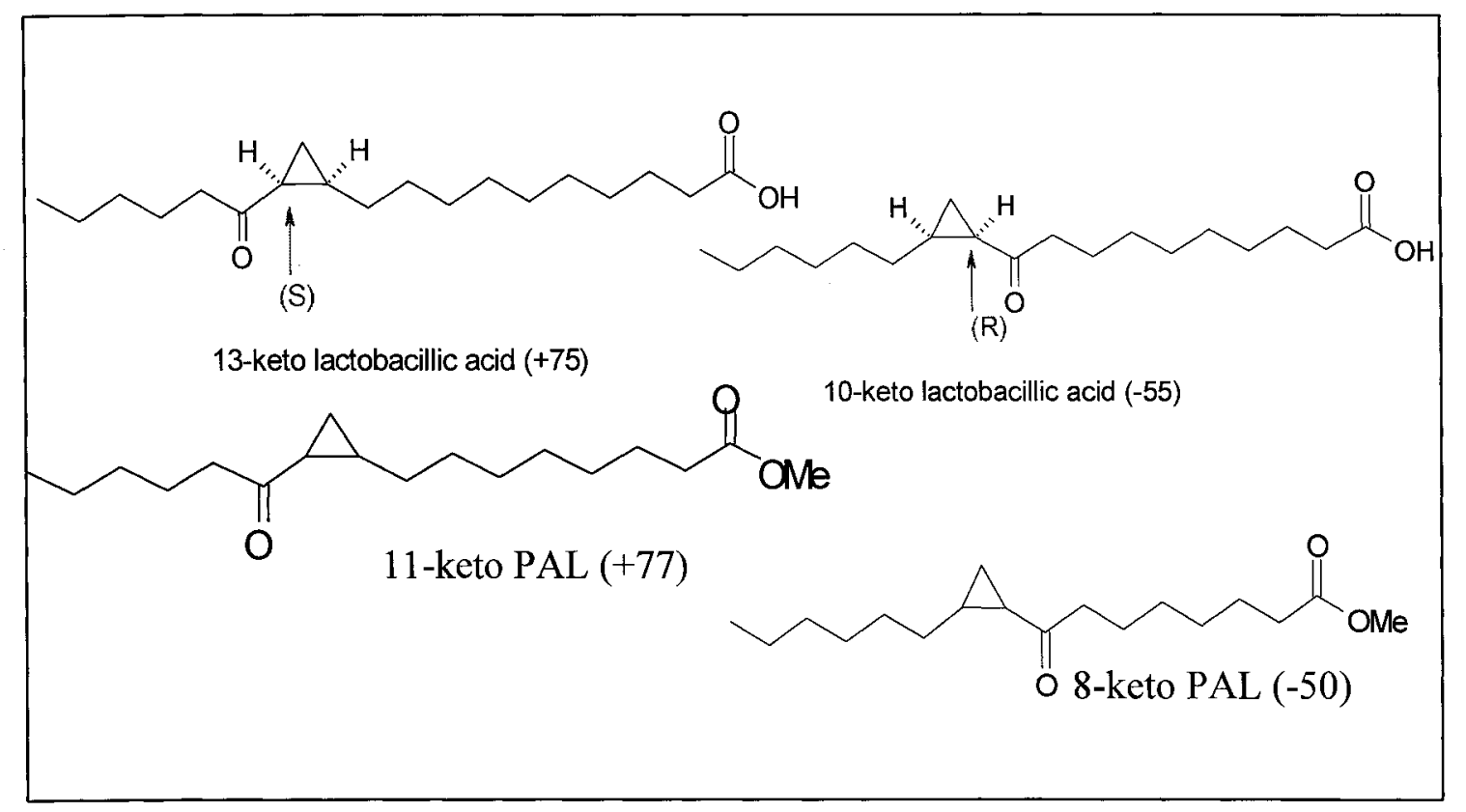

Figure 2.4.8 Lactobacillic acid Reference Structures ${ }^{52}$ and a-cyclopropyl Ketones of LB from E.coli .

This is in good agreement with the literature value for the absolute value of $[\phi]_{D}$ for DHS ketone B found in Lactobacillus +57 (this work); + 54 (Rasonyi) and the value of $[\phi]_{\mathrm{D}} \mathrm{LB}$ found in Lactobacillus - 42 (Rasonyi), -55 (Tocanne). ${ }^{29,52}$

Taken together, the results of this analysis support the conclusion stated above regarding the absolute configurations of $\mathrm{PAL}$ and $\mathrm{LB}$, namely that the absolute configurations of the $\mathrm{C} 17$ cyclopropane fatty acid (PAL) derived from palmitoleic acid and C19 cyclopropane fatty acid (LB) derived from cis-vaccenic acid bear the same relative relationship. Both are quasi-enantiomeric to DHS from L. plantarum. Both species are $(R)$-configured at the carbon nearest the carbonyl carbon and $(S)$-configured at the carbon nearest the methyl terminus. This is also true for DHS from Litchi chinensis $(9 R, 10 S)$. To date, the only CFA for which this rule has been found to be untrue is DHS produced from oleate in Lactobacillus plantarum. 


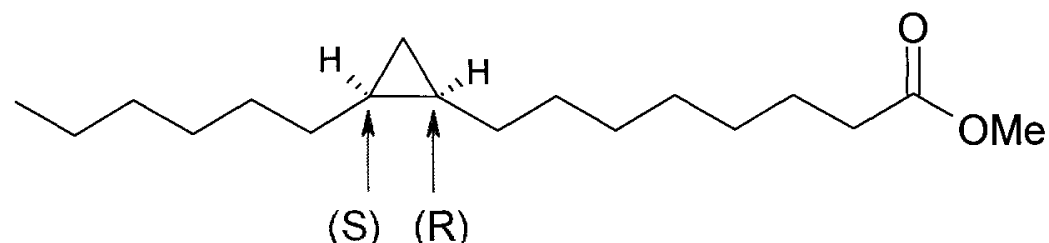

Figure 2.4.9 PAL From Escherichia coli.

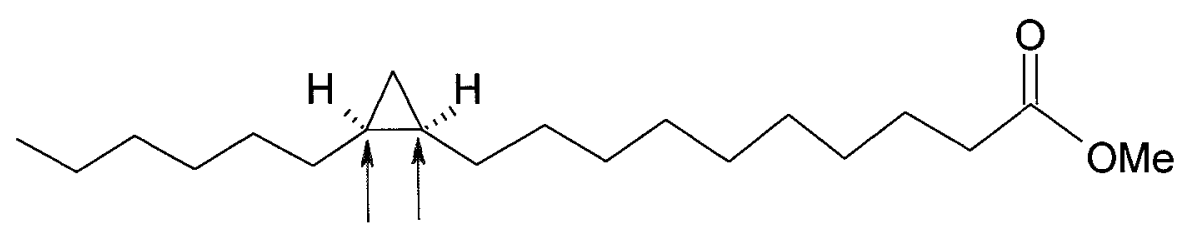

(S) (R)

Figure 2.4.10 Methyl Lactobacillate from L. plantarum and E. coli.

Interestingly, the absolute configuration of PAL reported here is opposite to the configuration reported for this molecule from the slime mold Physarium polycephalum. ${ }^{70}$ On closer inspection, it became clear that the configurational assignment for PAL (Physarium) was indirect and based on DNA polymerase inhibition data for the two synthetic PAL enantiomers linked to a glycerol moiety. ${ }^{70}$ Furthermore the sign of the specific rotation for the two synthetic PAL enantiomers is reversed from that expected based on the work of Tocanne and Baird. Clearly the Kobayashi work requires reinvestigation. 


\subsection{Saccharomyces cerevisiae Incubation Experiments}

In order to investigate the ability of Eukaryotes to desaturate DHS to sterculic acid, incubations of S. cerevisiae with DHS were carried out. S. cerevisae is known to desaturate a wide variety of fatty acid analogues. ${ }^{71}$ Tergitol, a detergent used to increase incorporation of exogenously supplied fatty acids, was added at a final concentration of $0.1 \%(\mathrm{w} / \mathrm{v})$. The DHS $(50 \mathrm{mg})$ was sterilized with ethanol $(100 \mu \mathrm{L})$ and added with $2 \mathrm{~mL}$ of the $10 \%$ Tergitol solution to fresh cultures. Controls containing $100 \mu \mathrm{L}$ ethanol and $1 \%$ Tergitol were run at the same time as the incubations with DHS. Yeast cultures (200mL) were grown for 24 hours at $30^{\circ} \mathrm{C}$ and $150 \mathrm{RPM}$. The cells were harvested by centrifugation (10,000 RPM, 15 minutes) to yield wet pellets $(\sim 3.5 \mathrm{~g})$. The pellets were saponified in $2 \mathrm{~N} \mathrm{KOH}$ in $50 \% \mathrm{EtOH}(100 \mathrm{~mL})$ for 3 hours. The fatty acids were extracted into ether $(3 \times 30 \mathrm{~mL})$ and the solvent removed in vacuo. The yields of fatty acids for the control and DHS fed cultures were $18.2+/-4.2 \mathrm{mg}$ and $25.9+/-2.5 \mathrm{mg}$, respectively $(\mathrm{N}=2)$. The fatty acids were methylated with diazomethane $(10 \mathrm{~mL})$. The etheral layer was removed under nitrogen flow. The FAMEs collected from $S$. cerevisiae had a mass of $16.1+/-3.6 \mathrm{mg}$ and $23.4+/-4.4 \mathrm{mg}$ for the control and DHS fed cultures respectively. The FAMEs were analyzed by GC/MS.

These results showed clearly that the DHS was being incorporated into the phospholipids of the yeast. No desaturation of DHS to sterculic acid occurred, as would have been evidenced by a peak with a retention time of $\sim 1$ minute longer than stearic acid (18:0), or slightly to the right of DHS. A methyl sterculate standard, available from previous work, was used to determine the retention time of the potential product of DHS desaturation. 
It is probable that $S$. cerevisiae does not have the enzyme required to perform this desaturation. It was hoped that the endogenous $\Delta 9$ desaturase of $S$. cerevisiae would use one of the enantiomers of DHS and carry out the desaturation; however, the bridging methylene likely caused steric problems for the enzyme. The putative desaturase from Sterculia foetida responsible for producing sterculic acid has recently been characterized at the genetic level and is said to share common hydrophobic domains with the yeast desaturase. Apparently the enzymes do not have enough in common for yeast to be able to carry out the desaturation of DHS.

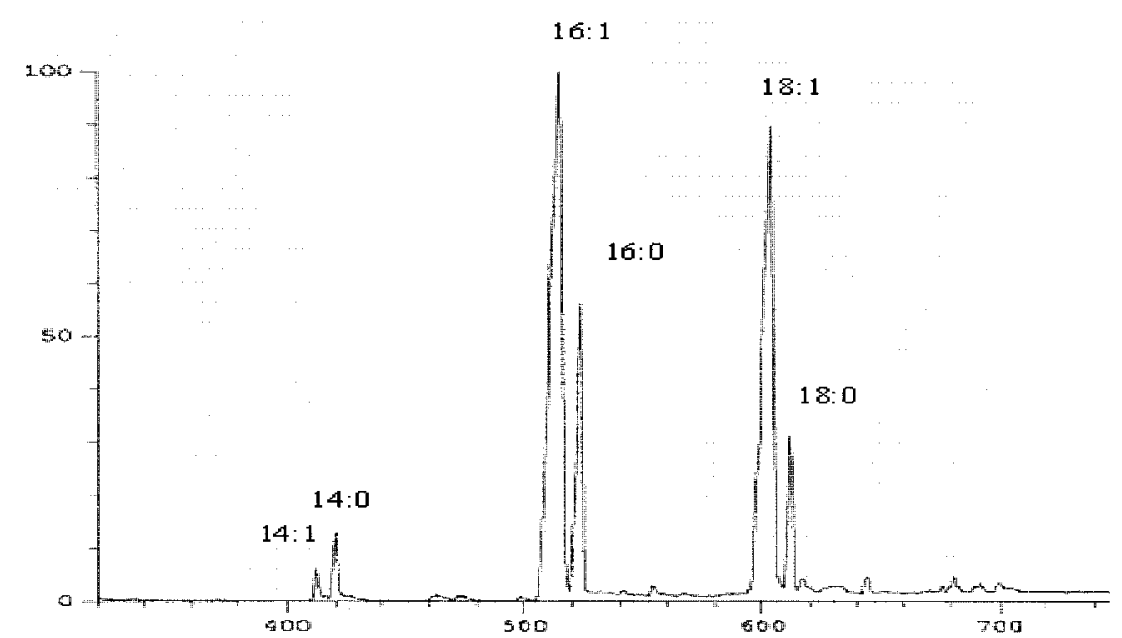

Figure 2.5.1 Gas Chromatograph of FAMEs from $S$. cerevisiae

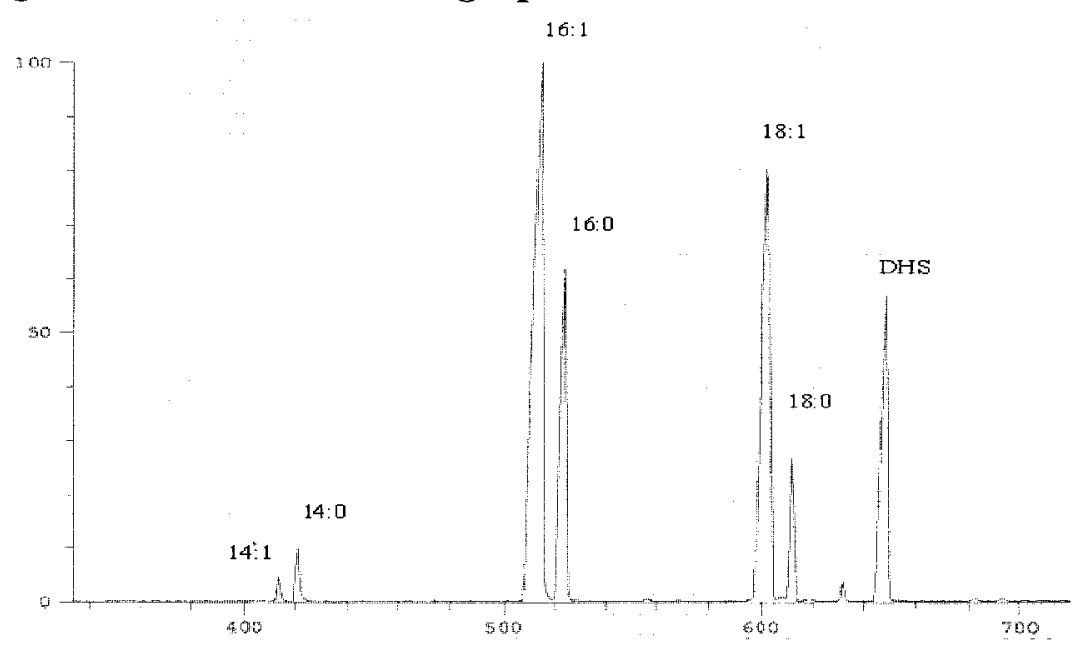

Figure 2.5.2 Gas Chromatograph of FAMEs from $S$. cerevisiae Incubated with Racemic DHS. 


\section{Conclusions and Future Directions}

Through the course of this project, the absolute configuration of three CFAs (one phyto, two bacterial) were determined for the first time and two were confirmed.

Sources of both enantiomers of dihydrosterculate were investigated with a view to future research on the stereochemistry of DHS desaturation. Motivated by our publication of the Litchi DHS stereochemistry ${ }^{63}$, E. J. Corey's group at Harvard has provided a new synthetic route to DHS enantiomers. ${ }^{64}$ The enantiomeric purity of DHS produced in this way has yet to be determined.

a)<smiles>CCCCCCCC[C@]1(C)C[C@@H]1CCCCCCCC(=O)OC</smiles>

(S) (R)

b)<smiles>CCCCCCCC[C@H]1CC1(C)CCCCCCCC(=O)OC</smiles>

(R) (S)

c)<smiles>CCCCCC[C@H]1C[C@H]1CCCCCCCC(=O)OC</smiles>

(S) (R)

d)<smiles>CCCCCC[C@]1(C)C[C@H]1CCCCCCCCCC(=O)OC</smiles>

(S) $(\mathrm{R})$

Figure 2.6.1 Absolute configurations of a) DHS from $L$. chinensis, b) DHS from $L$. plantarum, c) PAL from E. coli, d) Lactobacillate from L. plantarum and E. coli. 
Other projects that arise from the work described in this thesis include determining the absolute configuration of DHS from an $E$. coli fatty acid auxotrophic mutant. It has been shown that oleate is a substrate for the $E$. coli CFA synthase, but the absolute configuration of this fatty acid remains unknown. ${ }^{31}$ It would be interesting to compare the stereochemistry of DHS from E. coli with that isolated from L. plantarum and to determine whether these molecules are enantiomeric.

The crystal structure of one CFA synthase from Mycobacterium tuberculosis has recently been completed. ${ }^{33}$ It would be of interest to do homology modelling with the two CFA synthases from L. plantarum to explore how olefinic fatty acids are positioned within the active cavity. It would also be useful to functionally express both synthases in yeast and determine the regiochemical specificity of these enzymes.

Now that it is known that both enantiomers of DHS can be obtained separately, it is of interest to explore which of these molecules is desaturated to sterculic acid Investigations with racemic DHS fed to $S$. cerevisiae were unsuccessful in yielding any cyclopropene formation though DHS incorporation was seen. The enzyme thought to be responsible for this unusual desaturation reaction of DHS has been isolated from Sterculia foetida. ${ }^{72}$ Efforts are now being made to functionally express this gene in $S$. cerevisiae which would then allow us to put our enantiomers of DHS to use. The absolute configuration of residual DHS from $S$. foetida is also being determined, providing another insight into the stereochemistry of desaturation. Since only $0.5 \%$ of the total fatty acids of $S$. foetida seeds is DHS, this requires a very large amount of seed oil which has recently been obtained. ${ }^{14}$

It has been suggested that the DHS not desaturated to sterculic acid may be of the 
wrong stereochemistry for the desaturase. ${ }^{72}$ This suggestion is of interest because some plant species, such as Litchi, that produce DHS do not desaturate the CFA to sterculic acid. Once the genome of Litchi chinensis is known, it would be of interest to explore whether there is an enzyme homologous to the DHS desaturase from $S$. foetida present or not. Perhaps it is simply a matter of stereochemistry that prevents these species from producing this highly unusual cyclopropenyl fatty acid suspected of being an anti-feedant defense mechanism. ${ }^{34}$ 


\section{Chapter 3 Experimental}

\subsection{General}

${ }^{1} \mathrm{H}$ NMR $(400 \mathrm{MHz})$ and ${ }^{13} \mathrm{C}$ NMR $(100.6 \mathrm{MHz})$ spectra were recorded on a Bruker AMX 400 spectrometer. Deuterated chloroform was used to dissolve all NMR samples. Chemical shifts for all NMR spectra are in $\mathrm{ppm}(\delta)$ relative to trimethylsilane (TMS) and the residual nondeuterated chloroform impurity present in the deuterated solvent was used to standardize all chemical shifts.

Gas chromatography-mass spectrometry (GC/MS) was performed at the University of Ottawa using a Kratos Concept $1 \mathrm{H}$ mass spectrometer at $70 \mathrm{eV}$ interfaced with a J. \& W. $30 \mathrm{~m} \times 0.21 \mathrm{~mm}$ DB-5 capillary column. The column temperature was programmed for $120^{\circ} \mathrm{C}$, held for two minutes, then ramped up to $320^{\circ} \mathrm{C}$ at $10^{\circ} \mathrm{C} / \mathrm{min}$

Optical activity was determined with a Perkin-Elmer 141 polarimeter using a sodium lamp providing plane-polarized light at $589 \mathrm{~nm}$.

Media and glassware was autoclaved using a AMSCO 2021 gravity autoclave on a 20 minute "liquid" setting with a pressure of $\sim 1.2 \mathrm{~kg} / \mathrm{cm}^{2}$. Cell cultures were incubated in a model G25 Incubator Shaker $\left(30^{\circ} \mathrm{C}\right.$ and 150 RPM for S. cerevisiae; $37^{\circ} \mathrm{C}$ without shaking for L. plantarum).

Purification of the synthetic products and the biological extracts was carried out using flash chromatography: Merck silica gel 60 (230-400 mesh) was used with an air pressure of four psi. Fractions were analyzed by thin layer chromatography using glass Merck silica gel $(60 \AA)$ plates $(20 \mathrm{~cm} \times 5 \mathrm{~cm})$. Plates were developed using either $5 \%$ phosphomolybdic acid in ethanol, Iodine vapour, or water spray as appropriate.

Reagents and starting materials for synthetic reactions were purchased from Sigma- 
Aldrich and solvents were obtained from Caledon Chemical Company. All nonoxidative reactions were carried out under Nitrogen atmosphere. Organic solvents were removed in vacuo using a Buchi RE 111 Rotovapor rotoevaporator.

Media components for biological incubation experiments were purchased from VWR Canlab. Distilled deionized water $\left(\mathrm{ddH}_{2} \mathrm{O}\right)$ was obtained from a Millipore Milli-Q water system. Microbial cells were centrifuged at $10,000 \mathrm{RPM}$ and $2^{\circ} \mathrm{C}$ for 15 minutes. Cell pellets so obtained were routinely suspended in $0.8 \%$ saline solution and recentrifuged.

All microbiological work was done under asceptic conditions in a laminar flow hood. All implements used were sterilized via autoclaving and flamed immediately prior to use. All working surfaces were cleaned with $95 \%$ ethanol before and after use.

Cultures of Lactobacillus pentosus (plantarum) NRLL and Saccharomyces cerevisiae NRRL Y-2574 were obtained from Dr. Alejandro Rooney, Microbial Genomics and BioProcessing Research Unit, USDA, Peoria, Illinois, USA. E. coli BATCC 11303 lipids were purchased from Avanti Polar Lipids, Inc., Alabaster, Alabama, USA.

\subsection{Synthesis of Racemic Methyl Dihydrosterculate}

Zinc dust (4g) was suspended in $30 \mathrm{~mL}$ boiling acetic acid in a $250 \mathrm{~mL}$ three-necked round bottom flask. A solution of cupric acetate in boiling acetic acid $(800 \mathrm{mg}$ in $20 \mathrm{~mL})$ was then added to the zinc suspension. The mixture was stirred until the blue solution was seen to decolourize and the zinc coated with a red precipitate ( $\sim 3$ minutes $)$. After washing the zinc copper amalgam with acetic acid $(5 \times 30 \mathrm{~mL})$ and diethyl ether $(5 \mathrm{x}$ 
$30 \mathrm{~mL})$, the solids were suspended in $50 \mathrm{~mL}$ diethyl ether and diiodomethane $(25 \mathrm{~g})$ was added by pipette. A solution of methyl oleate $(0.9 \mathrm{~g})$ in diethyl ether was added to the mixture which was refluxed under $\mathrm{N}_{2}$ for 24 hours. Additional portions of diethyl ether was added to the reaction as required to maintain the initial volume.

After allowing the reaction mixture to cool to RT, the ether layer was carefully decanted into a $250 \mathrm{~mL}$ separatory funnel. The flask and precipitate were rinsed with diethyl ether $(2 \times 15 \mathrm{~mL})$ and the rinsings were added to the separatory funnel. The ether layer was washed with cold $1 \mathrm{~N}$ hydrochloric acid $(3 \times 40 \mathrm{~mL})$, distilled water $(3 \times 40 \mathrm{~mL})$, and saturated sodium chloride $(1 \times 40 \mathrm{~mL})$ before being dried over sodium sulfate. The solvent was removed in vacuo producing a viscous, dark brown liquid.

Excess diiodomethane was removed using high vacuum distillation and high vacuum bulb-to-bulb distillation of the remaining oil. Polar impurities were removed by filtering the product through a Florisil column $(20 \mathrm{~cm} \times 1 \mathrm{~cm})$ using $5 \%$ ethyl acetate in hexanes. Evaporation of the solvent yielded a yellow oil (980 mg).

To remove any remaining methyl oleate, the oil was dissolved in $2 \mathrm{~mL} \mathrm{CH}_{2} \mathrm{Cl}_{2}$ and treated with $0.5 \mathrm{~g}$ meta-chloroperbenzoic acid (MCPBA). The mixture was allowed to stand at $4{ }^{\circ} \mathrm{C}$ for 24 hours, diluted with hexanes $(10 \mathrm{~mL})$ and filtered to remove beige solids that had formed. The organic residue obtained after evaporation of solvent was purified by flash chromatography ( $10 \%$ ethyl acetate in hexanes) to yield the title compound as a brown oil (260 mg, 30\% yield). $R_{\mathrm{f}} 0.40\left(\mathrm{Et}_{2} \mathrm{O} /\right.$ hexane $\left.1: 10\right) ; \mathrm{IR}($ film) $2925,2854,1774,1465,1436,1360,1246,1197,1170,1113,1020 \mathrm{~cm}^{-1} ;{ }^{1} \mathrm{H}$ NMR (400 $\left.\mathrm{MHz}, \mathrm{CDCl}_{3}\right) \delta 3.67(3 \mathrm{H}, \mathrm{s}), 2.31(2 \mathrm{H}, \mathrm{t}, J=7.6 \mathrm{~Hz}), 1.62(2 \mathrm{H} \mathrm{m}), 1.1-1.4(24 \mathrm{H}, \mathrm{m})$, $0.88(3 \mathrm{H}, \mathrm{t}, J=6.9 \mathrm{~Hz}), 0.64(2 \mathrm{H}, \mathrm{m}), 0.56(1 \mathrm{H}, \mathrm{m}),-0.33(1 \mathrm{H}, \mathrm{m}) .{ }^{13} \mathrm{C} \mathrm{NMR}(100$ 
$\left.\mathrm{MHz}, \mathrm{CDCl}_{3}\right) \delta 174.38,51.44,34.14,31.94,30.23,30.14,29.70,29.70,29.47,29.38$,

$29.32,29.17,28.74,28.68,24.98,22.71,15.78,15.74,14.13,10.92 ;$ EI MS m/z 310

$\left(\mathrm{M}^{+}\right), 278\left([\mathrm{M}-32]^{+}\right)$.

\subsubsection{Trial Oxidation of Cyclopropyl Fatty Acids}

Racemic methyl dihydrosterculate $(127 \mathrm{mg})$ in $\mathrm{CCl}_{4}(1 \mathrm{~mL})$ was added to an oxidant solution consisting of $\mathrm{CrO}_{3}(247 \mathrm{mg})$ dissolved in $5.5 \mathrm{~mL}$ acetic acid/ water $(97 / 3)$ contained in a $\mathrm{xL} \mathrm{RB}$ flask. The dark orange mixture was stirred for 66 hours at RT after which excess oxidant quenched with the addition of methanol (500 $\mu \mathrm{L})$. The dark green solution was transferred to a $50 \mathrm{~mL}$ separatory funnel and the FAMEs extracted into hexanes $(3 \times 20 \mathrm{~mL})$. The organic layers were collected and washed with ice-cold water $(20 \mathrm{~mL})$, saturated sodium bicarbonate $(20 \mathrm{~mL})$, and distilled water $(20 \mathrm{~mL})$. The organic extract was dried over sodium sulfate, and then concentrated in vacuo to give a yellow oil $(93 \mathrm{mg})$. The oxidized mixture (colourless oil) was made up of starting CFA and methyl 8-ketodihydrosterculate and methyl 11ketodihydrosterculate and was a colourless oil as determined by GC-MS analysis.

The analytical data for each ketone is given in the section below dealing with oxidation of Litchi CFA.

\subsection{Analysis of CFAs isolated from $L$. chinensis seeds}

99 litchi seeds were removed from the inside of the fruit, rinsed clean, and ground into a fine powder using a coffee grinder. The powder was weighed $(200 \mathrm{~g})$ and transferred to a $500 \mathrm{~mL}$ round bottom flask with $150 \mathrm{~mL} 2: 1$ chloroform:methanol. The brown mixture was allowed to stir at room temperature under nitrogen for 24 hours. The mixture was filtered by suction to remove the large particles and the solids were rinsed 
with 2:1 chloroform:methanol. The filtrate was transferred to a $1 \mathrm{~L}$ separatory funnel, and the crude litchi seed oil was extracted into methylene chloride $(3 \times 100 \mathrm{~mL})$. The organic layers were collected and dried over $\mathrm{MgSO}_{4}$. The solvent was removed in vacuo and the oil brought to constant weight under $\mathrm{N}_{2}$. The fatty acids were methylated using sodium methoxide which had been freshly prepared by combining $0.3 \mathrm{~g}$ sodium metal with $15 \mathrm{~mL}$ dry methanol. This reaction proceeded on ice, under $\mathrm{N}_{2}$ until the solution was no longer bubbling. The sodium methoxide was immediately transferred to the round bottom flask containing the dry triglycerides. The heterogenous solution (clear liquid with dark brown oil) was swirled at room temperature for 10 minutes, then placed in the refrigerator for 48 hours to allow complete methylation.

The sodium methoxide solution containing the fatty acid methyl esters was removed from the fridge and transferred to a $250 \mathrm{~mL}$ separatory funnel. The FAMEs were extracted into hexanes and the organic layer was washed with saturated sodium chloride. The hexanes were dried over magnesium sulphate and the solvent removed in vacuo. The FAMEs were brought to constant weight under $\mathrm{N}_{2}(1.005 \mathrm{~g})$. A sample was used for GC/MS and NMR analysis. The gas chromatograph provided information to establish the percent olefin present in the mixture (42\%). This number was used to determine how much m-chloroperbenzoinc acid (m-CPBA) would be required for complete epoxidation of all olefinic material $(0.3 \mathrm{mmol} \mathrm{m}-\mathrm{CPBA} / 100 \mathrm{mg}$ olefin $)$. The FAMEs were dissolved in $1 \mathrm{~mL}$ dichloromethane and placed in the freezer for 15 minutes. The m-CPBA was added to the cold solution, and the mixture left in the freezer over-night. Upon removal from the freezer, a wet beige powdery solid was seen. This was filtered by vacuum and the solid rinsed with hexanes. The liquid was transferred to 
a $50 \mathrm{~mL}$ tear-drop shaped $\mathrm{RBF}$ and the solvent removed in vacuo. A white precipitate was visible on the edges of the flask. A small amount of hexanes was used to rinse the material to the bottom of the flask; the solvent was then gently removed with $\mathrm{N}_{2}$ flow to prevent spreading the contents around the flask.

A 10:1 mixture of hexanes:ether was prepared $(500 \mathrm{~mL})$. A flash-chromatography column was packed using 230-400 mesh silica gel and the hexanes:ether solvent mixture. The contents of the RBF were dissolved in a minimal amount $(<1 \mathrm{~mL})$ of the mixture and carefully transferred to the surface of the column. The column was run at 4 psi until forty $10 \mathrm{~mL}$ fractions had been collected. Thin layer chromatography developed with PMA was used to determine which fractions contained the purified cyclopropyl fatty acid methyl esters of interest. These fractions were collected, the solvent removed and the purified oil weighed prior to GC-MS and NMR analysis.

Oxidation of the cyclopropyl Fames was accomplished by stirring $102 \mathrm{mg}$ of the purified FAMEs (dissolved in $1 \mathrm{~mL}$ carbon tetrachloride) with a solution of chromium trioxide (220mg, $2.2 \mathrm{mmol}$ ) in $5.5 \mathrm{~mL}$ of $97 \%$ acetic acid for 66 hours. The reaction was carried out in a $10 \mathrm{~mL}$ tear-drop shaped RBF. The stir plate was set slightly off centre to encourage some bouncing of the stir bar to give better contact between the two separate layers (bottom clear $\mathrm{CCl}_{4} /$ top red-brown chromium trioxide + acetic acid).

After 66 hours, $250 \mu \mathrm{L}$ of methanol was added to stop the reaction. The red-brown layer was seen to turn dark olive-green within 10 minutes. The solution was transferred to a $50 \mathrm{~mL}$ separatory funnel and the FAMEs extracted into hexanes $(25 \mathrm{~mL})$. The slightly green organic layer was rinsed with ice-water, then with saturated sodium bicarbonate, during which some bubbling was seen indicating the presence of acetic acid. 
The hexanes were then washed with distilled water and sat $\mathrm{NaCl}$ before being dried over $\mathrm{Na}_{2} \mathrm{SO}_{4}$. The solvent was removed in vacuo, and the oil brought to constant weight under nitrogen. The final weight of the oxidized mixture was $50 \mathrm{mg}$. GC-MS and NMS analyses were done of the resultant oil.

TLC was used to establish appropriate solvent for the separation of the cyclopropyl FAMEs and the two cyclopropyl ketones. A mixture of 10:1 hexanes:ether was found to give adequate separation, thus was used for flash-chromatography. Eighty fraction of $10 \mathrm{~mL}$ each were collected. TLC was used to determine which fraction contained pure samples of each cyclopropyl ketones. These fractions were collected, the solvent removed, and the oils carefully weighed. $27 \mathrm{mg}$ of unoxidized starting material, $10 \mathrm{mg}$ of 8-keto-dihydrostersculate, and $11 \mathrm{mg}$ of 11-keto-dihydrosterculate were recovered.

Polarimetry was conducted on the cyclopropyl ketones in $1 \mathrm{~mL}$ ether to determine the optical rotation of each ketone. The analytical data for each ketone is given here: Methyl 8-ketodihydrosterculate (Methyl (Z)-8-(2-octylcyclopropane-1-yl)-8-oxooctanoate) $R_{\mathrm{f}} 0.15$ (Et $\mathrm{E}_{2} \mathrm{O} /$ hexane 1:10); IR (film) 2926, 2855, 1741, 1458, 1394, 1258, 1196, 1166, 1079, $1021 \mathrm{~cm}^{-1} ;{ }^{1} \mathrm{H}$ NMR $\left(400 \mathrm{MHz}, \mathrm{CDCl}_{3}\right) \delta 3.66(3 \mathrm{H}, \mathrm{s}), 2.54(2 \mathrm{H}, \mathrm{t}, J$ $=7.4 \mathrm{~Hz}), 2.30(2 \mathrm{H}, \mathrm{t}, J=7.4 \mathrm{~Hz}), 2.00(1 \mathrm{H}, \mathrm{m}), 1.61(4 \mathrm{H}, \mathrm{m}), 1.15-1.50(19 \mathrm{H}, \mathrm{m}), 1.06$ $(1 \mathrm{H}, \mathrm{m}), 0.94(1 \mathrm{H}, \mathrm{m}), 0.87(3 \mathrm{H}, \mathrm{t}, J=6.9 \mathrm{~Hz}) ;{ }^{13} \mathrm{C} \mathrm{NMR}\left(100 \mathrm{MHz}, \mathrm{CDCl}_{3}\right) \delta 209.31$, $174.23,51.47,44.71,34.03,31.88,29.97,29.60,29.36,29.30,28.97,28.94,26.23$, 25.74, 25.52, 24.80, 23.89, 22.69, 14.32, 14.12; EI MS m/z $324\left(\mathrm{M}^{+}\right), 293$ ([M - 31] $\left.]^{+}\right)$, $171\left(\left[\mathrm{CO}\left(\mathrm{CH}_{2}\right)_{6} \mathrm{CO}_{2} \mathrm{CH}_{3}\right]^{+}\right)$; HRMS (EI): $\mathrm{m} / \mathrm{z}$ calcd for $\mathrm{C}_{20} \mathrm{H}_{36} \mathrm{O}_{3}:$ 324.2665. Found: $324.2675 ;[\alpha]_{\mathrm{D}}^{21}=-14.8\left(c 0.9, \mathrm{Et}_{2} \mathrm{O}\right)$.

Methyl 11-ketodihydrosterculate (Methyl (Z)-8-(2-(1-oxo)-octylcyclopropane-1- 
yl)- octanoate) $R_{\mathrm{f}} 0.18\left(\mathrm{Et}_{2} \mathrm{O} /\right.$ hexane $\left.1: 10\right) ; \mathrm{IR},{ }^{\mathrm{l}} \mathrm{H}$ NMR similar to $3 ;{ }^{13} \mathrm{C}$ NMR (100 $\left.\mathrm{MHz}, \mathrm{CDCl}_{3}\right) \delta 209.58,174.34,51.45,44.90,34.11,31.73,29.87,29.31,29.22,29.14$, $29.14,29.12,26.19,25.68,25.41,24.94,24.16,22.64,14.30,14.09 ;$ EI MS m/z 324 $\left(\mathrm{M}^{+}\right), 293\left([\mathrm{M}-31]^{+}\right), 127\left(\left[\mathrm{CH}_{3}\left(\mathrm{CH}_{2}\right)_{6} \mathrm{CO}\right]^{+}\right)$; HRMS (EI): $\mathrm{m} / \mathrm{z}$ calcd for $\mathrm{C}_{20} \mathrm{H}_{36} \mathrm{O}_{3}$ : 324.2665. Found: 324.2681; $[\alpha]_{\mathrm{D}}^{21}=+20.7\left(c 1, \mathrm{Et}_{2} \mathrm{O}\right)$.

\subsection{Cell cultures}

\section{Saccharomyces cerevisiae}

Medium for growing $S$. cerevisiae was prepared by combining $10 \mathrm{~g}$ BACTO ${ }^{\mathrm{TM}}$ Yeast Extract, 20g BACTO ${ }^{\mathrm{TM}}$ peptone and $900 \mathrm{~mL}$ deionized distilled water $\left(\mathrm{ddH}_{2} \mathrm{O}\right)$. The medium was sterilized through autoclaving and stored in the refrigerator until use. Agar plates were used to maintain the cell line, and were prepared by adding $15 \mathrm{~g}$ of agar to the $900 \mathrm{~mL}$ medium prior to autoclaving. Glucose $(20 \mathrm{~g} / 900 \mathrm{~mL})$ was autoclaved in $100 \mathrm{~mL}$ deionized water and added to the medium after cooling for 1 hour. The plates were then poured and allowed to set. Plates were sealed with parafilm and stored in the refrigerator.

Starter cultures were prepared by autoclaving $9 \mathrm{~mL}$ medium in a $25 \mathrm{~mL}$ Erlenmyer flask. Glucose solution ( $4 \mathrm{~g}$ in $10 \mathrm{~mL}$ deionized water) was made and autoclaved separately. The solutions were allowed to cool for 1 hour, then $1 \mathrm{~mL}$ of glucose solution was added to the medium. Yeast were transferred from agar plates to the liquid culture using a flamed loop. The cells were then incubated at $30^{\circ} \mathrm{C}$ and $150 \mathrm{RPM}$ for 24 hours. S. cerevisiae cultures of $200 \mathrm{~mL}$ were used for lipid extraction. These were prepared with $200 \mathrm{~mL}$ of medium and $4 \mathrm{~g}$ of glucose. $1 \mathrm{~mL}$ starter culture was added to each flask and 
the cells were incubated at $30^{\circ} \mathrm{C}$ and 150 RPM for 24 hours.

To aid the incorporation of foreign fatty acids into the yeast cultures, $0.1 \%$ tergitol solution was used ( $1 \mathrm{~mL} 10 \%$ tergitol in water $[\mathrm{w} / \mathrm{v}]$ per $100 \mathrm{~mL}$ medium). The fatty acid methyl esters to be added were dissolved in $100 \mu \mathrm{L} 95 \%$ ethanol and transferred with the tergitol solution to the medium prior to inoculation.

\section{Lacotbacillus pentosus (plantarum)}

\section{A)MRS Broth}

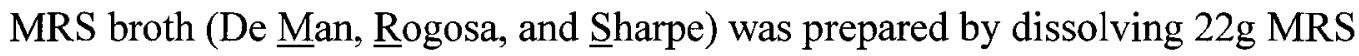

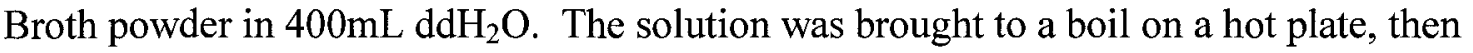
transferred to $25 \mathrm{~mL}$ screw cap test tubes $(10 \mathrm{~mL}$ per tube). Agar tubes were prepared similarly, however; agar ( $3 \mathrm{~g} / 100 \mathrm{~mL}$ medium) was added to the solution prior to boiling. The lids were screwed on loosely and all of the tubes were autoclaved. After cooling for 1 hour in a flow hood, the lids were sealed and the tubes stored at $4^{\circ} \mathrm{C}$.

The sealed vial containing the lyophilized culture was snapped open and, using a flamed spatula, a portion of the dried cells was transferred to each of two liquid medium tubes that had been brought to $37^{\circ} \mathrm{C}$. The inoculums were allowed to grow at $37^{\circ} \mathrm{C}$ for 48 hours, at which point the dark brown medium was seen to have become an opaque beige colour throughout. Stab cultures were prepared by inserting a sterilized bacterial knife into the liquid culture, then the knife was inserted into the center of an agar tube brought to $37^{\circ} \mathrm{C}$. These cultures were grown for 24 hours, then stored in the refrigerator until use. Starter cultures were prepared by inoculating $10 \mathrm{~mL}$ liquid tubes with a loop of cells from the agar stab cultures. $1 \mathrm{~L}$ of MRS broth was made by combining $55 \mathrm{~g}$ powder medium in $1 \mathrm{~L} \mathrm{ddH}_{2} \mathrm{O}$. The medium was autoclaved and, after cooling, was inoculated 
with two $10 \mathrm{~mL}$ liquid cultures that had been grown for 24 hours. The cultures were grown for 24 hours at $37^{\circ} \mathrm{C}$.

B) Biotin Assay Medium (BAM)

$1 \mathrm{~L}$ of BAM was made by combining $37 \mathrm{~g}$ powder medium in $1 \mathrm{~L} \mathrm{ddH_{2 }} \mathrm{O}$. This solution was brought to a boil and, after cooling briefly, 50mL Vitamin Free Caseine Hydrolysate (ICN Pharmaceuticals) was added by air displacement. To this mixture, $1 \mathrm{~mL}$ biotin stock solution (10mg biotin/1 $\mathrm{L} \mathrm{ddH}_{2} \mathrm{O}$ ) was added. The medium was autoclaved and, after cooling, was inoculated with two $10 \mathrm{~mL}$ liquid cultures that had been grown for 24 hours. The cells were allowed to grow for 48 hours at $37^{\circ} \mathrm{C}$.

E. coli B - ATCC 11303 lyophilized lipids were purchased from Avanti PolarLipids, Inc., Alabaster, Alabama USA.

\subsection{Fatty Acid Analysis}

All cell pellets (bacterial and yeast) and purchased E. coli lipids were saponified following the same protocol which used a hydrolysis solution consisting of $2 \mathrm{~N} \mathrm{KOH}$ in $50 \%$ ethanol. Approximately $20 \mathrm{~mL}$ hydrolysis solution was used per gram of cell pellet or purchased lipid for the saponification process. The cell pellet or lyophilized lipids were transferred to an appropriately sized round bottom flask and the determined volume of hydrolysis solution was added. The mixture was refluxed with stirring for 5 hours under nitrogen. The solution was cooled and allowed to settle then filtered by suction. The solids were rinsed with $95 \%$ ethanol. The ethanolic solution was transferred to a $1 \mathrm{~L}$ tear-drop shaped RBF and the ethanol removed in vacuo. The basic extract was transferred to a $250 \mathrm{~mL}$ separatory funnel and washed with $50 \mathrm{~mL}$ ether. This layer was 
removed and stored. The basic aqueous layer was chilled on ice and acidified to $\mathrm{pH}=2$ with $3 \mathrm{M} \mathrm{H}_{2} \mathrm{SO}_{4}$, at which time the brown solution became a pale beige colour and a precipitate was visible. The aqueous layer was extracted with diethyl ether $(3 \times 100 \mathrm{~mL})$ using a 1L separatory funnel. The ether layers were combined in the separatory funnel and washed with saturated sodium chloride $(100 \mathrm{~mL})$. The aqueous layer was removed and the ether layer was slowly drained through a conical funnel containing $\mathrm{Na}_{2} \mathrm{SO}_{4}$ into a $500 \mathrm{~mL}$ RBF. The ether was removed in vacuo. The fatty acids were transferred to a preweighed $250 \mathrm{~mL}$ RBF using a small amount of ether, then brought to constant weight under nitrogen.

Methylation of bacterial extracts was done using $\mathrm{BF}_{3} /$ methanol. Ten $\mathrm{mL}$ of $\mathrm{BF}_{3}$ etherate was added to $32 \mathrm{~mL}$ dry methanol using a $10 \mathrm{~mL}$ syringe. The solution was added immediately to the RBF containing the fatty acids and the mixture was refluxed for 3 hours under $\mathrm{N}_{2}$. The solution was cooled, diluted with $100 \mathrm{~mL}$ distilled water, then extracted with hexanes $(3 \times 40 \mathrm{~mL})$. The organic layers were combined and washed with $30 \mathrm{~mL}$ saturated $\mathrm{NaCl}$, then dried over sodium sulfate. The solvent was removed in vacuo and the FAMEs brought to constant weight under nitrogen.

After analysis by GC/MS and ${ }^{\mathrm{I}} \mathrm{H}$ and ${ }^{13} \mathrm{C}$ NMR, the microbial FAMEs were treated with $m$-CPBA, purified by flash chromatography, and oxidized with $\mathrm{CrO}_{3}$ using the same procedures as were used for the Litchi experiments and preparation of racemic DHS. The separation of the cyclopropyl ketones proceeded in similar fashion as previously described. The details are given in the $\mathrm{R}$ and $\mathrm{D}$ section of this thesis.

Methylation of the $S$. cerevisiae fatty acids had to be carried out using diazomethane (CAUTION: Toxic and explosive) to avoid decomposition of any 
cyclopropenyl fatty acids that may have been biosynthesized when the cells were incubated with racemic DHS. The diazomethane solution was prepared by dissolving $2 \mathrm{~g}$

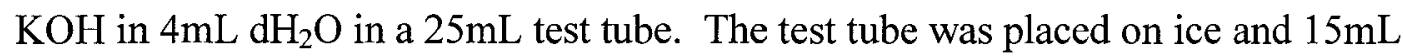
diethyl ether was added. N-nitroso-methyl urea $(\sim 250 \mathrm{mg})$ was added to the ether/KOH solution and the ether layer was seen to turn bright yellow. Once bubbling ceased, the yellow ethereal layer was dried over sodium sulphate in a second test tube, then transferred to the RBF containing the fatty acids. The flask was placed in an ice bath and allowed to react for 10 minutes. Unreacted diazomethane was carefully blown off in the fume hood and the FAMEs brought to constant weight under $\mathrm{N}_{2}$. 


\section{References}

1. J.D. Weete "Lipid Biochemistry of Fungi and Other Organisms", Plenum Press, New York, 1980.

2. W.M. Becker, J.B. Reece and M.F. Poenie "The World of the Cell", Benjamin/Cummings Publishing Company, Don Mills, 1996.

3. G.J. Schroepfer and K. Bloch. 1965. J Biol Chem. 240. 54.

4. http://www.elmhurst.edu/ chm/vchembook/551 fattyacids.html.

5. P.H. Raven, R.F. Evert and S.E. Eichhorn. 1999. "Biology of Plants, $6^{\text {th }}$ edition", W.H. Freeman and Co. New York.

6. B. Alberts D. Bray, J. Lewis, M. Raff, K. Roberts and J.D. Watson. 1983. “ Molecular Biology of the Cell", Garland Publishing, Inc. New York.

7. N.A. Campbell “Biology $3^{\text {rd }}$ Edition”, Benjamin/Cummings Publishing Company, Don Mills, 1993.

8. http://www.io.uwinnipeg.ca/ $\sim \operatorname{simmons}$

9. D. Voet and J.G. Voet. 1995. "Biochemistry, $2^{\text {nd }}$ edition", John Wiley and Sons, Inc. New York.

10. www.nanomedicine.com/ NMI/Figures

11. K. Hofmann and R.A. Lucas. 1950. J. Am. Chem. Soc. 72. 4328.

12. D.W. Grogan and J.E. Cronan Jr. 1997. Microbiol Mol Biol Rev, 61. 429.

13. M.P. Lechivallier. 1977. Crit. Rev. Microbiol. 5. 109.

14. W.W. Christie. "Topics in Lipid Chemistry, vol l”. John Wiley \& Sons, Inc., New York. 1970.

15. F.D. Taylor, D.W. Grogan and J.E. Cronan Jr. 1981. Methods Enzymol. 71. 133.

16. C.J. Su, R. Reusch and H.L. Sadoff. 1979. J. Bacteriol. 137. 1434.

17. X. Bao, J.J. Thelen, G. Bonaventure and J.B. Ohlrogge. 2003. J. Biol. Chem. 278. 12846. 
18. J.E.Cronan Jr., W.D. Nunn and J.G. Batchelor. 1974. Biochem Biophys Acta. 348. 63.

19. J.H. Law. 1971. Acc. Chem. Res. 4. 199.

20. P.J. Thomas and J.H. Law. 1966. J. Biol. Chem. 241. 5013.

21. A.Y. Wang, D.W. Grogan and J.E. Cronan Jr. 1992. Biochemistry. 31. 11020.

22. W.M. O'Leary. 1962. “Transmethylation and Biomethylation”. University of Chicago Press, Chicago.

23. J.E. Cronan Jr., R. Reed, F.R. Taylor and M.B. Jackson. 1979. J Bacteriol. 138. 118.

24. F.R. Taylor and J.E. Cronan Jr. 1979. Biochemistry. 15. 3292.

25. E. Lederer. 1969. Q. Rev. Chem. Soc. 23. 453.

26. D.F. Iwig, A. T. Grippe, T.A. McIntyre and S.J. Booker. 2004. Biochem. 43. 13510.

27. P.H. Buist and D.B. MacLean. 1981. Can. J. Chem. 59. 828.

28. P.H. Buist and D.B. MacLean. 1982. Can. J. Chem. 60. 371.

29. S. Rasonyi. 1995. Diss ETH. 11318

30. L.A. Marianri, H. Goldfine and C. Panos. 1978. Biochemistry. 13. 1978.

31. J.B. Ohlrogge, F. Gunstone and I. Ismail, W.E.M. Lands. 1976. Biochem. Biophys. Acta. 431. 257.

32. P.H. Buist and R.A. Pon. 1990. J. Org. Chem. 55. 6260.

33. C. Huang, C.V. Smith, M.S. Glickman, W.R. Jacobs Jr. and J.C. Sacchettini. 2002. J. Biol. Chem. 277. 11559.

34. A.R. Johnson, J.A. Pearson, F.S. Shenstone and A.C Fogerty. 1967. Nature. 214. 1244.

35. F.C. Neidhart, J.L. Ingraham and M. Schaechter. 1990. "Physiology of the bacterial cell: a molecular approach". Sinauer Associates, Sunderland.

36. H.E. Umbarger. 1978. Annu. Rev. Biochem. 47. 533. 
37. A.Y. Wang and J.E. Cronan Jr. 1994. Mol. Moicrobiol. 11. 1009.

38. L.A. Pratt and T.J. Silhavy. 1996. Proc. Natl. Acad. Sci. USA. 93. 2488.

39. D.W. Grogan and J.E. Cronan Jr. 1986. J. Bacteriol. 166. 872.

40. Y.Y. Chang and J.E. Cronan Jr. 1999. Mol Microbiol. 33. 249.

41. J.E. Cronan Jr. 2002. Curr. Opin. Microbiol. 5. 202.

42. J.L. Brown, T. Ross and T.A. McMeekin. 1997. Int J.Food Micobiol. 37.163.

43. P.J. Brєnnan and H. Nikaido. 1995. Annu. Rev. Biochem. 64. 29.

44. D. Chatterjee. 1997. Curr. Opin. Chem. Biol. 4. 579.

45. M.S. Glickman, J.S. Cox and W.R. Jacobs Jr. 2000. Mol Cell. 5. 717.

46. K.M George, Y. Yuan, D.R. Sherman and C.E. Barry III. 1995. J. Biol. Chem. 270. 27292.

47. Y. Yuan, R.E. Lee, G.S. Bersa, J.T. Belisle and C.E. Barry III. 1995. Proc. Nat. Acad. Sci. USA. 92. 6630.

48. W.H. Brown. 1997. "Introduction to Organic Chemistry", Saunders College Publishing, Orlando.

49. http://www.lbl.gov/Science-Articles/Archive/assets/images/2002/Apr-222002/Enantiomers.jpg

50. O.W. Thiele, C. Lacave and J. Asselineau. 1969. Eur. J. Biochem. 7. 393.

51. J.C. Prome. 1968. Bull. Soc. Chim. France. 655.

52. J.F. Tocanne and R.G. Bergmann. 1972. Tetrahedron. 28. 373.

53. H.E. Simmons and R.D. Smith. 1958. J. Am. Chem. Soc. 80. 5323.

54. orgchem.chem.uconn.edu/namereact/simmons.html

55. J. Furukawa, N. Kawabata and J. Nishimura. 1968. Tetrahedron. 24. 53.

56. E. Pretsch, T. Clerc, J. Seibl and W. Simon. 1989. "Tables of Spectral Data for Structure Determination of Organic Compounds", Springer-Verlag, New York. 
57. S.E. Denmark and J.P. Edwards. 1991. J. Am. Chem. Soc. 113. 723.

58. S. Meyerson and A. W. Weitkamp. 1968. Org. Mass. Spectrom. 1. 659.

59. E.M. Gaydou, J. Rasoarahona and J.P. Bianchini. 1983. J. Sci. Food. Agri. 34. 1130.

60. C. Asselineau, G. Tocanne and J.F. Tocanne. 1970. Bull. Soc. Chim. Fr. 1455.

61. A.P. Tulloch and M. Maazurek. 1985. Chem. Phys. Lipid. 36. 253.

62. P.H. Buist. 1980. PHd Thesis. McMaster University, Hamilton, ON.

63. L.J. Stuart and P.H. Buist. 2004. Tet. Asym. 15. 401.

64. Y. Lou, M. Horikawa, R.A. Kloster, N.A. Hawryluk and E.J. Corey. 2004. J. Am. Chem. Soc. 126. 8916.

65. B. Behrouzian and P.H. Buist. 2002. Prostaglandins, Leukotrienes Essent. Fatty Acids. 68. 107.

66. J.D. De Man, M.A. Rogosa and M.E. Sharpe. 1960. J. Appl. Bact. 23. 130.

67. K. Hofmann. 1963. "Fatty Acid Metabolism in Microorganisms", John Wiley and Sons, Inc. New York.

68. C. M. McGinley and W.A. van der Donk. 2003. Chem. Comm. 2843.

69. J.A. Al Dulayymi, M.S. Baird and K. Jones. 2004. Tetrahedrom. 60. 341.

70. S. Kobayashi, R. Tokunoh, M. Shibasaki, R. Shinagawa and K. MurakamiMurofushi. 1993. Tet. Letts. 34. 4047.

71. P.H. Buist. 2004. Nat. Prod. Rep. 21. 249.

72. Mike Pollard, personal communication, July, 2005. 